Supporting Information for

\title{
Immobilization of Proteins with Controlled Load and Orientation
}

Riley M. Bednar ${ }^{1}$, Thaddeus W. Golbek ${ }^{2}$, Kelsey M. Kean ${ }^{1}$, Wesley J. Brown ${ }^{1}$, Subhashis Jana ${ }^{1}$, Joe E. Baio ${ }^{2}$, P. Andrew Karplus ${ }^{1}$, Ryan A. Mehl ${ }^{1 *}$

${ }^{1}$ Department of Biochemistry and Biophysics, Oregon State University, 2011 Ag Life Sciences Bldg, Corvallis, OR, 97331-7305 USA

${ }^{2}$ School of Chemical, Biological and Environmental Engineering, Oregon State University, 116 Johnson Hall, 105 SW 26th St., Corvallis, OR, 97331 USA

Correspondence to: ryan.mehl@ oregonstate.edu

This PDF file includes:

Materials and Methods

Supplementary Text

Schemes S1-3

Figures S1-24

Tables S1-4

References 54-90 


\section{Contents}

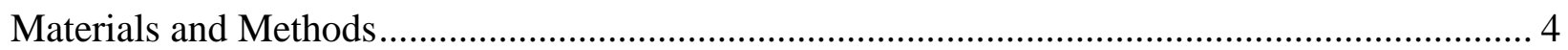

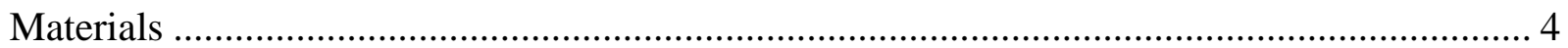

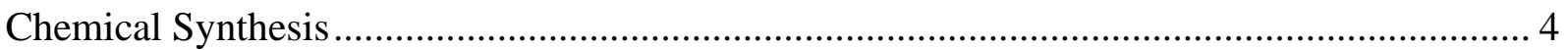

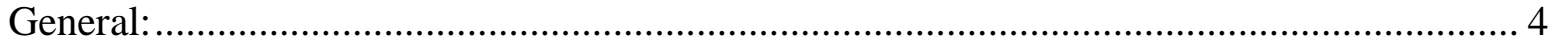

(Z)-bicyclo[6.1.0]non-4-en-9-ylmethanol (sCCO, 3): ……................................................. 4

(E)-bicyclo[6.1.0]non-4-en-9-ylmethanol (sTCO, 4) …................................................... 4

(E)-bicyclo[6.1.0]non-4-en-9-ylmethyl (4-nitrophenyl) carbonate, 1) …………................... 5

(E)-bicyclo[6.1.0]non-4-ene-9-carboxylic acid (sTCO-CO2H, 5) …................................. 5

(4E,4'E)-N,N'-(Disulfanediylbis(ethane-2,1-diyl))bis(bicyclo[6.1.0]non-4-ene-9-

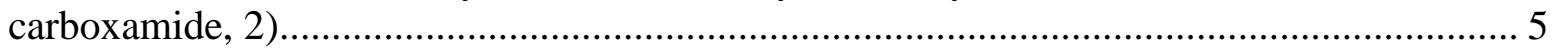

Chloride salt of (S)-2-amino-3-(4-(6-methyl-1,2,4,5-tetrazin-3-yl)phenyl) propanoic acid (7,

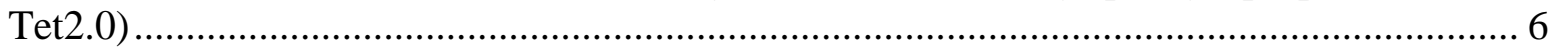

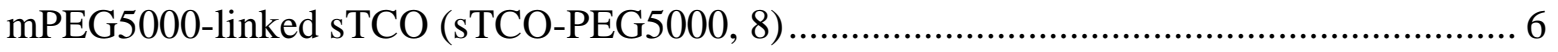

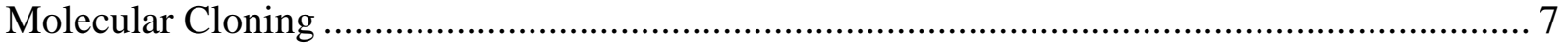

Protein Expression, Amber Suppression, and Purification ....................................................... 7

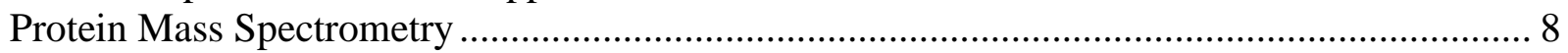

tsCA Bioconjugation and Size Exclusion Chromatography ………………………………....... 8

Preparation of sTCO-Beads and tsCA Immobilization ......................................................... 8

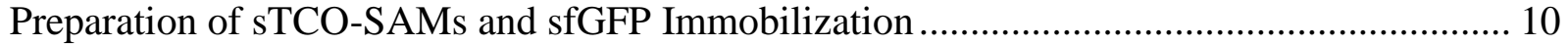

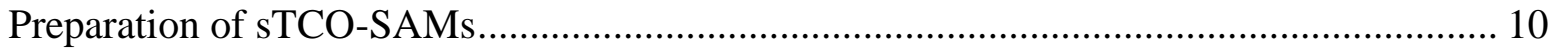

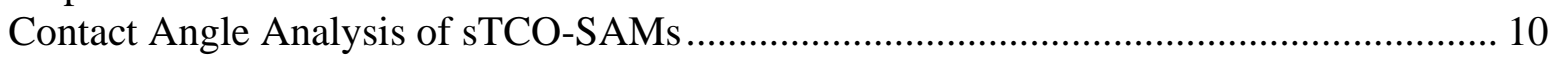

sfGFP Immobilization........................................................................................... 10

Total Internal Reflection Fluorescence Microscopy (TIRFm) Analysis ............................... 11

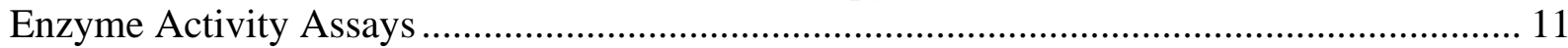

Metabolic Radiolabeling with ${ }^{35} \mathrm{~S}$ and Detection of Radiolabeled tsCA .................................. 11

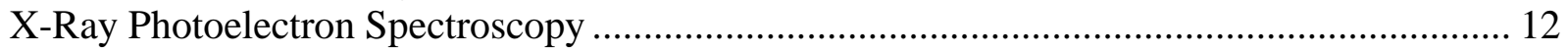

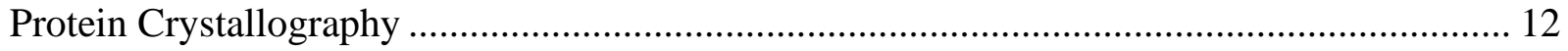

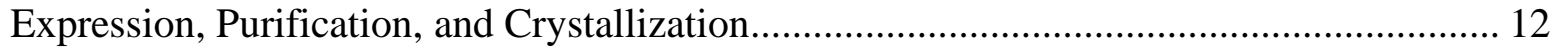

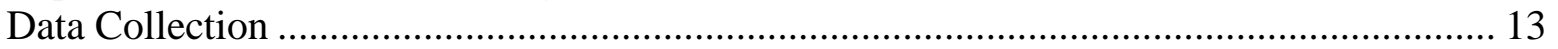

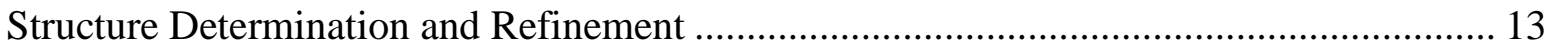

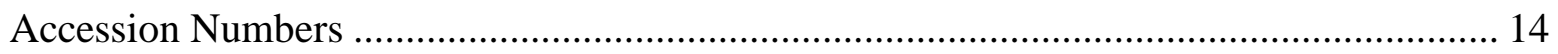

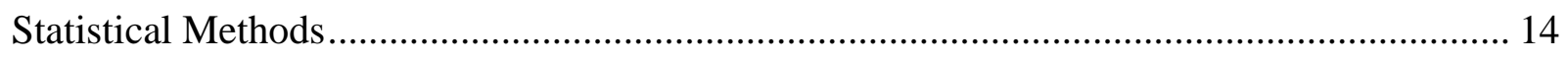

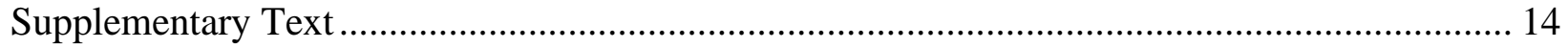

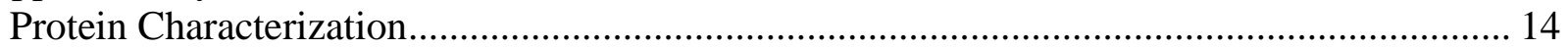

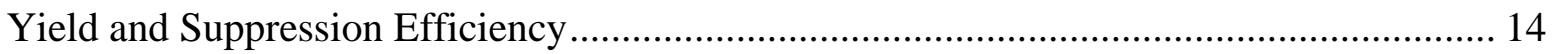

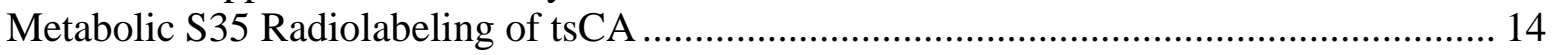

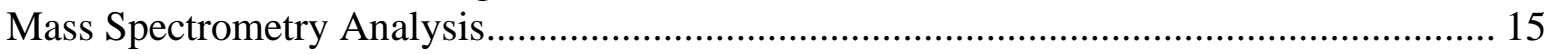

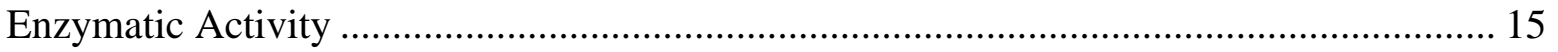

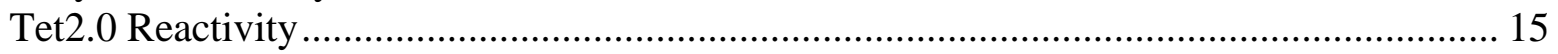

X-Ray Crystallography of tsCA-Tet2.0 and ligation product............................................ 16

Characterization of Surfaces ......................................................................................... 17

Contact Angle Analysis of sTCO-SAMs ..................................................................... 17

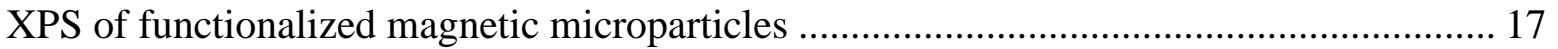

XPS of functionalized flat gold surfaces with thiolated sTCO .............................................. 18

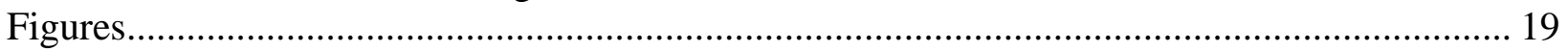




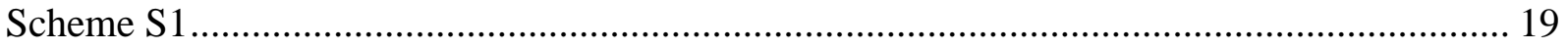

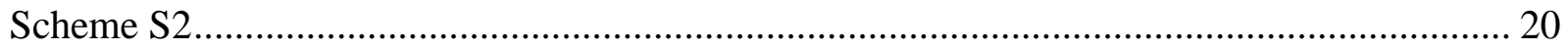

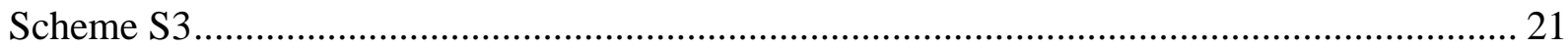

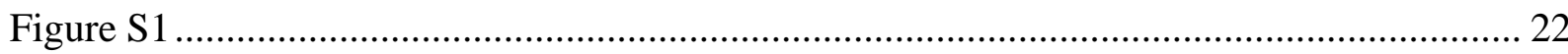

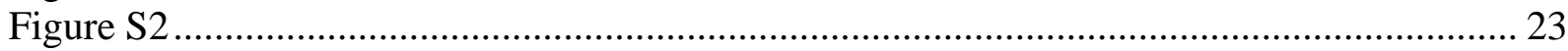

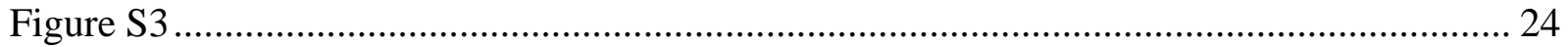

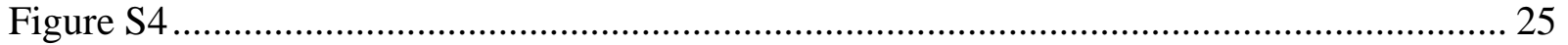

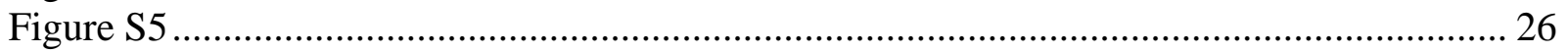

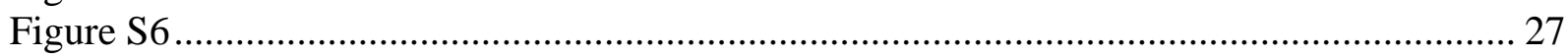

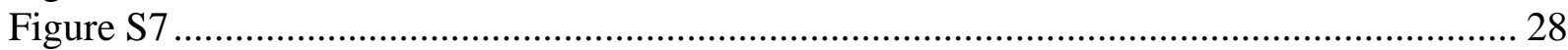

Figure S8

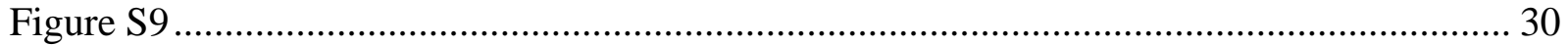

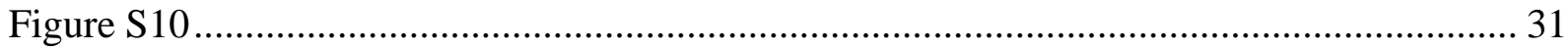

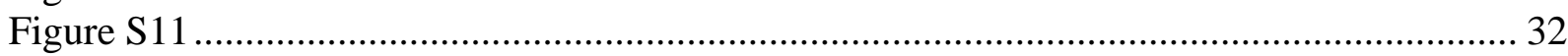

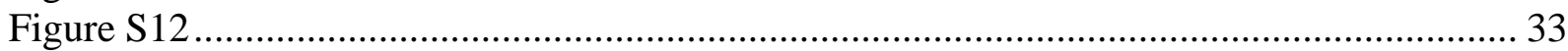

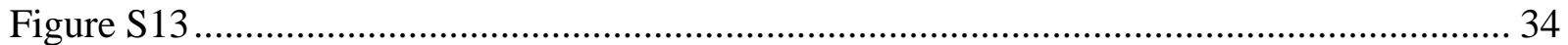

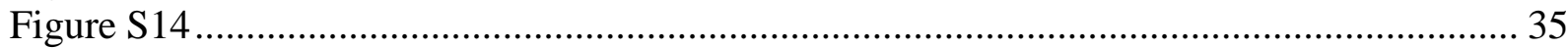

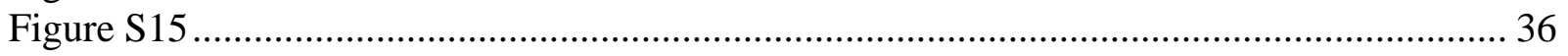

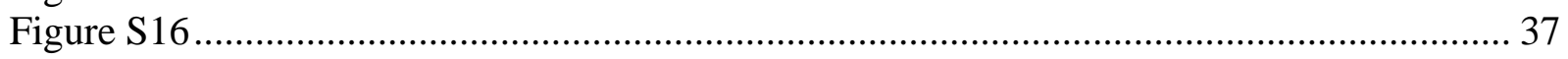

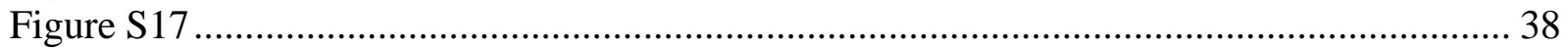

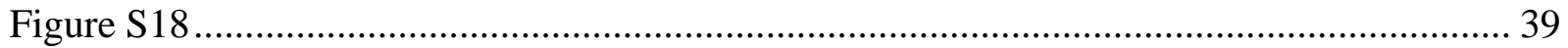

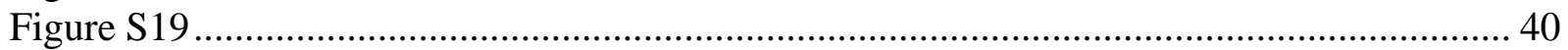

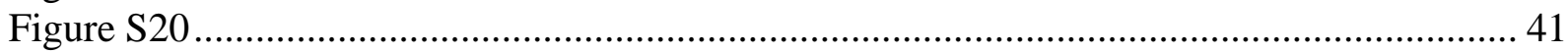

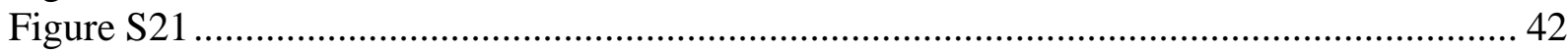

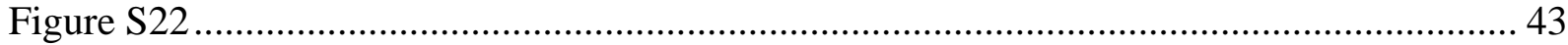

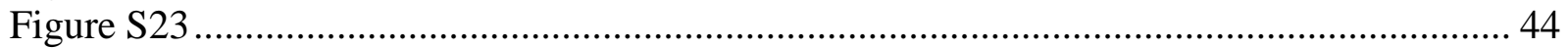

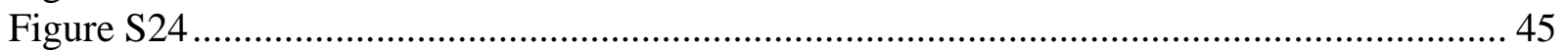

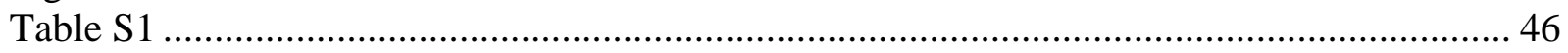

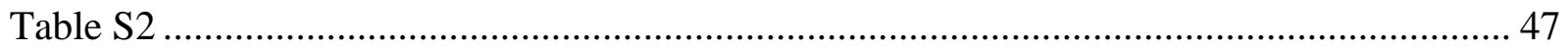

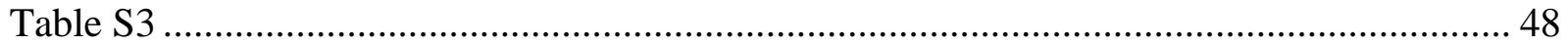

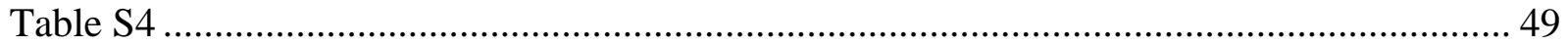

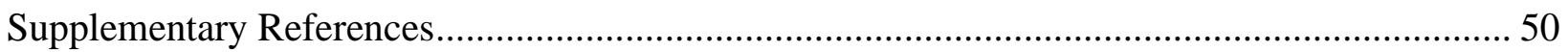




\section{Materials and Methods}

\section{Materials}

All solutions were prepared using ultrapure (Type 1) water which was deionized using a Synergy UV water purification system equipped with a Biopak Polisher (MilliporeSigma, USA) to a resistivity of $\geq 18 \mathrm{M} \Omega$.

\section{Chemical Synthesis}

General: Purchased chemicals were used without further purification. Anhydrous dichloromethane was prepared by overnight stirring with calcium hydride and distillation under argon atmosphere. All sTCO-derivatives were stored either as a dried powder or as a solution at $20{ }^{\circ} \mathrm{C}$ away from light. Tet2.0 was stored at room temperature in the powdered form. Thin-layer chromatography (TLC) was performed on silica 60F-254 plates (MilliporeSigma, USA). The TLC spots of alkenes were charred by potassium permanganate staining. Flash chromatographic purifications of synthetic products were performed using a CombiFlash Rf MPLC system with silica gel 60 columns (230-400 mesh size) (Teledyne ISCO, USA). ${ }^{1} \mathrm{H}$ NMR spectra were recorded on Bruker $400 \mathrm{MHz}$ and $700 \mathrm{MHz}$ instruments and ${ }^{13} \mathrm{C}$ NMR spectra were recorded at $175 \mathrm{MHz}$.. Chemical shifts are shown in ppm with the residual non-deuterated solvent peaks of $\mathrm{CDCl}_{3}(\delta$ $=7.26$ in ${ }^{1} \mathrm{H}$ NMR, $\delta=77.23$ in $\left.{ }^{13} \mathrm{C} \mathrm{NMR}\right), \mathrm{CD}_{3} \mathrm{OD}\left(\delta=3.31\right.$ in ${ }^{1} \mathrm{H} \mathrm{NMR}, \delta=49.2$ in $\left.{ }^{13} \mathrm{C} \mathrm{NMR}\right)$, or $\mathrm{d}_{6}$-DMSO ( $\delta=2.5$ in ${ }^{1} \mathrm{H}$ NMR, $\delta=39.5$ in ${ }^{13} \mathrm{C}$ NMR) serving as internal standards. Splitting patterns of protons are designated as singlet (s), doublet (d), triplet (t), quartet (q), multiplet (m), doublet of doublets (dd). Mass spectrometry spectra are from a Waters Synapt G2 mass spectrometer coupled to a 2D nanoAcquity liquid chromatography system (Waters Corporation, USA).

(Z)-bicyclo[6.1.0]non-4-en-9-ylmethanol (sCCO, 3): Synthetic procedure ${ }^{54}$. ${ }^{1} \mathrm{H}$ NMR (700MHz, HO $\left.\quad \mathrm{CD}_{3} \mathrm{OD}\right) \delta 5.64-5.60(2 \mathrm{H}, \mathrm{m}), 3.38(2 \mathrm{H}, \mathrm{d}, J=7 \mathrm{~Hz}), 2.30-2.26(2 \mathrm{H}, \mathrm{m}), 2.19-2.15(2 \mathrm{H}$,<smiles>CCC1C2CC=CCCC12</smiles>
$\mathrm{m}), 2.09-2.04(2 \mathrm{H}, \mathrm{m}), 1.73-1.43(2 \mathrm{H}, \mathrm{m}), 0.79-0.74(2 \mathrm{H}, \mathrm{m}), 0.58-0.55(1 \mathrm{H}, \mathrm{m})$.

(E)-bicyclo[6.1.0]non-4-en-9-ylmethanol (sTCO, 4): Synthetic procedure ${ }^{55} \cdot{ }^{1} \mathrm{H}$ NMR (700MHz, HO $\begin{aligned} & \left.\mathrm{CD}_{3} \mathrm{OD}\right) \delta 5.89-5.84(1 \mathrm{H}, \mathrm{m}), 5.15-5.10(1 \mathrm{H}, \mathrm{m}), 3.44-3.39(2 \mathrm{H}, \mathrm{m}), 2.37(1 \mathrm{H}, \mathrm{d}, J \\ & =13.3 \mathrm{~Hz}), 2.27(1 \mathrm{H}, \mathrm{dt}, J=12.6,4.2 \mathrm{~Hz}), 2.25-2.23(1 \mathrm{H}, \mathrm{m}), 2.19-2.15(1 \mathrm{H}, \mathrm{m}), \\ & 1.94-1.87(2 \mathrm{H}, \mathrm{m}), 0.92-0.87(1 \mathrm{H}, \mathrm{m}), 0.64-0.58(1 \mathrm{H}, \mathrm{m}), 0.50-0.46(1 \mathrm{H}, \mathrm{m}), 0.37- \\ & 0.31(2 \mathrm{H}, \mathrm{m}) .\end{aligned}$ 
(E)-bicyclo[6.1.0]non-4-en-9-ylmethyl (4-nitrophenyl) carbonate, 1): In a dry round-bottom flask, sTCO 4 (0.3 gm, $1.97 \mathrm{mmol})$ was dissolved in anhydrous dichloromethane (DCM) under inert

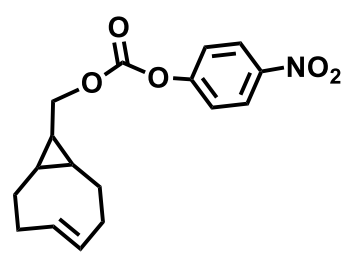
atmosphere. Subsequently, trimethylamine $\left(\mathrm{Et}_{3} \mathrm{~N}\right)(650 \mu \mathrm{L}, 4.9 \mathrm{mmol})$ and 4-Nitrophenyl chloroformate $(0.43 \mathrm{gm}, 2.16 \mathrm{mmol})$ were added to the solution and stirred at $30-35{ }^{\circ} \mathrm{C}$ for $2-3 \mathrm{hrs}$. After consumption of all starting material (monitored by TLC), $15 \mathrm{~mL}$ of DCM was added to the reaction mixture and washed with water. The aqueous layer was reextracted twice with DCM. The organic layers were combined, dried with anhydrous $\mathrm{Na}_{2} \mathrm{SO}_{4}$, and concentrated using rotary evaporator. Purification was performed using silica gel flash column chromatography (5\% ethyl acetate in hexane) yielded yellowish white solid material $1(0.51 \mathrm{gm}, 1.6 \mathrm{mmol})$. Yield $81 \%$. ${ }^{1} \mathrm{H} \mathrm{NMR}\left(400 \mathrm{MHz}, \mathrm{CDCl}_{3}\right) \delta 8.27(2 \mathrm{H}, \mathrm{d}, J=9.6$ $\mathrm{Hz}), 7.37(2 \mathrm{H}, \mathrm{d}, J=9.6 \mathrm{~Hz}), \quad 5.88-5.82(1 \mathrm{H}, \mathrm{m}), 5.18-5.14(1 \mathrm{H}, \mathrm{m}), 4.18(2 \mathrm{H}, \mathrm{d}, J=7.2 \mathrm{~Hz})$, 2.43-2.39 (1H, m), 2.35-2.22 (3H, m), 1.96-1.90 $(2 \mathrm{H}, \mathrm{m}), 0.94-0.83(1 \mathrm{H}, \mathrm{m}), 0.69-0.64(1 \mathrm{H}, \mathrm{m})$, $0.62-0.49(3 \mathrm{H}, \mathrm{m})$.

(E)-bicyclo[6.1.0]non-4-ene-9-carboxylic acid (sTCO-CO2H, 5): In a dry quartz flask, the cisisomer of sTCO- $\mathrm{CO}_{2} \mathrm{H}(33,34)(1.2 \mathrm{~g}, 7.22 \mathrm{mmol})$ and methyl benzoate $(2.2 \mathrm{~mL}, 18.06 \mathrm{mmol})$

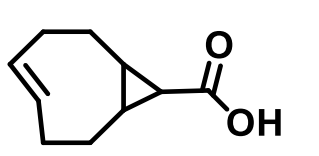
were dissolved in $400 \mathrm{~mL}$ of solvent (hexane : ether $=1: 1$ ). The flask was placed in a Rayonet reactor and connected via PTFE tubing to a column and FMI pump. The column was packed with dry silica $(60 \AA, 6 \mathrm{~cm})$ and silver impregnated silica $(17 \mathrm{gm})$. The column was rinsed with ether and set to a circulation flow rate of $80 \mathrm{~mL} / \mathrm{min}$ and 16 low pressure mercury lamps $(2537 \AA)$ turned were applied during this circulation. The photolysis of the reaction mixture continued for $7 \mathrm{hr}$. The column was washed with an additional $400 \mathrm{~mL}$ of ether then silica was poured into a $500 \mathrm{~mL}$ Erlenmeyer flask. The silica was stirred with saturated aq. sodium chloride solution $(200 \mathrm{~mL})$ and methylene chloride $(200 \mathrm{~mL})$ for $15 \mathrm{~min}$. After filtration of silica, the aqueous fraction was extracted with dichloromethane ( 3 times). The combined organic layers were again washed with $100 \mathrm{ml}$ water, dried with anhy. $\mathrm{Na}_{2} \mathrm{SO}_{4}$, and concentrated under reduced pressure to afford the trans isomer of the bi-cyclooctene derivative $5 .{ }^{1} \mathrm{H}$ NMR $\left(400 \mathrm{MHz}, \mathrm{CDCl}_{3}\right) \delta 5.91-5.83(1 \mathrm{H}, \mathrm{m})$, 5.20-5.12 $(1 \mathrm{H}, \mathrm{m}), 2.40(1 \mathrm{H}, \mathrm{d}, J=4.8 \mathrm{~Hz}), 2.32-2.22(3 \mathrm{H}, \mathrm{m}), 2.03-1.92(2 \mathrm{H}, \mathrm{m}), 1.37-1.33(1 \mathrm{H}$, $\mathrm{m}), 1.28-1.21(1 \mathrm{H}, \mathrm{m}), 0.96-0.89(2 \mathrm{H}, \mathrm{m}), 0.65(1 \mathrm{H}, \mathrm{q}, J=12.8 \mathrm{~Hz}) .{ }^{13} \mathrm{C} \mathrm{NMR}\left(175 \mathrm{MHz}, \mathrm{CD}_{3} \mathrm{OD}\right)$ $\delta 178.8,139.1,132.7,39.1,34.4,33.1,28.5,28.3,28.3,27.4$.

(4E,4'E)-N,N'-(Disulfanediylbis(ethane-2,1-diyl))bis(bicyclo[6.1.0]non-4-ene-9-carboxamide, 2): In a mixture of solvents comprising anhydrous dichloromethane (DCM) and N,Ndimethylformamide (DMF) (3:1, 5mL), sTCO-CO $\mathrm{CO}_{2} \mathrm{H}(250 \mathrm{mg}, 1.5 \mathrm{mmol}), 1-$ (2) ethyl-3-(3-dimethylaminopropyl) carbodiimide (EDC.HCl) (345 $\mathrm{mg}, 1.8 \mathrm{mmol})$ and hydroxybenzotriazole $(\mathrm{HOBt})(243 \mathrm{mg}, 1.8 \mathrm{mmol})$ were added under argon atmosphere and stirred for 30 minutes under ice cold conditions. Next, cystamine dihydrochloride $\mathbf{6}(191 \mathrm{mg}, 0.75 \mathrm{mmol})$ was added, followed by the addition of N,N-diisopropylethylamine (DIPEA) $(650 \mu \mathrm{l}, 2.5 \mathrm{mmol})$ to the reaction mixture. After 15 minutes the ice bath was removed and stirring was continued for another 20 hours at room temperature. Then, $20 \mathrm{~mL}$ DCM added to the reaction mixture and washed with water. The aqueous layer was re-extracted twice with DCM. The organic layers were combined, washed with brine solution, dried with anhydrous $\mathrm{Na}_{2} \mathrm{SO}_{4}$, and concentrated using a rotary evaporator. Purification was done using silica gel flash 
column chromatography (10-15\% methanol in dichloromethane) which yielded a white solid material 2 (143 mg, $0.316 \mathrm{mmol})$. Yield $42 \% .{ }^{1} \mathrm{H}$ NMR $\left(700 \mathrm{MHz}, \mathrm{CDCl}_{3}\right) \delta 6.52(2 \mathrm{H}, \mathrm{t}, J=6.3$ $\mathrm{Hz}), 5.91-5.86(2 \mathrm{H}, \mathrm{m}), 5.17-5.12(2 \mathrm{H}, \mathrm{m}), 3.56(4 \mathrm{H}, \mathrm{q}, J=6.3 \mathrm{~Hz}), 2.80(4 \mathrm{H}, \mathrm{t}, J=6.3 \mathrm{~Hz}), 2.38$ $(2 \mathrm{H}, \mathrm{d}, J=13.3 \mathrm{~Hz}), 2.30-2.22(6 \mathrm{H}, \mathrm{m}), 1.99-1.91(4 \mathrm{H}, \mathrm{m}), 1.25-1.22(2 \mathrm{H}, \mathrm{m}), 1.13-1.09(2 \mathrm{H}, \mathrm{m})$, $0.92-0.87(2 \mathrm{H}, \mathrm{m}), 0.80(2 \mathrm{H}, \mathrm{t}, J=4.2 \mathrm{~Hz}), 0.61(2 \mathrm{H}, \mathrm{q}, J=11.9 \mathrm{~Hz}) .{ }^{13} \mathrm{C} \mathrm{NMR}\left(175 \mathrm{MHz}, \mathrm{CDCl}_{3}\right)$ $\delta$ 174.2, 138.4, 131.6, 38.7, 38.3, 38.2, 33.6, 33.2, 29.4, 27.5, 25.8, 24.6. ESI-MS calcd for $\mathrm{C}_{24} \mathrm{H}_{37} \mathrm{~N}_{2} \mathrm{O}_{2} \mathrm{~S}_{2}\left([\mathrm{M}+\mathrm{H}]^{+}\right) 449.2291$, found 449.2299 .

Chloride salt of (S)-2-amino-3-(4-(6-methyl-1,2,4,5-tetrazin-3-yl)phenyl) propanoic acid (7, Tet2.0): Synthesis was carried out using a modified synthetic round, as described previously ${ }^{56}$ to further increase yields, as detailed below. In a flame dried $50 \mathrm{~mL}$ heavy walled reaction tube Bocprotected $4-\mathrm{CN}$ phenylalanine $(500 \mathrm{mg}, 1.72 \mathrm{mmol})$ was combined with $\mathrm{Ni}(\mathrm{OTf})_{2}(306 \mathrm{mg}, 0.86$ $\mathrm{mmol})$ and acetonitrile $(0.9 \mathrm{ml}, 17.2 \mathrm{mmol})$ under argon atmosphere. Next anhydrous hydrazine $(2.7 \mathrm{~mL}, 86 \mathrm{mmol}$ ) was slowly added to the reaction mixture and purged with argon for 5 to 10 minutes and the reaction vessel immediately sealed, and the reaction mixture then heated to $50{ }^{\circ} \mathrm{C}$ for $24 \mathrm{hr}$. Following, the reaction mixture was cooled to room temperature, opened slowly and 20 eqv. of $2 \mathrm{M} \mathrm{NaNO}_{2}$ in a $5 \mathrm{~mL}$ water solution was added. Next, the reaction mixture was washed with ethyl acetate $(1 \times 20 \mathrm{ml})$ to remove the homo coupling product. The collected aqueous phase was acidified with $4 \mathrm{M} \mathrm{HCl}(\mathrm{pH} 2)$ under ice cold conditions and extracted with ethyl acetate ( $3 \mathrm{x}$ $30 \mathrm{~mL}$ ). The combined organic layers were washed with brine, dried with anhydrous $\mathrm{Na}_{2} \mathrm{SO}_{4}$ and concentrated under reduced pressure. Silica gel flash column chromatography purification (30$35 \%$ ethyl acetate in hexanes with $1 \%$ acetic acid) provide $485 \mathrm{mg}$ of Boc-protected Tet2.0 (1.35 mmol, $78 \%)$ in the form of a pinkish red gummy material. ${ }^{1} \mathrm{H}$ NMR $\left(400 \mathrm{MHz}, \mathrm{CDCl}_{3}\right) \delta 8.54$ $(2 \mathrm{H}, \mathrm{d}, J=7.6 \mathrm{~Hz}), 7.44(2 \mathrm{H}, \mathrm{d}, J=8.0 \mathrm{~Hz}), 5.06(1 \mathrm{H}, \mathrm{d}, J=6.0 \mathrm{~Hz}), 4.71(\mathrm{bs}, 1 \mathrm{H}), 3.37-3.19$ $(2 \mathrm{H}, \mathrm{m}), 3.1(\mathrm{~s}, 3 \mathrm{H}), 1.44(\mathrm{~s}, 9 \mathrm{H}) .{ }^{13} \mathrm{C} \mathrm{NMR}\left(175 \mathrm{MHz}, \mathrm{CDCl}_{3}\right) \delta 175.3,167.2,163.9,155.3,141.2$, $130.5,130.4,128.1,80.4,54.1,37.9,28.3,21.2$.

The purified Boc-protected Tet2.0 amino acid $(450 \mathrm{mg}, 2.23 \mathrm{mmol})$ was dissolved in $5 \mathrm{~mL}$ ethyl acetate and charged with $3 \mathrm{~mL} \mathrm{HCl}$ gas saturated 1,4 Dioxane under argon atmosphere. The reaction mixture was allowed to stir at room temperature until the starting materials was consumed,

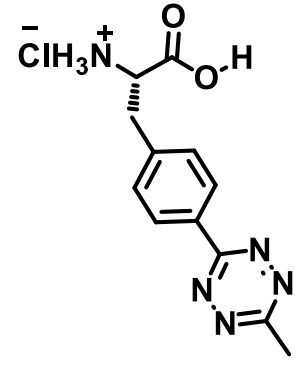
as monitored by TLC (typically 3 to $4 \mathrm{~h}$ ). The resulting product was concentrated under reduced pressure and re-dissolved in ethyl acetate $(2 \mathrm{x} 10$ $\mathrm{mL}$ ) and similarly concentrated to remove excess $\mathrm{HCl}$ gas which resulted in pink colored solid material of Tet2.0 7 in quantitative yield (98\%). ${ }^{1} \mathrm{H}$ NMR $\left(700 \mathrm{MHz}, \mathrm{CD}_{3} \mathrm{OD}\right) \delta 8.56(2 \mathrm{H}, \mathrm{d}, J=7.0 \mathrm{~Hz}), 7.60(2 \mathrm{H}, \mathrm{d}, \mathrm{J}=7.7 \mathrm{~Hz}), 4.39$ (1H, bs), 3.48- $3.33(2 \mathrm{H}, \mathrm{dd}, J=3.5,14 \mathrm{~Hz})$ ), 3.1 (s, 3H). ${ }^{13} \mathrm{C} \mathrm{NMR}(175 \mathrm{MHz}$, $\left.\mathrm{CD}_{3} \mathrm{OD}\right) \delta$ 171.2, 169.1, 165.3, 140.7, 133.3, 131.7, 129.6, 55.1, 37.4, 21.3. ESI-MS calculated for $\mathrm{C}_{12} \mathrm{H}_{14} \mathrm{~N}_{5} \mathrm{O}_{2}\left([\mathrm{M}+\mathrm{H}]^{+}\right) 260.114$, found 260.1 .

mPEG5000-linked sTCO (sTCO-PEG5000, 8): In $3 \mathrm{~mL}$ of anhydrous dichloromethane, $65 \mathrm{mg}$ (0.013 mmol) of mPEG5000-Amine (Laysan Bio, Inc., USA) were dissolved. The activated ester

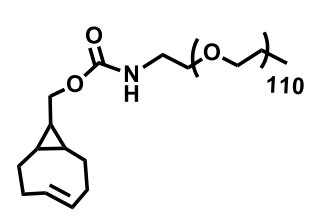
of sTCO 1 (6 mg, $0.16 \mathrm{mmol})$ was subsequently added, followed by triethylamine $(10 \mu \mathrm{L}, 0.05 \mathrm{mmol})$ both of which were added under argon atmosphere. The reaction mixture was stirred at room temperature for 24 hours. After that, the solvent was concentrated onto silica gel under reduced pressure and purified to yield our desired molecule 8 (47 $\mathrm{mg}, 0.009 \mathrm{mmol}$ ) by 
silica gel column chromatography (5\% methanol in dichloromethane). Yield $69 \%$. ${ }^{1} \mathrm{H}$ NMR $\left(400 \mathrm{MHz}, \mathrm{CD}_{3} \mathrm{OD}\right) \delta 5.90-5.82(1 \mathrm{H}, \mathrm{m}), 5.17-5.09(1 \mathrm{H}, \mathrm{m}), 3.91(2 \mathrm{H}, \mathrm{d}, J=6.8 \mathrm{~Hz}), 3.82-3.79$ $(3 \mathrm{H}, \mathrm{m}), 3.63(411 \mathrm{H}, \mathrm{bs}), 3.54-3.50(4 \mathrm{H}, \mathrm{m}), 3.45(2 \mathrm{H}, \mathrm{t}, J=4.8 \mathrm{~Hz}), 3.35(3 \mathrm{H}, \mathrm{s}), 3.26(2 \mathrm{H}, \mathrm{t}$, $J=5.6 \mathrm{~Hz}), 3.16(2 \mathrm{H}, \mathrm{q}, J=7.6 \mathrm{~Hz}), 2.35(1 \mathrm{H}, \mathrm{d}, J=15.2 \mathrm{~Hz}), 2.27-2.15(3 \mathrm{H}, \mathrm{m}), 1.97-1.88$ $(2 \mathrm{H}, \mathrm{m}), 0.95-0.84(1 \mathrm{H}, \mathrm{m}), 0.66-0.54(2 \mathrm{H}, \mathrm{m}), 0.48-0.41(2 \mathrm{H}, \mathrm{m})$.

\section{Molecular Cloning}

The tsCA thermostable variant was first described in a 2006 Canadian Patent 2541986 (also United States Patent 7521217). It contains six mutations (A65T, L100H, K154N, L224S, L240P, and A248T) discovered via random mutagenesis to individually increase thermostability. The codon-optimized gene for tsCA expression in E. coli was ordered from ATUM (formerly DNA 2.0) in a pJ201 plasmid. The plasmid was digested using NcoI and XhoI restriction enzymes (Thermo Scientific, USA) and ligated into a pBad expression vector. Amber stop codons (TAG sites) were introduced into tsCA by conventional overlap extension PCR using the primers described in Table $\mathrm{S}^{57}$. The construction of pBAD-sfGFP plasmids and pDule1-Tet2.0 were carried out as previously described ${ }^{22,58}$. It should be noted here that all plasmids used in this study were deposited to, and are available from Addgene (see Table S1 for Addgene ID number).

To prepare the strains outlined in Table S1, chemically competent E. coli DH10B cells were chemically transformed by incubation of approximately $25 \mu \mathrm{g}$ each of a plasmid housing the gene of interest and a machinery plasmid housing the suppression machinery (orthogonal aminoacyl tRNA synthetase enzyme specific for Tet 2.0 and a cognate orthogonal suppressor tRNACUA; see Table S1) if necessary, as specified in Table S1, for $\sim 15 \mathrm{~min}$ on ice prior to incubation at 42 ${ }^{\circ} \mathrm{C}$ for $45 \mathrm{~s}$. Cells were then recovered in $1 \mathrm{~mL}$ of SOC media $(10 \mathrm{mM} \mathrm{MgSO} 4$ and $0.4 \%$ glucose in $2 \mathrm{xYT}$ ) by shaking at $37{ }^{\circ} \mathrm{C}$ for $\sim 1 \mathrm{~h}$ before being plated on LB agar plates with the appropriate antibiotics. Individual colonies were selected and grown in $5 \mathrm{~mL}$ of $2 x Y T$ under appropriate antibiotic selection overnight prior to being frozen in $15 \%$ glycerol and stored at $-80{ }^{\circ} \mathrm{C}$ until needed. Overnight starter cultures grown at $37{ }^{\circ} \mathrm{C}$ in $5 \mathrm{~mL}$ of $2 \mathrm{xYT}$ under proper antibiotic selection were used to inoculate larger expression cultures.

\section{Protein Expression, Amber Suppression, and Purification}

$50 \mathrm{~mL}$ cultures were inoculated from overnight starter cultures under proper antibiotic selection in non-inducing ${ }^{59}$ media supplemented with $200 \mu \mathrm{M} \mathrm{ZnSO}_{4}$ and $500 \mu \mathrm{M}$ Tet2.0 (diluted from a $100 \mathrm{mM}$ solution in DMF). Cells were grown for $\sim 48 \mathrm{~h}$ at $37{ }^{\circ} \mathrm{C}$ with constant shaking at $250 \mathrm{rpm}$ in an I26 incubator-shaker (Eppendorf, KGaA, Germany; formerly New Brunswick Scientific, USA) in capped plastic $500 \mathrm{~mL}$ baffled flasks. They were harvested by centrifugation at 5,500 rcf for $10 \mathrm{~min}$ and the pellets stored at $-80{ }^{\circ} \mathrm{C}$. To purify protein, cell pellets were thawed on ice and resuspended in $5 \mathrm{~mL}$ of TALON Wash buffer $\left(50 \mathrm{mM} \mathrm{NaH}_{2} \mathrm{PO}_{4}, 500 \mathrm{mM} \mathrm{NaCl}, 5 \mathrm{mM}\right.$ Imidazole, $\mathrm{pH}$ 7.0) and subsequently microfluidized at 18,000 psi using a M-110P microfluidizer (Microfluidics Corp., USA). To remove insoluble cell debris, microfluidized lysate was centrifuged at $\sim 21,000 \mathrm{rcf}$ for $30 \mathrm{~min}$ at $4{ }^{\circ} \mathrm{C}$. No more than $50 \mathrm{~mL}$ of cleared lysate was then incubated with $1.0 \mathrm{~mL}$ of washed TALON Cobalt resin (Takara Bio, Japan) for $\sim 1 \mathrm{~h}$ at $4{ }^{\circ} \mathrm{C}$ with frequent agitation. The TALON resin was then transferred to a $10 \mathrm{~mL}$ column and washed with 50 $\mathrm{mL}$ of TALON Wash buffer. To elute, $3.0 \mathrm{~mL}$ of TALON Elution buffer $\left(50 \mathrm{mM} \mathrm{NaH} \mathrm{PO}_{4}, 500\right.$ $\mathrm{mM} \mathrm{NaCl}, 250 \mathrm{mM}$ Imidazole, $\mathrm{pH}$ 7.0) was added to the column, the first $0.5 \mathrm{~mL}$ being discarded 
as dead volume. The resulting $2.5 \mathrm{~mL}$ of eluate was transferred to a PD-10 de-salting column (GE Healthcare) and de-salted according to manufacturer's instructions into HEPES Buffer consisting of $100 \mathrm{mM}$ HEPES ( $\mathrm{pH} 7.5$ ), $150 \mathrm{mM} \mathrm{NaCl}$ and $1 \mu \mathrm{M} \mathrm{ZnSO}_{4}$. After de-salting, purified protein was spin-concentrated using a $15 \mathrm{~mL}$ Vivaspin-2 $10 \mathrm{kDa}$ MWCO disposable spin-concentrator (GE Healthcare, USA) according to manufacturer's instructions. Unless otherwise stated, protein concentration was determined by $\mathrm{A}_{280}$ measurement on a NanoDrop 2000 spectrophotometer using the following molar extinction coefficients: tsCAwT, $50070 \mathrm{M}^{-1} \mathrm{~cm}^{-1}$; tsCA 20 , tsCA 186 , and tsCA $_{233}, 61724 \mathrm{M}^{-1} \mathrm{~cm}^{-1}$; sfGFP ${ }_{\mathrm{WT}}, 24080 \mathrm{M}^{-1} \mathrm{~cm}^{-1}$; sfGFP $_{150}, 35734 \mathrm{M}^{-1} \mathrm{~cm}^{-1}$. Purified protein samples were stored for several hours at $4^{\circ} \mathrm{C}$ before being aliquoted and flash frozen by liquid nitrogen and stored at $-80{ }^{\circ} \mathrm{C}$ until needed. They were not re-frozen after thawing, and kept no longer than $7 \mathrm{~d}$ at $4{ }^{\circ} \mathrm{C}$. Note, expression, purification, and handling of tsCA prepared for crystallography and for ${ }^{35} \mathrm{~S}$ metabolic radiolabeling were different, and are detailed in the "Protein Crystallography" and "Metabolic Radiolabeling with ${ }^{35} \mathrm{~S}$ and Detection of Radiolabeled tsCA" subsections, respectively.

sfGFP was purified similarly, with notable modifications being a $24 \mathrm{hr}$ expression in autoinduction media not supplemented with $\mathrm{ZnSO}_{4}$, and protein being desalted into "PBS Buffer" consisting of $50 \mathrm{mM} \mathrm{Na}_{2} \mathrm{PO}_{4}, 100 \mathrm{mM} \mathrm{NaCl}, \mathrm{pH}$ 7.0.

\section{Protein Mass Spectrometry}

Purified protein was diluted to a concentration of approximately $50 \mu \mathrm{M}$ in either HEPES Buffer (tsCA) or PBS Buffer (sfGFP) and desalted using $\mathrm{C}_{4}$ ZipTips (MilliporeSigma, USA). Desalted protein was eluted from the $\mathrm{C}_{4}$ ZipTip using 50:50 MQ water:acetonitrile containing $0.01 \%$ formic acid and analyzed using electrospray ionization on a LTQ FT Ultra High Performance Mass Spectrometer (Thermo Scientific, USA) at Oregon State University's Mass Spectrometry Facility and deconvoluted using a multiple overlapping peak maximum entropy deconvolution software (SpectrumSqaure, USA).

\section{tsCA Bioconjugation and Size Exclusion Chromatography}

tsCA variants were diluted to $2 \mathrm{mg} / \mathrm{mL}(\sim 67 \mu \mathrm{M})$ and combined with 10 equivalents of sTCO-PEG $_{5000}(\sim 667 \mu \mathrm{M})$ and allowed to react for approximately $5 \mathrm{~min}$ at room temperature in HEPES Buffer. Reacted tsCA was then run through a Superdex S200 10/300 size exclusion column in-line with an AKTA Explorer 100 FPLC (Amersham Biosciences, UK) at room temperature. In short, $1 \mathrm{mg}$ of protein was loaded onto a column pre-equilibrated with HEPES Buffer and run isocratically at a rate of $0.3 \mathrm{~mL} / \mathrm{min}$, collecting $1.0 \mathrm{~mL}$ fractions and monitoring the absorbance at $280 \mathrm{~nm}$. Protein purity was checked by SDS-PAGE (see Figure S12).

\section{Preparation of sTCO-Beads and tsCA Immobilization}

sTCO-microparticles were prepared in $25 \mathrm{mg}$ batches from commercially produced aminefunctionalized magnetic microparticles. The manufacturer reports that these superparamagnetic microparticles (BioMag Amine magnetic microparticles, Bangs Laboratories Inc., USA) are composed of iron oxide with an amine-terminated overlayer comprised of a proprietary silane, are approximately $1.5 \mu \mathrm{m}$ in diameter, and possess an overall irregular morphology while the surface roughness is not reported. $500 \mu \mathrm{L}$ of $51 \mathrm{mg} / \mathrm{mL}$ BioMag Amine magnetic microparticles were 
washed three times with $1.0 \mathrm{~mL}$ of methanol, and three times again with $1.0 \mathrm{~mL}$ of dichloromethane to remove any residual surfactant. Washed beads were resuspended in $500 \mu \mathrm{L}$ of anhydrous dichloromethane transferred to a $1.0 \mathrm{~mL}$ glass vial, combined with $10 \mathrm{mg}$ of activated sTCO (compound 1) and 5.5 $\mu \mathrm{L}$ of DIPEA, backfilled with Ar gas, capped, parafilmed, coated with foil and left to react for approximately $24 \mathrm{hrs}$ at room temperature with constant agitation. After the reaction had completed, sTCO-functionalized microparticles were washed three times with $1.0 \mathrm{~mL}$ of dichloromethane, and three times again with $1.0 \mathrm{~mL}$ of methanol before being resuspended in $1.0 \mathrm{~mL}$ of methanol and stored in a $1.0 \mathrm{~mL}$ sealed glass vial coated with foil at 4 ${ }^{\circ} \mathrm{C}$. Protein binding capacity was determined empirically to be approximately $120 \mathrm{ng}$ of tsCA per $\mathrm{mg}$ of sTCO-beads by titrating protein onto decreasing amounts of beads (Fig. 2B).

To immobilize protein, 59.2 $\mu \mathrm{g}$ of sTCO-microparticles were washed twice with $\mathrm{MQ}-\mathrm{H}_{2} \mathrm{O}$ and again 4 times with $100 \mathrm{mM}$ HEPES buffer ( $\mathrm{pH} 7.5$, supplemented with $1 \mu \mathrm{M} \mathrm{ZnSO}_{4}$ ) and resuspended in $25 \mu \mathrm{L}$ of HEPES buffer per replicate (Scheme 1). To this washed microparticle solution $25 \mu \mathrm{L}$ of protein solution containing $0.125 \mathrm{nmol}$ of protein $(3.75 \mu \mathrm{g})$ were added to create a solution with a final bead concentration of $1.184 \mathrm{mg} / \mathrm{mL}$ and protein concentration of $2.5 \mu \mathrm{M}$. This amount of protein and beads corresponds with the typical 100\% load; for the 50\% and $25 \%$ load amounts, the bead amount was kept constant while the protein amount was reduced to 0.063 $\mathrm{nmol}(1.875 \mu \mathrm{g}$; final concentration of $1.125 \mu \mathrm{M})$ and $0.031(937.5 \mathrm{ng}$; final concentration of 625 $\mathrm{nM}$ ), respectively. This solution was allowed to react at room temperature for approximately 5 mins with frequent agitation. The microparticles were then separated from the supernatant by magnetic pull-down and washed three times with 1.0 mL of HEPES buffer supplemented with $0.05 \%$ Triton X-100 to remove non-specifically adsorbed protein, and three times again with 1.0 $\mathrm{mL}$ HEPES buffer before being resuspended in $500 \mu \mathrm{L}$ of HEPES buffer. A $500 \mu \mathrm{L}$ solution of beads afforded enough material to perform two activity assays, which were averaged as technical replicates. In a typical experiment, a $50 \mu \mathrm{L}$ master solution of $5 \mu \mathrm{M}$ tsCA is prepared per each replicate - this master solution was then split into two $25 \mu \mathrm{L}$ aliquots, one of which was exposed to sTCO-microparticles as described above, whereas the remaining aliquot was diluted to $500 \mu \mathrm{L}$ to serve as a free-enzyme control for activity assays. Likewise, the post-reaction supernatant was also collected and diluted to a final volume of $500 \mu \mathrm{L}$ to accompany activity assays; when necessary, each $1.0 \mathrm{~mL}$ wash solution was collected and the activity of the resulting solution was mathematically multiplied by a factor of two, to correct for dilution. For a graphical depiction of this immobilization and assay protocol, see scheme S1. We observed an approximate $15 \%$ loss in beads during the washing steps (primarily through beads sticking to the walls of the polypropylene tubes in which samples were handled; see figure S8), to account for this, we mathematically adjusted all bead-associated activity values by multiplying by a factor of 1.176 . When appropriate, the sTCO-beads were blocked with Tet2.0 via pre-reaction in a solution of $100 \mu \mathrm{M}$ Tet2.0 in HEPES buffer for approximately five minutes followed by three washes in HEPES prior to exposure to tsCA $\mathrm{C}_{186}$. Likewise, when appropriate, a $10 \mu \mathrm{M}$ solution of tsCA $\mathrm{A}_{186}$ was blocked with sTCO-OH via addition of an equal volume containing 10 molar equivalents of sTCO-OH for approximately five minutes prior to exposure to sTCO-beads.

To analyze sTCO-beads by XPS, the beads were mounted onto a silicon wafer support. To achieve this, silicon substrates were cut to $1 \mathrm{x} 1 \mathrm{~cm}^{2}$ (gift from the Oregon State University cleanroom), cleaned by sequential rinsing in $\mathrm{H}_{2} \mathrm{O}$ (MilliQ Direct-Q3) and acetone (PharmcoAaper), and then sequentially sonicated in dichloromethane, acetone and ethanol (PharmcoAaper). Following sonication steps, $30 \mu \mathrm{l}$ of functionalized Fe beads suspended in $\mathrm{H}_{2} \mathrm{O}$ were added to the surface in $10 \mu \mathrm{l}$ aliquots then the surfaces were dried under vacuum. The addition of $\mathrm{Fe}$ 
beads was done 3 times resulting in a uniform coating of functionalized Fe beads on the silicon substrates. The substrates were stored under nitrogen and away from light until analysis.

\section{Preparation of sTCO-SAMs and sfGFP Immobilization}

Preparation of sTCO-SAMs

Silicon wafer substrates were cleaned by soaking in MilliQ water overnight followed by rinsing in MilliQ water and acetone the next morning. The silicon substrates were then cleaned by sonication in DCM (dichloromethane), acetone, and ethanol then dried under a stream of nitrogen and stored until thermal evaporation (VEECO Thermal Evaporator). Substrates were prepared by thermal evaporation of $3.5 \mathrm{~nm}$ of titanium (99.995\%; Kurt. J. Lesker) followed by $100 \mathrm{~nm}$ of gold (99.999\% pure; Kurt. J. Lesker) onto a clean silicon wafer. Gold-coated wafers were immersed in an ethanolic solution of sTCO-disulfide 2 or 1-dodecanthiol (Sigma Aldrich, 98\% purity), a control for contact angle measurements, at a concentration of $1 \mu \mathrm{M}$. These solutions were prepared by either dissolving the reagent directly in ethanol, for the case of 1-dodecanthiol, or by diluting a $100 \mathrm{mM}$ stock of the compound dissolved in DMF, in the case of $\mathbf{2}$. The samples were parafilmed and backfilled with nitrogen for 24 hours in the absence of any light. After the 24 hours the samples were thoroughly rinsed in ethanol and dried under nitrogen. Samples were then stored under nitrogen in the absence of light until needed, being stored no later than a week before being used for protein immobilization

\section{Contact Angle Analysis of sTCO-SAMs}

A contact angle goniometer (First Ten Angstroms, Portsmouth, VA) was used to measure the contact angle of water on each substrate. Droplets $(10 \mu \mathrm{L})$ were pipetted onto each surface and a high-resolution image was collected $(n=3)$. The droplet shape, relative to the horizon line, was traced and a contact angle was generated by the provided instrument software.

\section{sfGFP Immobilization}

For protein immobilization, a $2 \mu \mathrm{L}$ solution of sfGFP at varying concentrations was deposited onto the sTCO-SAM in triplicate and allowed to react for approximately 5 minutes at room temperature under ambient humidity. To quench the reaction, a $1 \mu \mathrm{L}$ aqueous solution of $100 \mu \mathrm{M}$ sTCO-PEG 5000 was added to the $2 \mu \mathrm{L}$ protein droplet and given approximately 10 minutes to completely react. The surface was subsequently washed under a stream of buffer $(50 \mathrm{mM}$ $\mathrm{NaHPO}_{4}, 100 \mathrm{mM} \mathrm{NaCl}, \mathrm{pH}$ 7.50), followed by a stream of 50:50 buffer/deionized water, followed by a final stream of $100 \%$ deionized water for approximately 1 minute. When appropriate, sfGFP $_{150}$ was blocked with sTCO-PEG ${ }_{5000}$ by pre-reacting the protein at $1.0 \mu \mathrm{M}$ with 10 molar equivalents of sTCO-PEG 5000 for approximately five minutes in PBS buffer at room temperature prior to exposure to the sTCO-SAM surface. Likewise, when appropriate, the sTCO-SAM surface was blocked via pre-reaction with $1 \mathrm{uL}$ of 100 Methyl-Tetrazine-mPEG 5000 in water (Click Chemistry Tools, USA) at the location of eventual sfGFP 150 application for approximately five minutes at room temperature. Following immobilization, approximately $10 \mu \mathrm{L}$ of buffer $(50 \mathrm{mM}$ $\mathrm{NaHPO}_{4}, 100 \mathrm{mM} \mathrm{NaCl}, \mathrm{pH}$ 7.50) was then applied to the surface and a coverslip mounted, with moderate pressure applied to remove excessive buffer from between the coverslip and slide. The 
coverslip was then sealed to the slide using a store-bought nail polish preparation to prevent water loss during TIRFm observation.

\section{Total Internal Reflection Fluorescence Microscopy (TIRFm) Analysis}

To determine the relative amount of sfGFP present on the surface, fluorescent images of the surface were taken using an Axio Observer Z1 objective-type TIRF microscope (Zeiss) equipped with a 100×/1.46 numerical aperture oil-immersion objective and a back-thinned electron multiplier charge-coupled device camera (Photometrics) on TIR mode at a total magnification of 1000x (field of view being approximately $82 \mu \mathrm{m}$ x $82 \mu \mathrm{m}$ ) with an angle setting locked at $45^{\circ}$, and excitation using a $488 \mathrm{~nm}$ laser. To determine fluorescence intensity, three distinct (different fields of view) images were taken near the center of each spot where protein immobilization occurred, and their average intensity determined using Fiji (ImageJ) image analysis software ${ }^{60}$. The intensity of these three images were averaged and the mean of the three spots were then averaged to arrive at a final value for fluorescence intensity (total of nine images across three spots), with error bars representing the standard deviation between the three triplicate spot averages.

\section{Enzyme Activity Assays}

Enzyme activity was determined using a modified PNPA assay, as developed by Verpoorte, Mehta, and Edsall ${ }^{61}$. In this assay, tsCA samples were diluted to a concentration of 250 $\mathrm{nM}$ in a $1.7 \mathrm{~mL}$ polypropylene microcentrifuge tube. tsCA protein solutions ( $240 \mu \mathrm{L}$ at $250 \mathrm{nM})$ were added to a single well of a glass-coated 96-well microplate and combined with $60 \mu \mathrm{L}$ of a 20 $\mathrm{mM}$ para-nitrophenyl acetate (PNPA; Thermo Scientific, USA) solution dissolved in 1,2dimethoxyethane to yield a $300 \mu \mathrm{L}$ solution with a final protein concentration of $200 \mathrm{nM}$, and PNPA concentration of $4 \mathrm{mM}$ and 1,2-dimethoxyethane concentration of $20 \%$. The choice of 1,2dimethoxyethane over acetone was made since there is evidence that acetone is slightly inhibitory to bovine carbonic anhydrase ${ }^{62}$. For assaying activity of protein immobilized on beads, $240 \mathrm{uL}$ of the resulting $500 \mathrm{uL}$ solution yielded after adequate washing (see the section "Preparation of sTCO-Beads and tsCA Immobilization") was treated similarly to free-in-solution assays to yield a solution of similar protein, PNPA, and 1,2-dimethoxyethan concentrations. The final solution was then added to a BioTek Synergy2 plate reader (BioTek Instruments, Inc., USA) immediately following PNPA addition and the absorbance at $348 \mathrm{~nm}$ (PNPA isosbestic point ${ }^{63}$ ) was monitored every 18 seconds for 306 seconds with constant shaking between measurements. The enzyme activity was determined as the slope of the increasing absorbance at $384 \mathrm{~nm}\left(\mathrm{~A}_{348} / \mathrm{s}\right)$, and was mathematically blanked using the slope of a blank solution containing only HEPES solution, or, sTCO-microparticles for on-particle activity measurements. To calculate specific activity, A 348 changes were converted to nmols using an empirically-derived molar extinction coefficient for para-nitrophenol under assay conditions of $3586 \mathrm{M}^{-1}$. Unless otherwise stated, all activity readings composed of three replicates, each being the average of two technical replicates.

\section{Metabolic Radiolabeling with ${ }^{35} \mathrm{~S}$ and Detection of Radiolabeled tsCA}

To produce ${ }^{35} \mathrm{~S}$-radiolabeled tsCA $\mathrm{AT}_{\mathrm{W}}$ and tsCA $\mathrm{CA}_{233}$, strains 1 and 3 (Table $\mathrm{S} 1$ ) were grown in $25 \mathrm{~mL}$ of autoinduction media as mentioned prior, with additional supplementation of EasyTag $^{\text {TM }}$ EXPRESS35S Protein Labeling Mix (Perkin Elmer, Inc, USA) at a final concentration 
of $0.48 \mathrm{mCi} / \mathrm{mL}$. Cultures were grown for $24 \mathrm{hrs}$ before harvest and purified as previously mentioned, with lysis being carried out using BugBuster® Protein Extraction Reagent (Merck Millipore, KGaA, Germany). Protein was stored at $4^{\circ} \mathrm{C}$ until needed. Protein quantification was achieved via Bradford assay ${ }^{64}$. Unless otherwise mentioned, detection of all radiolabeled proteins was carried out by forming a mixture of $1 \mathrm{~mL}$ HEPES solution containing radiolabeled protein (either free or immobilized) and $9 \mathrm{~mL}$ of Ultima-Flo M liquid scintillation cocktail (Perkin Elmer Inc, USA) in a $20 \mathrm{~mL}$ borosilicate scintillation vial and counting for 5 minutes under the S35 setting in either a Beckman LS6500 or Beckman LS6000 liquid scintillation counter (Beckman Coulter Inc, USA), with radioactivity being reported as raw CPM values. It should be noted here that radioactive tsCA was not assayed for its enzymatic activity. As such, enzymatic activity and radioactivity measurements were performed on two separate preparations of tsCAwT and tsCA 233 .

\section{X-Ray Photoelectron Spectroscopy}

The XPS data was collected with a PHI 5600 system (Physical Electronics, USA) using a monochromatic Al Ka X-ray source (hv $=1486.6 \mathrm{eV}, 300 \mathrm{~W}, 15 \mathrm{kV})$ and take-off angle of $45^{\circ}$ (angle between the surface normal and the axis of the analyzer beam). Atomic compositions were calculated from $\mathrm{C}_{1 \mathrm{~s}}, \mathrm{~N}_{1 \mathrm{~s}}, \mathrm{O}_{1 \mathrm{~s}}, \mathrm{Fe}_{2 \mathrm{p}}, \mathrm{Au}_{4 \mathrm{f}}$, and $\mathrm{Si}_{2 \mathrm{p}}$ peak areas obtained from survey and highresolution scans (analyzer pass energy $=187.85 \mathrm{eV}$ and $23.5 \mathrm{eV}$ for survey and high-resolution scans, respectively). The spectra were collected at fresh spots on the sample $(n=3)$ and were charge corrected to the $\mathrm{C}_{1 \mathrm{~s}}$ aliphatic carbon binding energy at $285.0 \mathrm{eV}$ and a linear background was subtracted for all peak area quantifications except Fe, which used a Shirley background. Error bars in the reported data represent the standard deviation of the atomic percent average of the three spots. The peak areas were normalized by the sensitivity factors provided by the manufacturer and surface concentrations were calculated using CASA XPS (Casa Software Ltd).

The amount of protein on the surface of the Fe beads can be followed by the nitrogen atomic percent determined from the $\mathrm{N}_{1 \mathrm{~s}}$ signal. The nitrogen from just the protein layer can be calculated by examining the attenuation of the $\mathrm{Fe}_{2 p}$ signal from the core of the magnetic beads after protein is covalently attached to the surface by equation 1 .

$N_{\text {Norm }}=N_{p}-N_{s}\left(F e_{p} / F e_{s}\right)$

Where, $\mathrm{N}_{\mathrm{s}}$ and $\mathrm{Fe}_{\mathrm{s}}$ are the measured $\mathrm{N}$ and $\mathrm{Fe}$ atomic percent, respectively, from the $\mathrm{Fe}$ beads prior to either sTCO or covalent attachment of protein; $\mathrm{N}_{\mathrm{p}}$ and $\mathrm{Fe}_{\mathrm{p}}$ are the measured $\mathrm{N}$ and Fe atomic percent, respectively, from the Fe beads after addition of sTCO and covalent attachment of protein; and $\mathrm{N}_{\mathrm{Norm}}$ is the nitrogen atomic percent that accounts for just the covalently attached protein.

\section{Protein Crystallography}

Expression, Purification, and Crystallization. Proteins were expressed in a similar fashion as stated in the section "Protein Expression, Amber Suppression, and Purification" with the following modifications: culture volumes were $100 \mathrm{~mL}$, and proteins were purified via a two-step process by first passing cleared lysate in TALON wash buffer over a HisTrap HP 5 mL column and eluting in TALON elution buffer followed by purification over a Superdex S200 10/300 column, both performed on an AKTA Explorer FPLC (columns and FPLC from Amersham 
Biosciences, UK). The proteins were de-salted into $10 \mathrm{mM}$ HEPES (pH 7.5) and spin-concentrated to $11 \mathrm{mg} / \mathrm{mL}$ and $15 \mathrm{mg} / \mathrm{mL}$, for tsCA 186 , and tsCA 233 , respectively, and stored at $4{ }^{\circ} \mathrm{C}$.

Two approaches were taken to prepare crystals of $\mathrm{tsCA}_{186}$ and tsCA $\mathrm{CA}_{233}$ reacted with sTCO$\mathrm{OH}$ 4. For ts $\mathrm{CA}_{186}$, the protein was first crystallized as described below, and subsequently reacted with 4 in crystallo by soaking crystals in a solution of $880 \mu \mathrm{M} 4$ (final methanol concentration $\sim 10 \%$ ) in artificial mother liquor with cryoprotectant for at least $1 \mathrm{~min}$ before being frozen in liquid nitrogen. These crystals showed visible cracking during the sTCO soak, suggestive of an in crystallo Tet2.0-sTCO reaction. For tsCA $\mathrm{A}_{233}$, freshly purified protein was reacted in solution through exposure to two equivalents of 4 (final concentration of 4 was approximately $82 \mu \mathrm{M}$, with 9.67\% methanol in $1 \mathrm{~mL}$ of $10 \mathrm{mM}$ HEPES, $\mathrm{pH}$ 7.5) for $15 \mathrm{~min}$. The protein was de-salted using a PD-10 desalting column (GE Healthcare, USA), spin-concentrated to a final concentration of $\sim 20 \mathrm{mg} / \mathrm{mL}$ using a VivaSpin-2 10k MWCO disposable spin-concentrator (GE Healthcare, USA), and stored at $4{ }^{\circ} \mathrm{C}$.

In all cases, the enzymes were crystallized at $4{ }^{\circ} \mathrm{C}$ in hanging drops. tsCA $\mathrm{A}_{186}$ was crystallized using a reservoir solution of $0.2 \mathrm{M}$ ammonium sulfate and 30\% PEG 4000. tsCA $\mathrm{A}_{233}$ (Ordered Tet2.0) was crystallized using a reservoir solution of $0.2 \mathrm{M}$ ammonium acetate, $0.1 \mathrm{M}$ sodium acetate trihydrate $\mathrm{pH} 4.6$, and 30\% $\mathrm{PEG}_{4000}$. tsCA233 (Disordered Tet2.0) and tsCA $233^{-}$ sTCO were crystallized using a reservoir solution of $0.2 \mathrm{M}$ sodium chloride, $0.1 \mathrm{M}$ Tris $\mathrm{pH} 8.5$, and $25 \%$ PEG 3350. Crystals grew in clusters of plates which were separated into individual crystals for data collection.

Data Collection. For diffraction data collection at $-170{ }^{\circ} \mathrm{C}$, all crystals were passed through artificial mother liquor containing cryoprotectant (15\% for all except $20 \%$ glycerol for tsCA $\mathrm{A}_{186}$ ) and then cryo-cooled by plunging into liquid nitrogen. Data were collected at beamline 5.0.2 with $\square=1.0 \AA$ (tsCA $\mathrm{t}_{186}, \mathrm{tsCA}_{233}$ (Ordered Tet2.0), ts $\mathrm{CA}_{233}$ (Disordered Tet2.0), tsCA 233 -sTCO) and beamline 5.0.3 with $\square=0.976 \AA$ (tsCA $\left.{ }_{186}+\mathrm{sTCO}\right)$ at the Advanced Light Source (Berkley, CA). Data were collected for $360^{\circ}$ at a detector distance of $\mathrm{D}=180 \mathrm{~mm}$ with $\Delta \varphi=0.25^{\circ}$ and $0.1 \mathrm{~s}$ exposure for tsCA $\mathrm{CA}_{233}$ (Ordered Tet2.0), at $\mathrm{D}=210 \mathrm{~mm}$ with $\Delta \varphi=0.25^{\circ}$ and $0.1 \mathrm{~s}$ exposure for tsCA $\mathrm{A}_{233}$ (Disordered Tet2.0) and tsCA233-sTCO, and at $\mathrm{D}=220 \mathrm{~mm}$ with $\Delta \varphi=1^{\circ}$ and $3 \mathrm{~s}$ exposure for tsCA $_{186}+$ sTCO. For tsCA ${ }_{186}$, data were collected from 2 crystals, each for $360^{\circ}$ at $\mathrm{D}=200 \mathrm{~mm}$ with $\Delta \varphi=1^{\circ}$ and $2 \mathrm{~s}$ exposures.

Images were processed using $\mathrm{XDS}^{65}$ or Mosflm ${ }^{66}$ and the $\mathrm{CCP} 4^{67}$ suite of programs. For tsCA $_{186}$, images showing substantial decay based on visual examination were excluded. For the first and second crystals, the first 185 and 131 images, respectively, were included. In all cases, a $\mathrm{CC}_{1 / 2}$ of $\sim 0.2$ was the resolution cutoff criterion (see Table 1 for corresponding resolutions) and a random $5 \%$ of reflections were marked for cross-validation

Structure Determination and Refinement. In all cases, the structures were solved using molecular replacement with a structure of human carbonic anhydrase II (PDB code 1CA2 with $97 \%$ sequence identity) as the search model. All manual model building was done in Coot $^{68}$. The Tet 2.0 coordinates and crystallographic information file was generated using phenix.elbow ${ }^{69}$ with restraints further manually edited to allow Tet 2.0 to fit into high resolution density. Refinements were carried out using Phenix ${ }^{70}$ with TLS and riding hydrogens for ts $\mathrm{CA}_{186}$, tsCA $_{233}$ (Disordered Tet2.0), tsCA233-sTCO, and tsCA $\mathrm{A}_{186}+\mathrm{sTCO}$ and unrestrained individual anisotropic refinement $(\mathrm{wu}=0)$ for $\mathrm{tsCA}_{233}$ (Ordered Tet2.0). 
Accession Numbers. Coordinates and structure factors for tsCA $186, \mathrm{tsCA}_{186-\mathrm{sTCO}}$, tsCA $\mathrm{A}_{233}$ (Ordered Tet2.0), tsCA $\mathrm{CA}_{233}$ (Disordered Tet2.0), and tsCA $\mathrm{A}_{233-\mathrm{sTCO}}$ have been deposited in the Protein Data Bank with accession numbers 6NJ2, 6NJ6, 6NJ3, 6NJ5, and 6NJ4, respectively.

\section{Statistical Methods}

Experiments were carried out in triplicate and error bars represent the standard deviation of the individual measurements. Reported p-values are based on heteroskedastic, two-tailed t-tests performed using Microsoft Excel. For enzyme activity and radioactivity measurements, each value represents the mean of three measurements, with each measurement being the mean of two technical replicates. For XPS, an average and standard deviation were calculated $(n=3)$ for each sample type.

\section{Supplementary Text}

\section{Protein Characterization}

Yield and Suppression Efficiency. Site-specific incorporation of Tet2.0 was accomplished through the use of the standard amber suppression approach ${ }^{71}$. This method relies on the use of an orthogonal amino acyl-tRNA synthetase (aaRS) and its cognate tRNACUA (together referred to as a suppression pair) that is used to genetically direct the incorporation of a noncanonical amino acid (ncAA) at the position of an amber stop codon. In this study, Tet2.0 incorporation was achieved through use of a previously designed and characterized suppression pair consisting of: 1) an $M j$ TyrRS that has been engineered specifically to recognize Tet2.0, and 2) its cognate, recoded MjtRNA ${ }_{\text {CUA }}^{\text {Tyr }}$ originating from Methanocaldococcus jannashii that recognizes amber stop codons. Both components of the Tet 2.0 suppression pair are orthogonal in E. coli and produce protein with high efficiency and fidelity only when ncAA is supplemented to the media ${ }^{72}$.

For tsCA, optimal suppression and yield could be achieved through growth and autoinduction in autoinduction media for $48 \mathrm{hrs}$ at $500 \mu \mathrm{M}$ Tet2.0. Under these conditions, yields of approximately 20-50 mg of high-purity protein per liter of culture were achieved with good suppression efficiencies with yields of the Tet2.0-containing proteins being comparable to that of WT protein (Figure S1). The high expression yield of tsCA required supplementation of the autoinduction media with $200 \mu \mathrm{M} \mathrm{ZnSO}_{4}$ to achieve consistent enzymatic activity of the variants, which may be due to the $\mathrm{Zn}$ ion being a limiting cofactor during expression in the defined autoinduction media.

For sfGFP, optimal expression required $24 \mathrm{hrs}$ of expression at similar conditions $\left(\mathrm{ZnSO}_{4}\right.$ supplementation was not necessary) which resulted in high yields ( 100-200 mg of high-purity protein per liter of culture) and a suppression efficiency of $46 \%$ for $\mathrm{sfGFP}_{150}$, which is similar to our previous work with this system (Figure S6) ${ }^{22}$.

Metabolic S35 Radiolabeling of tsCA. tsCA contains three sulfur-containing residues (M1, C205, M240), which allowed incorporation of $\mathrm{S}^{35}$-containing methionine and cysteine through metabolic incorporation ${ }^{73}$. We chose to use metabolic incorporation as opposed to the more commonly used $\mathrm{I}^{125}$ modification, since there is evidence that this method can lead to erroneous protein quantification results due either to free $\mathrm{I}^{125}$ or changes in sorption properties of iodinated 
proteins $^{74-76}$. By tracking the amount of radioactivity in the culture supernatant, cell lysis flowthrough, and final wash (assumed to be representative of the amount in each of the five $10 \mathrm{~mL}$ washes) and correcting for dilution, we estimated that roughly $32 \%$ of the radioactivity was cellularly incorporated, and of that approximately $17 \%$ and $21 \%$ of the total radioactivity was incorporated in tsCAwT and tsCA 233 (Figure S7A). We then determined the radioactivity (CPM) per pmol of tsCA for both tsCAwT and tsCA233 to be approximately 48.3 and 31 CPM, respectively, indicating that a typical $100 \%$ load of protein $(3.75 \mu \mathrm{g}$, or $125 \mathrm{pmol})$ should produce approximately 6000 , and $3900 \mathrm{CPM}$ for tsCAwT and tsCA 233 , respectively, which we observed to be empirically consistent and well above background (Figure S7B).

Mass Spectrometry Analysis. Successful site-specific incorporation of Tet2.0 into tsCA was verified by electrospray ionization protein mass spectrometry. For tsCA, we observed a tsCAwT mass of $30002.2 \pm 1 \mathrm{Da}$ (Figure S8). tsCA $\mathrm{WT}_{\mathrm{WT}}$ had a loss of $131.1 \pm 1 \mathrm{Da}$, and addition of $63.4 \pm 1$ Da consistent with removal of $\mathrm{N}$ - terminal methionine and addition of $\mathrm{Zn}$ ion to the three active site histidine ligands, respectively ${ }^{77}$. The incorporation of Tet 2.0 at tsCA glutamate sites 186 and 233 showed the appropriate mass shift of 112.1 and $113.5 \pm 1 \mathrm{Da}$, respectively, while incorporation at phenylalanine site 20 showed the appropriate mass shift of 95.6 Da. Samples also showed $+23.0 \pm 1 \mathrm{Da}$, corresponding to the mass of sodium adducts. No other peaks were observed that would correlate with background incorporation of natural amino acids (Figure S8). For sfGFP we observed similar results, with the sfGFP ${ }_{w T}$ variant matching the predicted mass, and sfGFP $_{150}$ showing a mass change consistent with Tet2.0 incorporation, $128.0 \pm 1 \mathrm{Da}$, (expected $127.3 \pm 1$ Da) (Figure S9). These samples also showed $+23.0 \pm 1 \mathrm{Da}$, corresponding to the mass of sodium adducts. Taken together, these results corroborate SDS-PAGE analysis of purified tsCA and GFP protein (Figure S10 and Figure S11) confirm that Tet2.0 has been site-specifically incorporated into tsCA and sfGFP.

Enzymatic Activity. To assess enzymatic activity, an adapted version of a common esterase activity assay developed for carbonic anhydrase was employed (40). This assay relies on the innate esterase activity of carbonic anhydrase towards para-nitrophenol acetate (PNPA), which is a colorless compound that is hydrolyzed by tsCA to the colored product para-nitrophenol (PNP). To avoid any influences of $\mathrm{pH}$ that may arise from tsCA's interconversion of ambient $\mathrm{CO}_{2}$ to $\mathrm{HCO}_{3}$ prior to activity readings, we chose to monitor colorimetric increases at PNP's isosbestic point $(438 \mathrm{~nm})$.

Overall, we observed little effect of Tet2.0 incorporation on the enzymic activity for tsCA $\mathrm{C}_{186}$ and tsCA $\mathrm{CA}_{233}(\sim 10 \%$ decrease) (Figure $\mathrm{S} 2)$. For tsCA $\mathrm{A}_{20}$ on the other hand, we observed a consistent $\sim 25 \%$ reduction in activity, the reasons for which we discuss in the main body of the work but may likely be due to its proximity to the active-site. Subsequent reaction of Tet 2.0 with an sTCO-PEG 5000 polymer led to a further slight decrease in activity for tsCA $\mathrm{A}_{186}$ and tsCA $\mathrm{A}_{233}$ $(\sim 10 \%)$, but conversely for $\mathrm{tsCA}_{20}$ seemed to restore activity of this variant to that similar to tsCAwt. These details are addressed further in the main body of the work and in the supplemental section " $X$-Ray Crystallography of tsCA."

Tet2.0 Reactivity. To assess the in proteo reactivity of Tet2.0, we relied on both an SDSPAGE mobility shift assay and size exclusion chromatography (SEC). In short, Tet2.0-containing protein is reacted with an excess (approximately 10 molar equivalents) of sTCO-PEG5000 polymer for approximately 5 minutes to allow complete reaction. This sample is then analyzed by either 
SDS-PAGE followed by Coomassie staining, or by SEC. If successful bioconjugation has occurred, a protein mobility shift is observed due to the attachment of a large polymer, which is detectable as an increase in the apparent molecular weight of the protein by SDS-PAGE or by decrease in retention volume by SEC. The ratio of unshifted (unreacted) and shifted (reacted) bands, as determined by densitometry analysis for SDS-PAGE analysis and by comparison of the reacted and reacted peaks for SEC, provides a means of assessing the in proteo reactivity of Tet2.0.

SDS-PAGE analysis revealed a nearly complete bioconjugation of protein $(95-99 \%$ mobility shift) within 5 minutes at a protein concentration of approximately $9 \mu \mathrm{M}$ for all three tsCA variants and sfGFP $_{150}$, confirming that these locations are accessible and sufficient for efficient immobilization within the 5 minute immobilization period (Figs, S10 and S11). Importantly, no appreciable mobility shift for tsCAwT or sfGFP ${ }_{W T}$ was observed, which suggests that the reaction between Tet2.0 and sTCO is specific and bioorthogonal (Figs. S10 and S11). By SEC, both the reacted and unreacted proteins are effectively resolved, with a decrease in retention time of approximately $2 \mathrm{~mL}$ being observed for the reacted (retention volume of $\sim 15.1 \mathrm{~mL}$ ) protein relative to the unreacted protein (retention volume of $17.2 \mathrm{~mL}$ ), which permitted isolation of the PEGylated tsCA $\mathrm{Aet}_{\mathrm{T} .0}$ variants (Figure S12).

X-Ray Crystallography of tsCA-Tet2.0 and ligation product. There is little information available to determine how bioorthogonal handles on proteins effect protein structure. Here, we report the first structural characterization of tetrazines and their reaction within proteins to assess the effects of Tet2.0 incorporation and its reaction with sTCO have on the structure of the tsCA enzyme. These structures provide details of the Tet 2.0 structure in a protein environment with resolutions ranging between 1.01 and $1.60 \AA$. In our attempts to obtain structures of tsCA $\mathrm{A}_{233}$, two different crystal forms compatible with tsCA $\mathrm{CA}_{233}$ were identified-one in which the Tet 2.0 at site 233 is part of the crystal packing interface, and therefore ordered and able to be modeled (tsCA $\mathrm{A}_{233}$ (Ordered Tet2.0); space group P $2{ }_{1} 2_{1} 2_{1}$ ), and another in which the Tet2.0 at site 233 is solvent exposed and disordered and was not modeled ( $\mathrm{tsCA}_{233}$ (Disordered Tet2.0); space group C222 ${ }_{1}$ ). However, following reaction with sTCO-OH 4 we were only able to achieve crystals of the space group where the Tet2.0 was disordered (tsCA233-sTCO; space group $\mathrm{C} 222_{1}$ ), and consequently, the ligation product was also disordered and could not be modeled. A summary of the data and refinement statistics for the crystal structures that were obtained are included in Table S3. The structures presented in Fig. 3A and 3B represent those structures for which we obtained clear density for the Tet2.0 (tsCA 233 (Ordered Tet2.0), tsCA 186 ). In the context of tsCA233, our analysis focused on the structure in which the Tet 2.0 is ordered, has clear $2 \mathrm{~F}_{\mathrm{o}}-\mathrm{F}_{\mathrm{c}}$ density, and could be modeled. In both tsCA $\mathrm{A}_{186}$ and $\mathrm{tsCA}_{233}$ (Ordered Tet2.0), Tet2.0 has clear density for the amino acid sidechain. The Tet2.0 conformation varies between crystal forms and chains in the asymmetric unit. The lack of density for Tet2.0 in tsCA $\mathrm{CA}_{233}$ (Disordered Tet2.0) and tsCA 233 -sTCO, where Tet2.0 is solvent exposed, provides evidence for mobility of the Tet2.0 side chain within this crystal form. Attempts to capture an atomic resolution snapshot of the Tet2.0-sTCO ligation did not provide sufficient electron density to model the ligation product; however, we it is worthy to note that we could only obtain crystals for ts $\mathrm{CA}_{233}$ in the $\mathrm{C} 222_{1}$ space group where the Tet2.0 is disordered, suggesting that the $\mathrm{P} 2{ }_{1} 2_{1} 2_{1}$ space group cannot accommodate the ligation product. Our primary findings of structural changes in response to Tet2.0-sTCO ligation and Tet2.0 incorporation are discussed in the main body of the work. 


\section{Characterization of Surfaces}

Contact Angle Analysis of sTCO-SAMs. Equilibrium contact angle reflects the relative strength of molecular interactions at the solid liquid interface an provides information about the first few monolayers of a surface. For our surface chemistry, as depicted in Figure S13, we chose to compare our thiolated sTCO to two other surfaces of 1-dodecanethiol and bare gold. Static contact angle goniometry, with $10 \mu \mathrm{L}$ ultrapure water as the test fluid, was used to measure the angle between droplet and substrate, with low angles less than $90^{\circ}$ correlating to hydrophilicity and angles greater than $90^{\circ}$ correlating to hydrophobicity. Contact angles of $94^{\circ} \pm 1^{\circ}, 103^{\circ} \pm 1^{\circ}$, and $66^{\circ} \pm 1^{\circ}$ were measured for the bare gold, 1-dodecanthiol, sTCO SAM, surfaces respectively (Figure S13). These results for the bare gold surface indicate that the surface is hydrophobic, which suggests that there is likely a partial monolayer of carbon contamination on the surface since pristine clean gold surfaces are typically hydrophilic ${ }^{78}$. Modifying the surface to a selfassembled monolayer (SAM) of 1-dodecanethiol ${ }^{79}$ yields a surface contact angle that is hydrophobic $\left(103^{\circ} \pm 1^{\circ}\right)$ which is the expected outcome for 1-dodecanethiol. For our selfassembled monolayers of thiolated sTCO, on the other hand, the contact angle results in a hydrophilic surface. which may likely be due to the polar amide bond in the sTCO-S-S-sTCO compound $\mathbf{2}^{80}$.

XPS of functionalized magnetic microparticles. XPS is a surface analytical technique able to provide precise atomic level compositions of the first approximately $10 \mathrm{~nm}$ of a surface ${ }^{11-12,81}$. Previously, XPS has been used to calculate the elemental compositions of micro- and nanoparticles on flat surfaces as well as monolayer coverage of proteins on charged surfaces and membrane environments ${ }^{11-12,81-87}$. In this study, XPS was used to follow the addition of sTCO and precise loading of ts $\mathrm{CA}_{23}$ on amine-functionalized iron oxide microparticles (Fe beads). Figure $\mathrm{S} 14$ shows the XPS average atomic compositions of $\mathrm{C}_{1 \mathrm{~s}}, \mathrm{~N}_{1 \mathrm{~s}}$, and $\mathrm{Fe}_{2 \mathrm{p}}$ for each sample type. We collected XPS spectra for each step in the sample preparation in order to track the precise loading (either $25 \%, 50 \%$, or $100 \%$ ) of $\mathrm{tsCA}_{233}$ on the surface of the microparticles. Specifically, our samples are bare Fe beads, sTCO functionalized Fe beads, sTCO functionalized Fe beads with tsCAwt, $25 \%$ loading of tsCA $233,50 \%$ loading of $\mathrm{tsCA}_{233}$, or $100 \%$ loading of tsCA233. In all cases, except for the incubation of tsCAwT and the sTCO functionalized Fe beads, we expect the average elemental atomic compositions relating to carbon and nitrogen to increase while the average atomic percent composition of iron will decrease, which can be directly related to the $\mathrm{C}_{1 \mathrm{~s}}, \mathrm{~N}_{1 \mathrm{~s}}$, and $\mathrm{Fe}_{2 p}$ core level electron ${ }^{11,82,86,88}$. Adding sTCO adds carbon to the system and thus we expect that the detected nitrogen and iron atomic percent will decrease while the carbon increases, and this is what we observe for the addition of sTCO to the Fe beads. As tsCA233 was applied, which contain carbon and nitrogen, to the microparticles, the concentration of carbon and nitrogen should increase, which is directly detectable as an increase in the atomic percentage of $\mathrm{C}_{1 \mathrm{~s}}$ and $\mathrm{N}_{1 \mathrm{~s}}$. Furthermore, adding biomolecules to the surface increases the overlayer thickness on the microparticles, increasing the attenuation of electrons from the Fe core of the microparticles, subsequently decreasing the detected average atomic percent of $\mathrm{Fe}$ in the samples ${ }^{82}$. Experimental results support these theoretical trends (Figure S14) which suggests successful functionalization of the amine surface with sTCO and subsequent successful immobilization of tsCA233. It is important to note that while tsCAwT does not contain Tet2.0, and thus cannot react with sTCO, non-specifically bound protein leftover from the washing step, as was observed with radiolabeling and enzymatic activity, can explain the minor increase in carbon and nitrogen concomitant with 
slight a decrease in iron. Thus, these XPS data confirm the conversion of functionalized aminebeads to sTCO-beads and subsequently confirms the immobilization of tsCA 233 .

Next, we sought to determine the surface load of protein at each step and compare it to theoretical loading amounts. It is important to normalize each sample to the starting sample of bare Fe beads so that we can determine the monolayer load of the protein on the beads as seen in Figure $\mathrm{S} 14^{11,82,89}$. By normalizing the $\mathrm{N}_{1 \mathrm{~s}}$ atomic percent composition of each sample and comparing the value to published XPS data for monolayers we can estimate the load of tsCA $\mathrm{A}_{233}{ }^{11,82}$. The values for the normalized $\mathrm{N}_{1 \mathrm{~s}}$ XPS data are: sTCO functionalized Fe beads $(0.08 \pm 0.06)$, tsCAwT $(0.49 \pm 0.06), 25 \%$ tsCA $233(2.19 \pm 0.31), 50 \% \operatorname{tsCA}_{233}(3.49 \pm 0.10), 100 \% \operatorname{tsCA}_{233}(6.36 \pm 0.12)$. For protein load on the sTCO-beads this normalized $\mathrm{N}_{1 \mathrm{~s}}$ corresponds to $\sim 52 \pm 1 \%$ for the "100\%" tsCA233 (50\% binding capacity), $28 \pm 1 \%$ for the "50\%" tsCA233 (25\% binding capacity) load, and $\sim 18 \pm 3 \%$ for the $25 \%$ tsCA233 (12.5\% binding capacity) load. The experimental results closely match our theoretical loading percent compositions, and thus, our ability to perform protein-limited immobilization is well supported by XPS. Survey spectra of $\mathrm{NH}_{2}$-beads under each of these loading conditions are shown in figure S15. High resolution XPS plots of the carbonyl and amide peaks used in quantification of the various load amounts are shown in figure S16.

XPS of functionalized flat gold surfaces with thiolated sTCO. XPS was also used to follow the formation of sTCO-SAMs and immobilization of sfGFP $_{150}$ on flat gold surfaces. Figure S17 shows the XPS average atomic compositions of $\mathrm{Au}_{4 \mathrm{f}}, \mathrm{C}_{1 \mathrm{~s}}$, and $\mathrm{N}_{1 \mathrm{~s}}$, for each sample type. We collected XPS spectra for each step in the sample preparation in order to track the addition of sTCO and sfGFP 150 on the surface of the gold substrates. Specifically, our samples include bare gold, sTCO-SAM functionalized bare gold, sTCO-SAM functionalized bare gold with sfGFP 150 loaded at $1.0 \mu \mathrm{M}$. In all cases, we expect the average elemental atomic compositions relating to carbon and nitrogen to increase while the average atomic percent composition of gold will decrease, which can be directly related to the $\mathrm{C}_{1 \mathrm{~s}}, \mathrm{~N}_{1 \mathrm{~s}}$, and $\mathrm{Au}_{4 \mathrm{f}}$ core level electrons ${ }^{11,82,86,88}$. Formation of sTCOSAMs increases carbon and nitrogen in the system and thus we expect that the nitrogen and carbon detected atomic percent will increase while the gold signal decreases, and this is what was observed for both nitrogen and gold (Figure S17). However, the carbon atomic percent appeared constant, which can be attributed to advantageous carbon present in the bare gold sample when compared to the sample with sTCO-SAM. Immobilization of sfGFP 150 , which contains carbon and nitrogen, causes a directly detectable increase in the atomic percentage of these elements, while simultaneously increasing the overlayer thickness which attenuates liberated electrons from the $\mathrm{Au}$ surface, thereby decreasing the atomic percentage of $\mathrm{Au}$ in the sample ${ }^{82}$. Experimental results match these theoretical trends (Figure S17) which supports the successful formation of sTCOSAMs and subsequent immobilization of sfGFP 150 . Taken together, these results match the trend for immobilization of tsCA $\mathrm{A}_{233}$ onto sTCO-beads, which supports the ability of this immobilization reaction to enable protein-limited loading on different surfaces. 


\section{Figures}

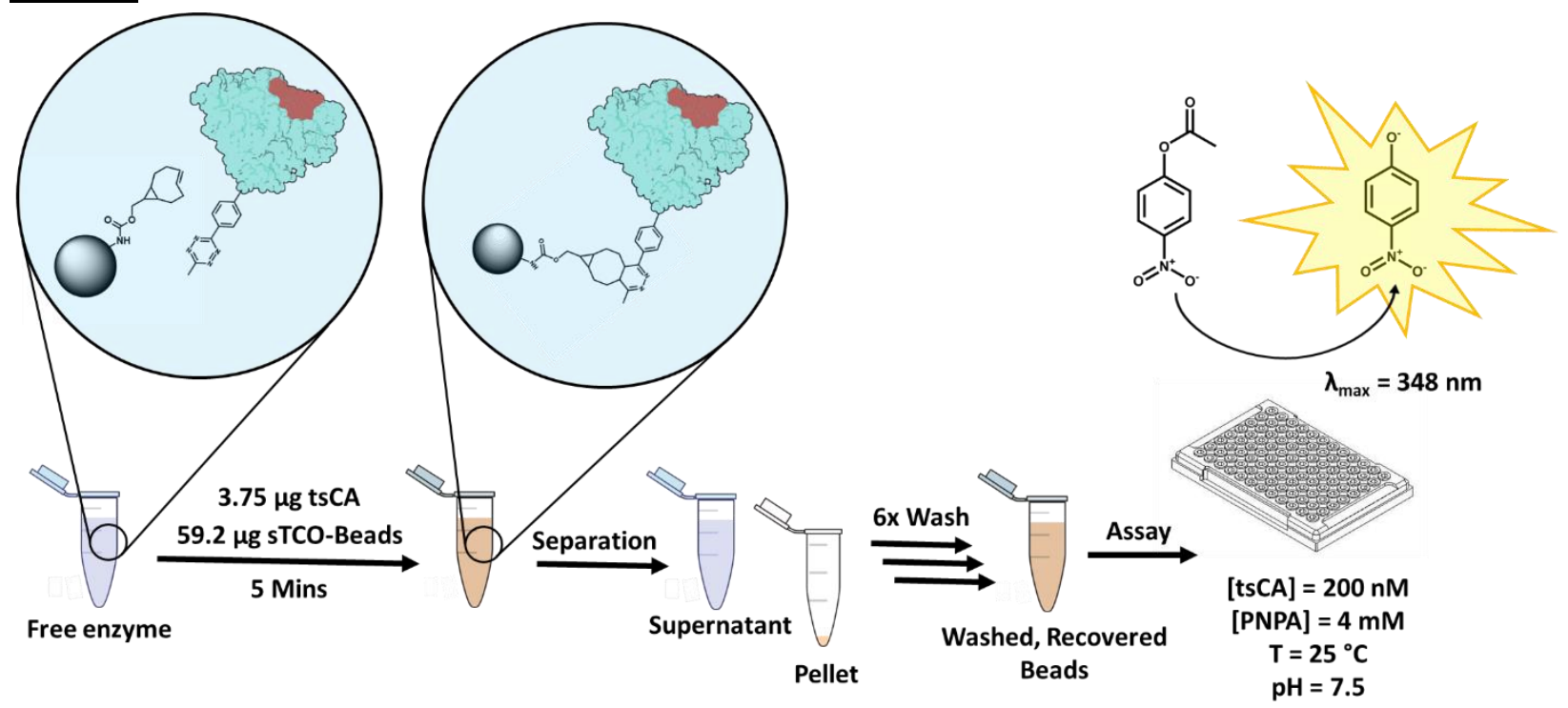

Scheme S1. Immobilization and subsequent activity assay protocol for tsCATet2.0 on sTCObeads. 

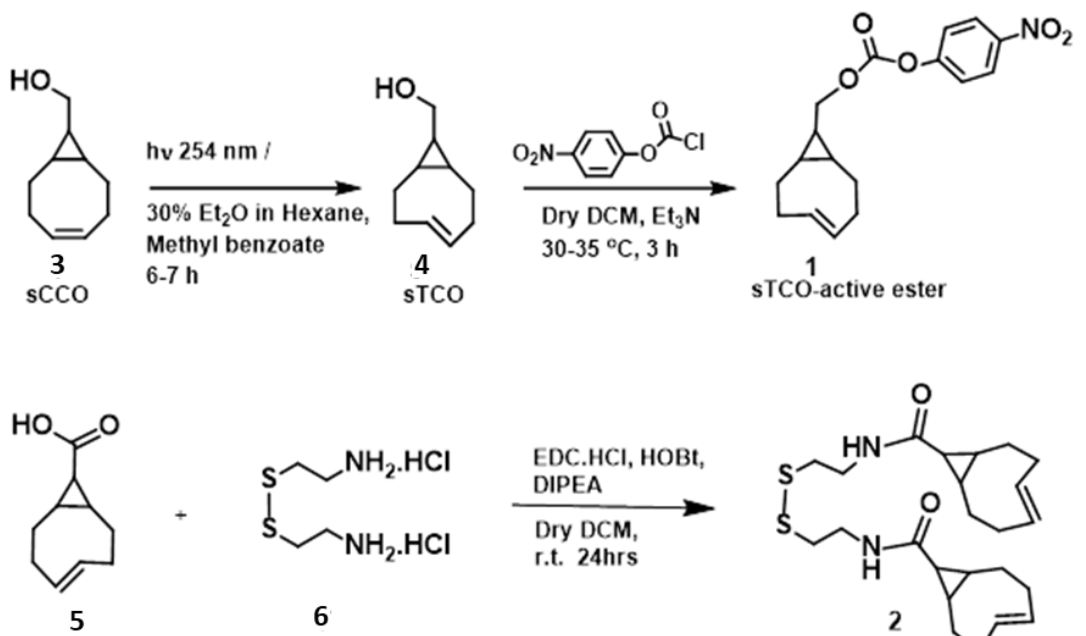

6

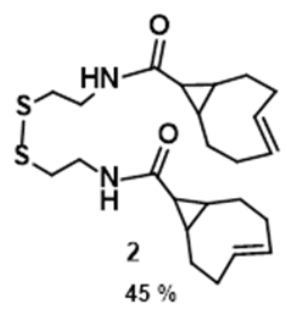

Scheme S2. Synthesis of 4-nitrophenyl active ester of trans-cyclooctene (sTCO) and disulfide attached di-sTCO derivatives 

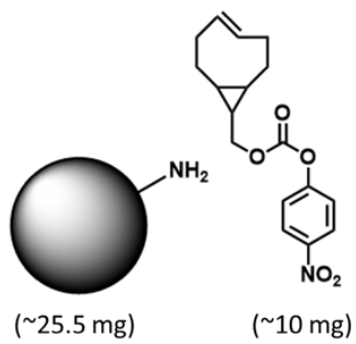

$\underset{\sim 24 \mathrm{hrs} \text { at RT in DCM }}{\stackrel{5.5 \mu \mathrm{L} \text { DiPEA }}{\longrightarrow}}$

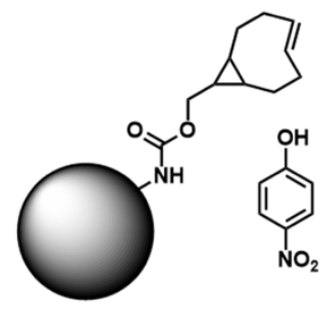

Scheme S3. Reaction for functionalization of $\mathrm{NH}_{2}$-beads to sTCO-beads 


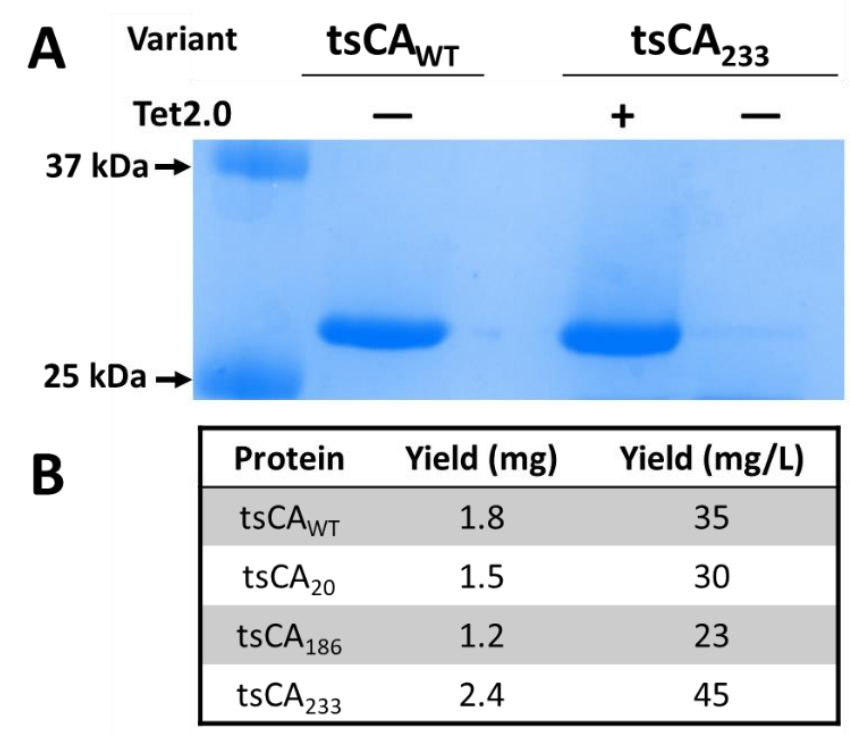

Figure S1. Suppression gel and table of yields for tsCA. (A) Suppression gel showing the relative yield of purified tsCAwT and tsC $\mathrm{CA}_{233}$ grown in the presence (tsCA 233 only) and absence (both) of Tet2.0. (B) Yields of tsCA used in this study. Included are the yield of tsCA protein from purification of $50 \mathrm{~mL}$ cell pellet, as well as the yield of protein as reported in $\mathrm{mg} / \mathrm{L}$. 


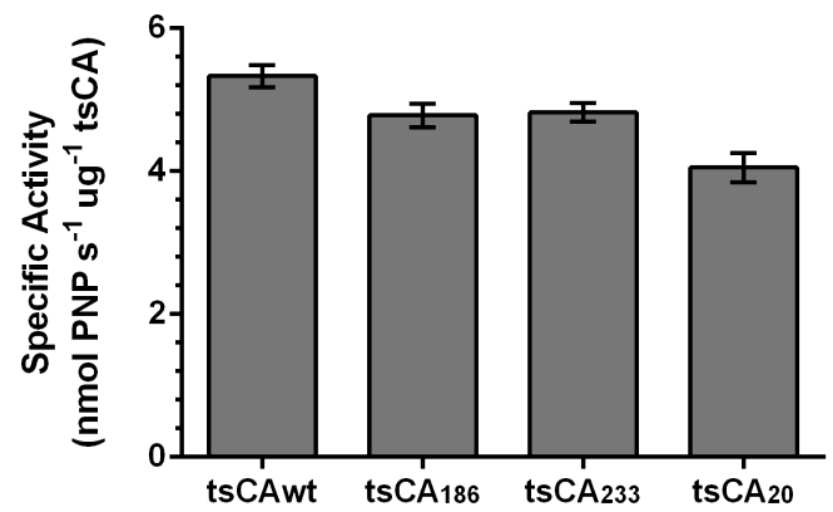

Figure S2. Specific activity of purified tsCA enzymes. Activity is reported in units of nmol of para-nitrophenol (PNP) produced per second per $\mu \mathrm{g}$ tsCA (nmol PNP s${ }^{-1} \mathrm{~mol}^{-1}$ tsCA). Concentration of protein was determined using a Bradford Assay. Activities of tsCA $\mathrm{A}_{186}, \mathrm{ts}_{\mathrm{CA}} \mathrm{A}_{233}$, and tsCA $\mathrm{A}_{20}$ relative to tsCAwT are $89.6 \%( \pm 3.4 \%), 90.4 \%( \pm 2.6 \%)$, and $76 \%( \pm 5.1 \%)$, respectively. 


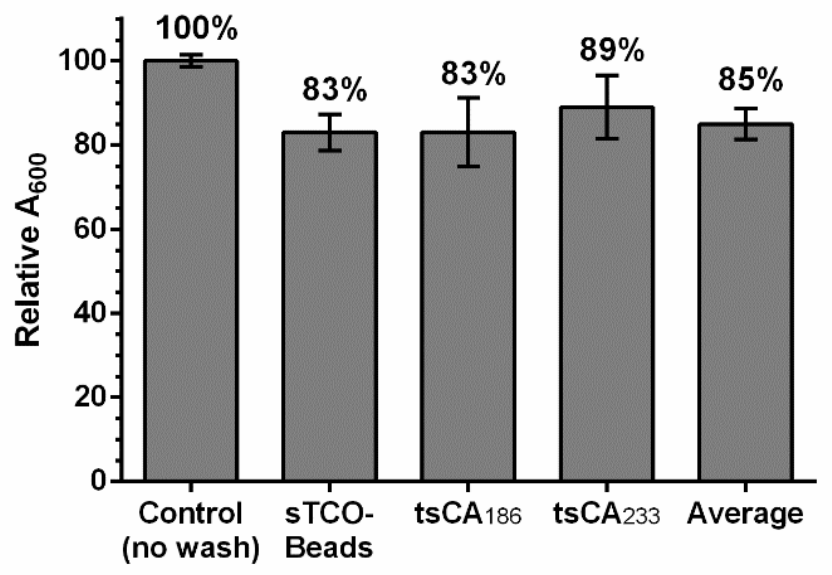

Figure S3. Bead loss during a standard post-reaction washing procedure. Relative absorbance at $600 \mathrm{~nm}$ of recovered sTCO-microparticles exposed to various tsCA protein types after six washes, normalized to a no-wash control. 


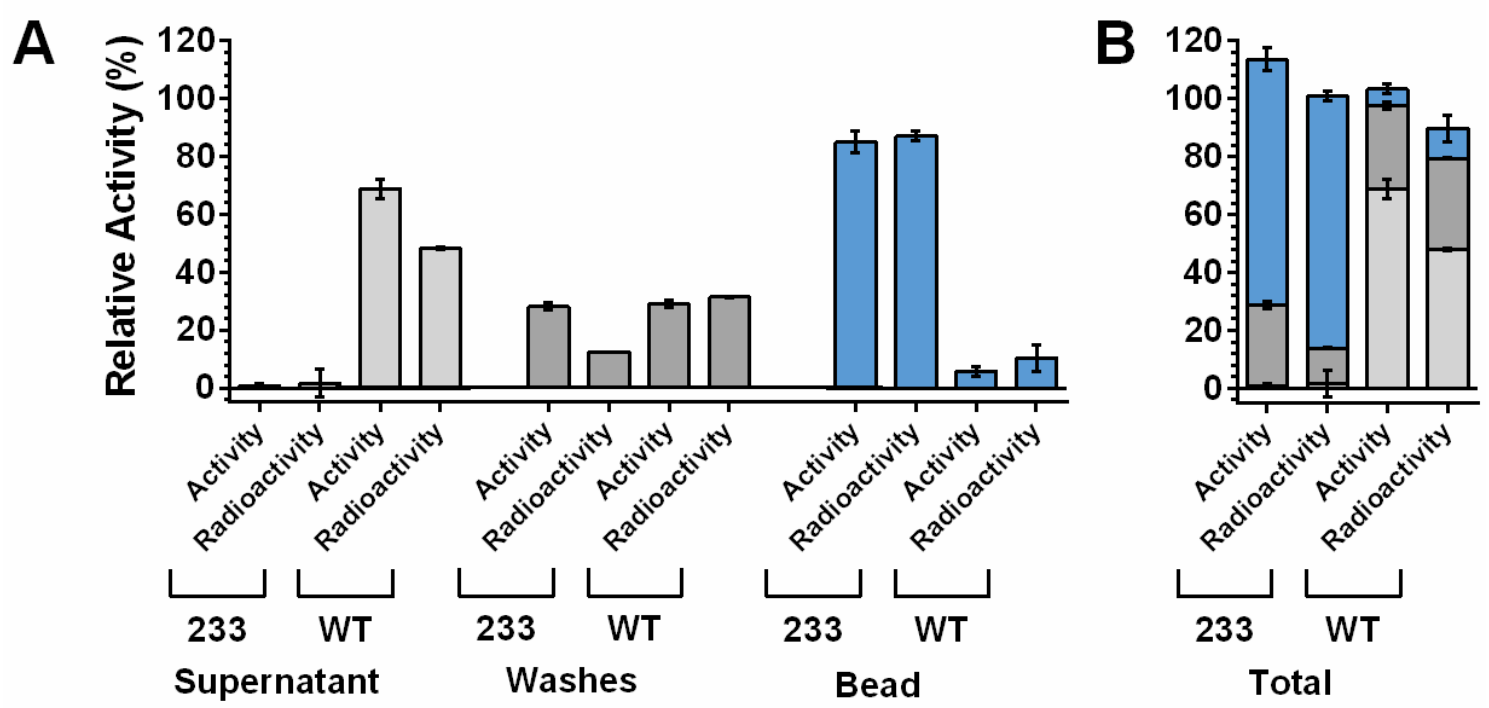

Figure S4. tsCA mass balance during a typical washing procedure. (A) Relative enzymatic activity and radioactivity of both ts $\mathrm{CA}_{233}$ and tsCAwT associated with the various fractions collected during typical handling steps, including: the post-immobilization supernatant (supernatant, light gray), the six subsequent washes (washes, dark gray), and recovered beads (beads, blue). (B) Total cumulative amount of enzymatic and radioactivity recovered from these fractions depicted as a stacked column. 


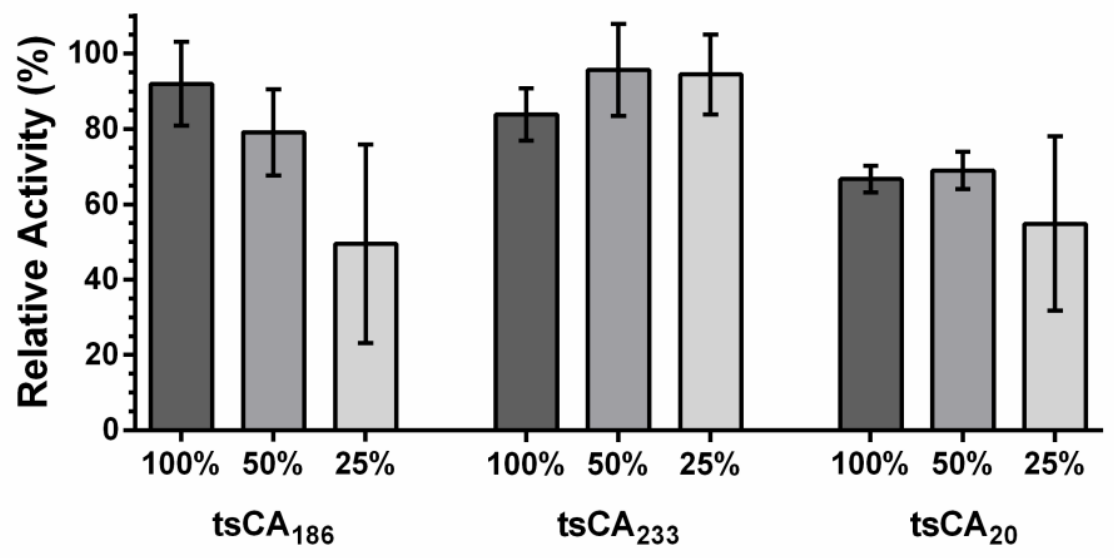

Figure S5. Orientational- and density-dependent effects on immobilized tsCA activity. Enzyme activity relative to a free-in-solution control for tsCA $\mathrm{A}_{186}, \mathrm{tsCA}_{233}$ and tsCA $\mathrm{A}_{20}$ at $100 \%$ (dark gray), $50 \%$ (gray), and 25\% (light gray) loads. Data is adapted from Figure 3C. 


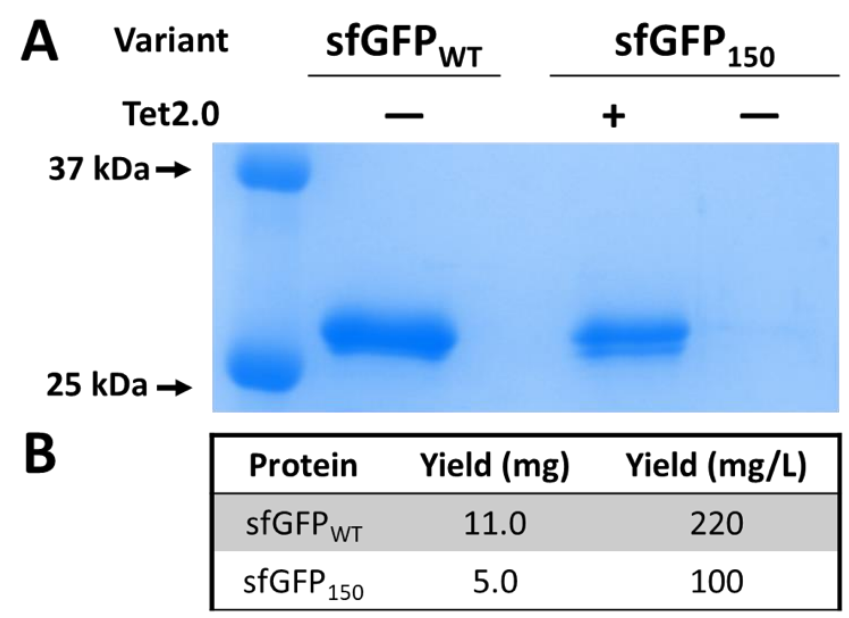

Figure S6. Suppression gel and table of yields for tsCA. (A) Suppression gel showing the relative yields of purified sfGFP ${ }_{\mathrm{WT}}$ and $\mathrm{sfGFP}_{150}$ grown in the presence ( $\mathrm{sfGFP}_{150}$ only) and absence (both) of Tet2.0. (B) Yield of sfGFP observed in this study. Included are the yield of sfGFP protein from purification of $50 \mathrm{~mL}$ cell pellet, as well as the yield of protein as reported in $\mathrm{mg} / \mathrm{L}$ culture. 

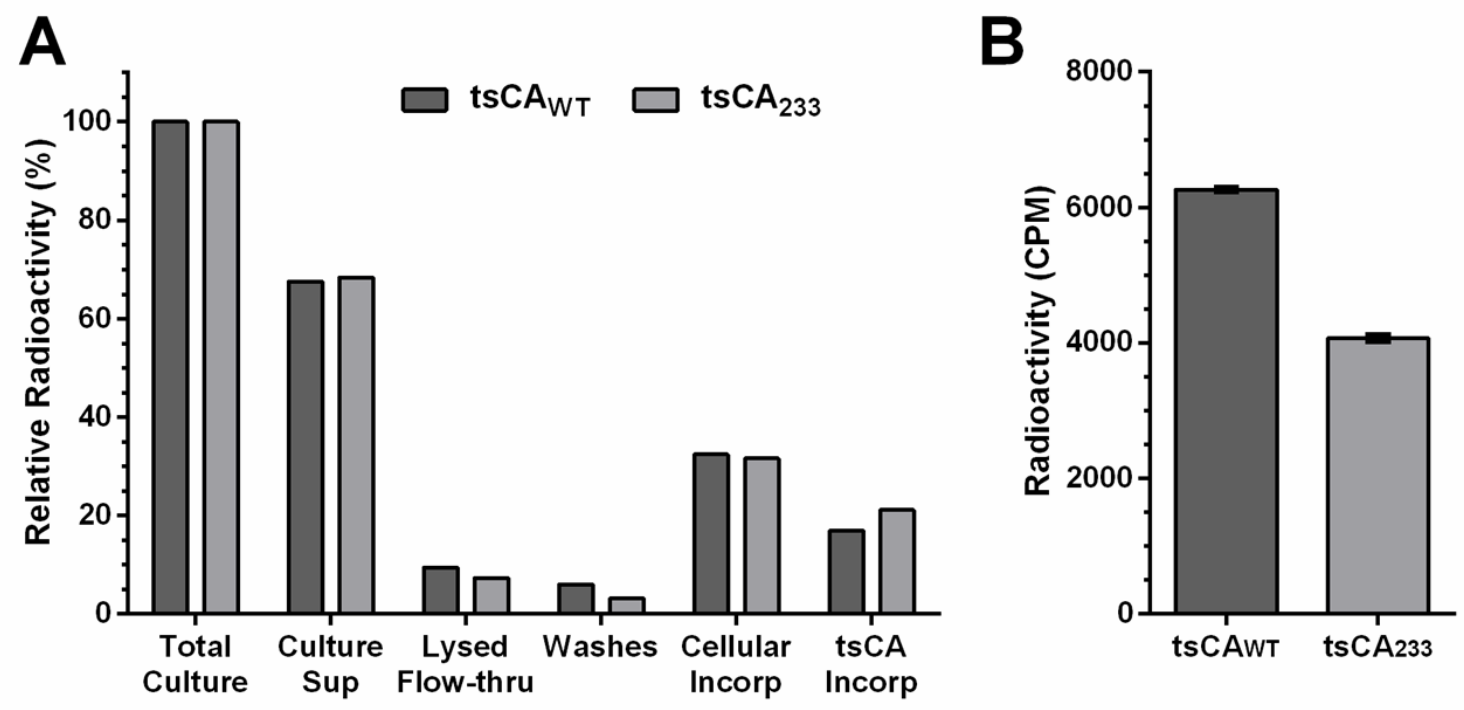

Figure S7. Radioactivity of $\mathrm{S}^{35}$-radiolabeled tsCAwT and tsCA233. (A) Relative radioactivity of various fractions collected during purification of both tsCAwT (dark gray) and tsCA233 (light gray), including the total culture, the supernatant of the culture after cell pelleting (Culture Sup), the lysed cellular flow-through collected after separation of TALON resin (Lysed flow-thru), and the final $1 \mathrm{~mL}$ of wash volume multiplied by 50 to represent the total wash volume (Washes). Included at right are the estimated percentage of radioactivity that has been cellularly incorporated (cellular incorp = total culture - culture sup) and that has been incorporated into tsCA (tsCA incorp = cellular incorp - lysed flow-thru - washes). Note, these measurements were made with $n=1$ replicates. (B) Radioactivity, reported in CPM, associated with 125 pmol (3.75 $\mu \mathrm{g}$ ) of tsCAwT (dark gray) and tsCA $\mathrm{CA}_{233}$ (light gray). 


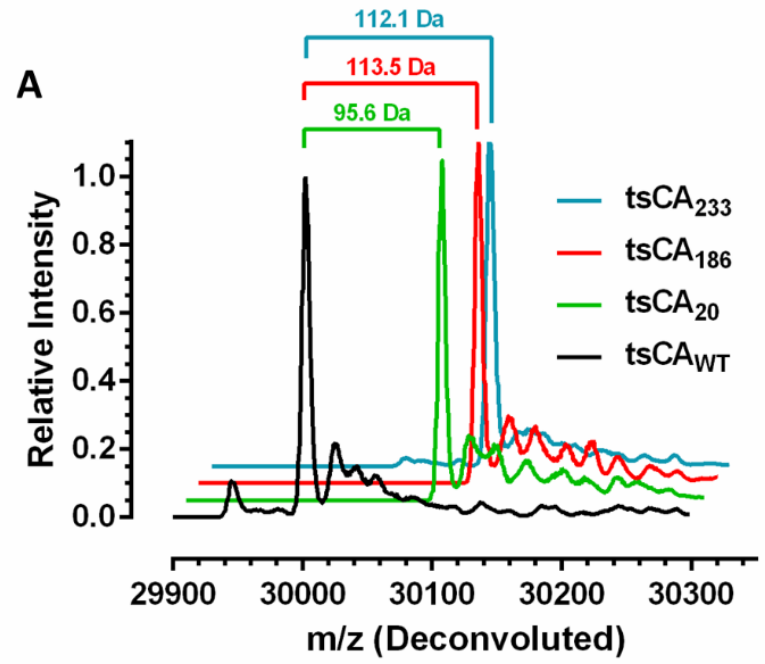

\begin{tabular}{|lccc|}
\hline Variant & $\begin{array}{c}\text { Observed } \\
\text { Mass }\end{array}$ & $\begin{array}{c}\text { Expected } \\
\text { Difference }\end{array}$ & $\begin{array}{c}\text { Observed } \\
\text { Difference }\end{array}$ \\
\hline tsCA & $30002.2 \mathrm{Da}$ & $\mathrm{N} / \mathrm{A}$ & $\mathrm{N} / \mathrm{A}$ \\
tsCA $_{186}$ & $30115.7 \mathrm{Da}$ & $112.2 \mathrm{Da}$ & $113.5 \mathrm{Da}$ \\
tsCA $_{\mathbf{2 3 3}}$ & $30114.3 \mathrm{Da}$ & $112.2 \mathrm{Da}$ & $112.1 \mathrm{Da}$ \\
tsCA $_{\mathbf{2 0}}$ & $30096.3 \mathrm{Da}$ & $94.1 \mathrm{Da}$ & $95.6 \mathrm{Da}$ \\
\hline
\end{tabular}

Figure S8. Mass spectrometry analysis of tsCA proteins. (A) Mass spectrometry traces of tsCA proteins presented as relative abundance per $\mathrm{m} / \mathrm{z}$, including tsCAwt (black), tsCA 186 (red), tsCA233 (blue), tsCA 20 (green). Note, traces have been offset to minimize overlap. (B) Comparison of observed and expected masses relative to tsCAWT. Each sample had a loss of $131.1 \pm 1 \mathrm{Da}$, and addition of $63.4 \pm 1 \mathrm{Da}$ consistent with removal of $\mathrm{N}$ - terminal methionine and addition of $\mathrm{Zn}$ ion to the three active site histidine ligands, respectively. Samples also showed $+23.0 \pm 1$, corresponding to the mass of sodium adducts. No other peaks were observed that would correlate with background incorporation of natural amino acids. 


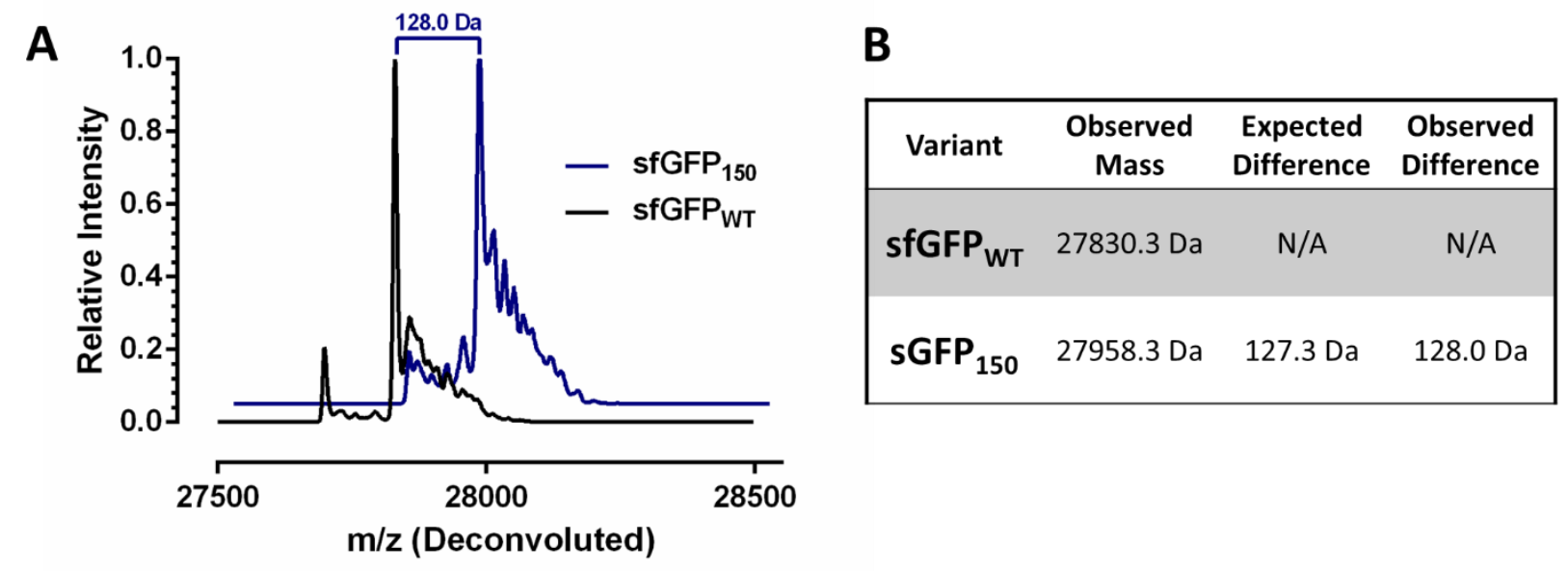

Figure S9. Mass spectrometry analysis of sfGFP proteins. (A) Mass spectrometry traces of GFP proteins presented as relative abundance per $\mathrm{m} / \mathrm{z}$, including $\mathrm{sGFP}_{\mathrm{WT}}$ (black trace), sfGFP $_{150}$ (dark blue trace). Note, traces have been offset to minimize overlap. (B) Comparison of observed and expected masses. Each sample had a loss of $131.1 \pm 1$ Da consistent with removal of $\mathrm{N}$ - terminal methionine. Samples also showed $+23.0 \pm 1$, corresponding to the mass of sodium adducts. 


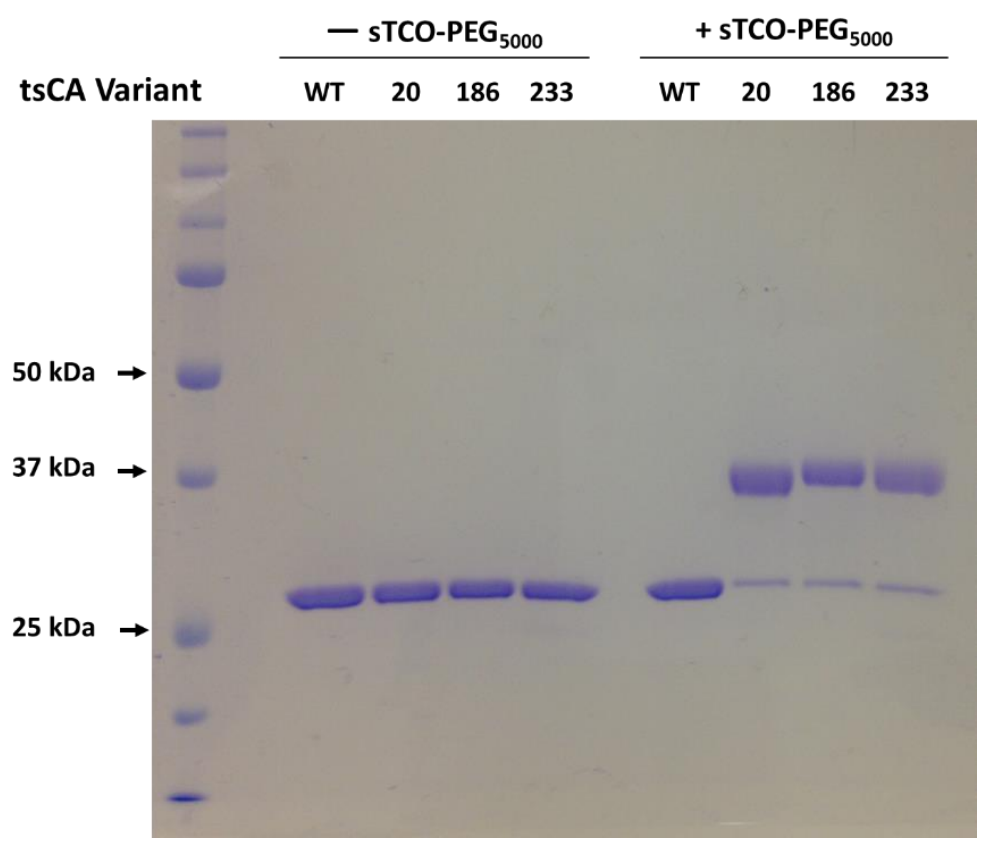

Figure S10. Mobility shift of tsCA variants upon exposure to sTCO-PEG5000. SDS-PAGE analysis of tsCA variants reacted with 10 molar equivalents of sTCO-PEG ${ }_{5000}$ and confirm the high reactivity of Tet-containing CA Contents of each lane are specified above the gel image. 


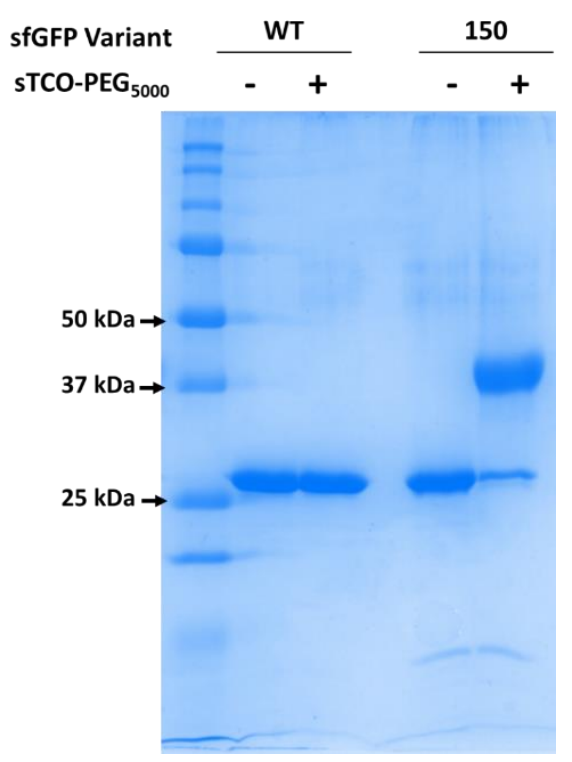

Figure S11. Mobility shift of sfGFP variants upon exposure to sTCO-PEG ${ }_{5000}$. SDS-PAGE analysis of sfGFP variants reacted with 10 molar equivalents of sTCO-PEG5000. Contents of each lane are specified above the gel image. 

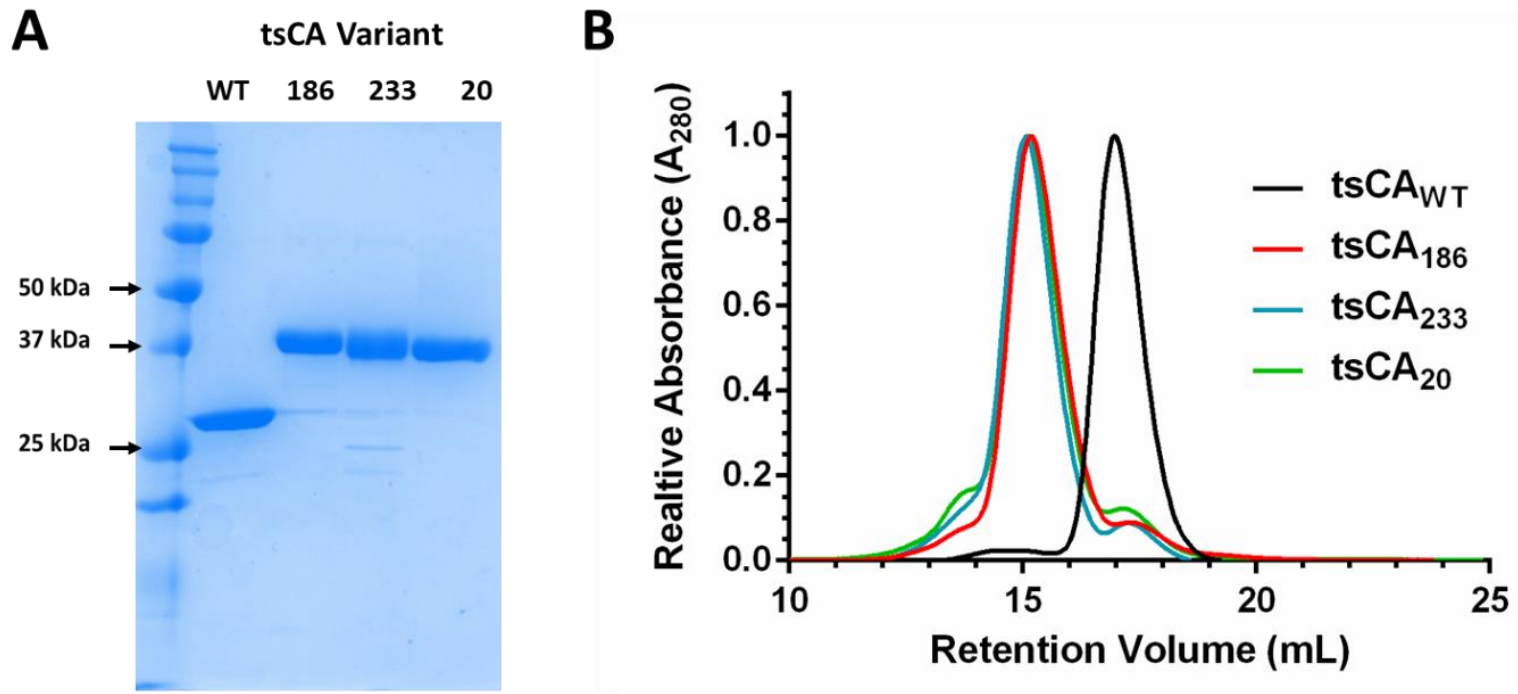

Figure S12. Size exclusion chromatography separation of tsCA $\mathrm{Ae}_{\mathrm{T} 2.0}-\mathrm{sTCO}_{\mathrm{PEG}} \mathrm{P}_{500}$ variants. (A) SDS-PAGE image of isolated tsCA $\mathrm{A}_{\mathrm{Te} 2.0}-\mathrm{sTCO}_{\mathrm{PEG}} \mathrm{P}_{500}$ variants after size exclusion chromatography. (B) Overlay of chromatograms of tsCA $\mathrm{wT}_{\mathrm{T}}$ (black), tsCA 186 (red), tsCA $\mathrm{A}_{233}$ (blue), and tsCA $\mathrm{A}_{20}$ (green) after reaction with sTCO-PEG 5000 measured at $280 \mathrm{~nm}$. 


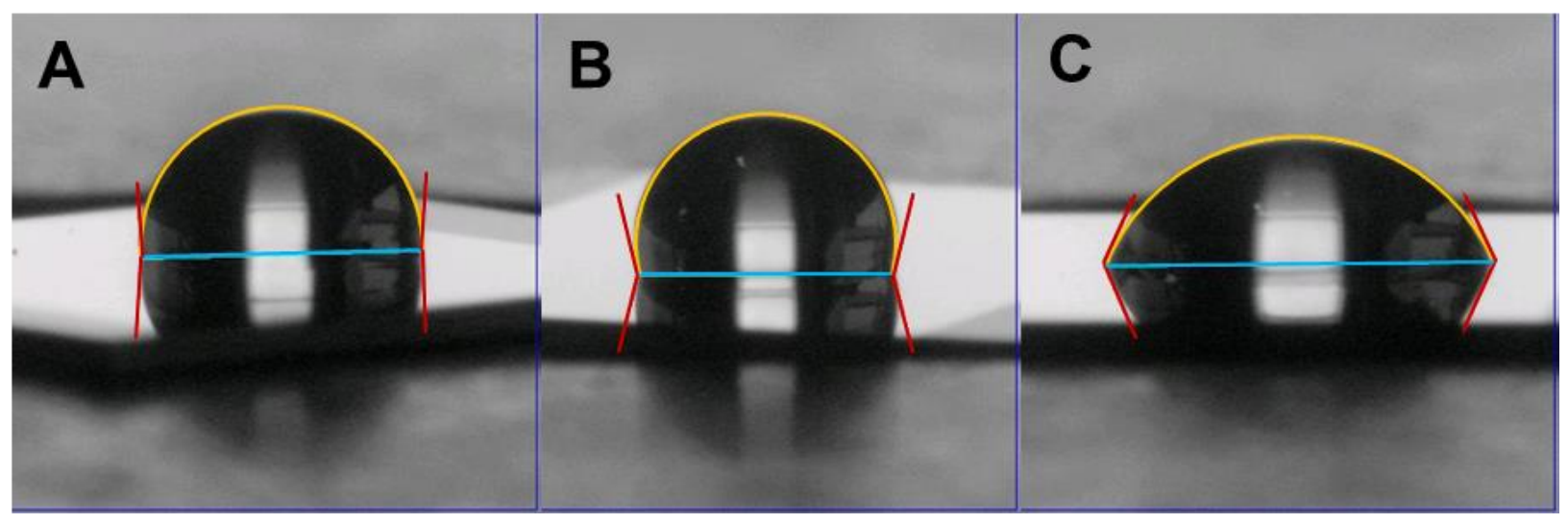

Figure S13. Contact angle goniometric analysis of sTCO-SAMs on gold. Contact angle measurements of water on bare (A) gold, (B) dodecanethiol SAM grown on gold, and (C) sTCO SAM grown on gold with contact angles of $94^{\circ} \pm 1^{\circ}, 103^{\circ} \pm 1^{\circ}$, and $66^{\circ} \pm 1^{\circ}$, respectively.

Yellow and cyan lines represent fitting of the water droplet and horizon line, respectively, while red lines represent the measured contact angle from the horizon line. 


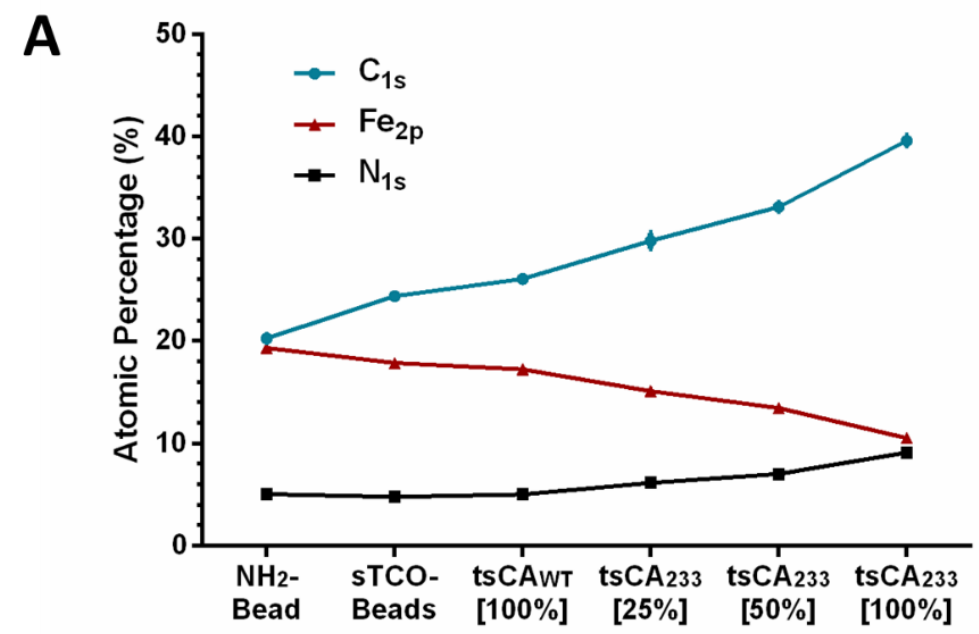

B

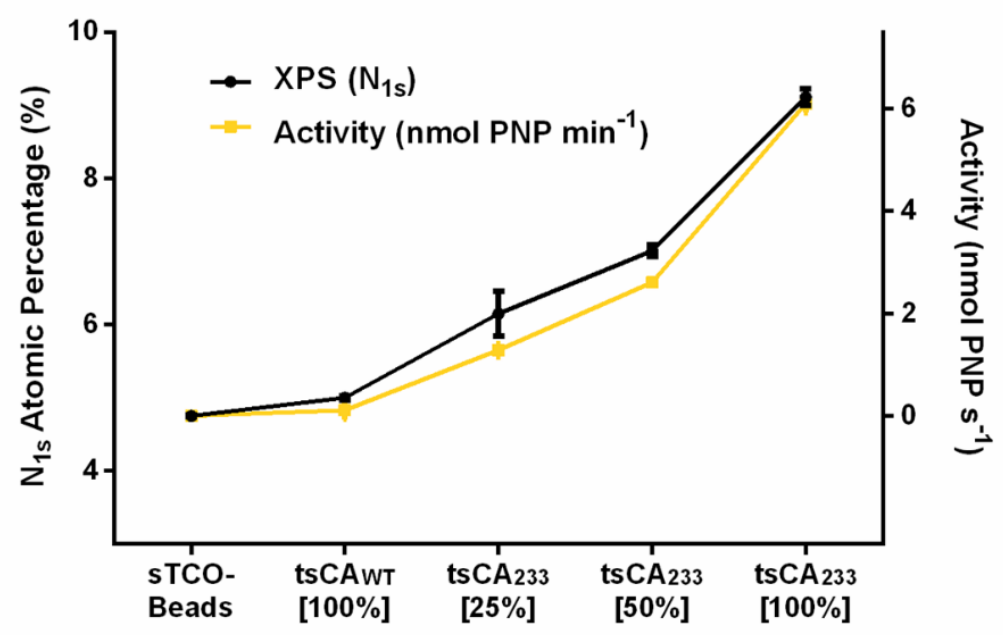

Figure S14. XPS Analysis of sTCO-beads. (A) Plot of XPS survey scan atomic percent of $\mathrm{Fe}_{2 p}$ (red triangles), $\mathrm{C}_{1 \mathrm{~s}}$ (blue circles), and $\mathrm{N}_{1 \mathrm{~s}}$ (black squares). (B) Normalized XPS $\mathrm{N}_{1 \mathrm{~s}}$ atomic percent of sTCO-beads and associated enzyme activity for the same beads exposed to either tsCAwT $(100 \%)$ or tsCA 233 (100\%, 50\%, and $25 \%$ loads). Note, overlay of $\mathrm{N}_{1 \mathrm{~s}}$ atomic percentage and activity are arbitrarily set by the scaling of their respective axes to highlight their similarity. 

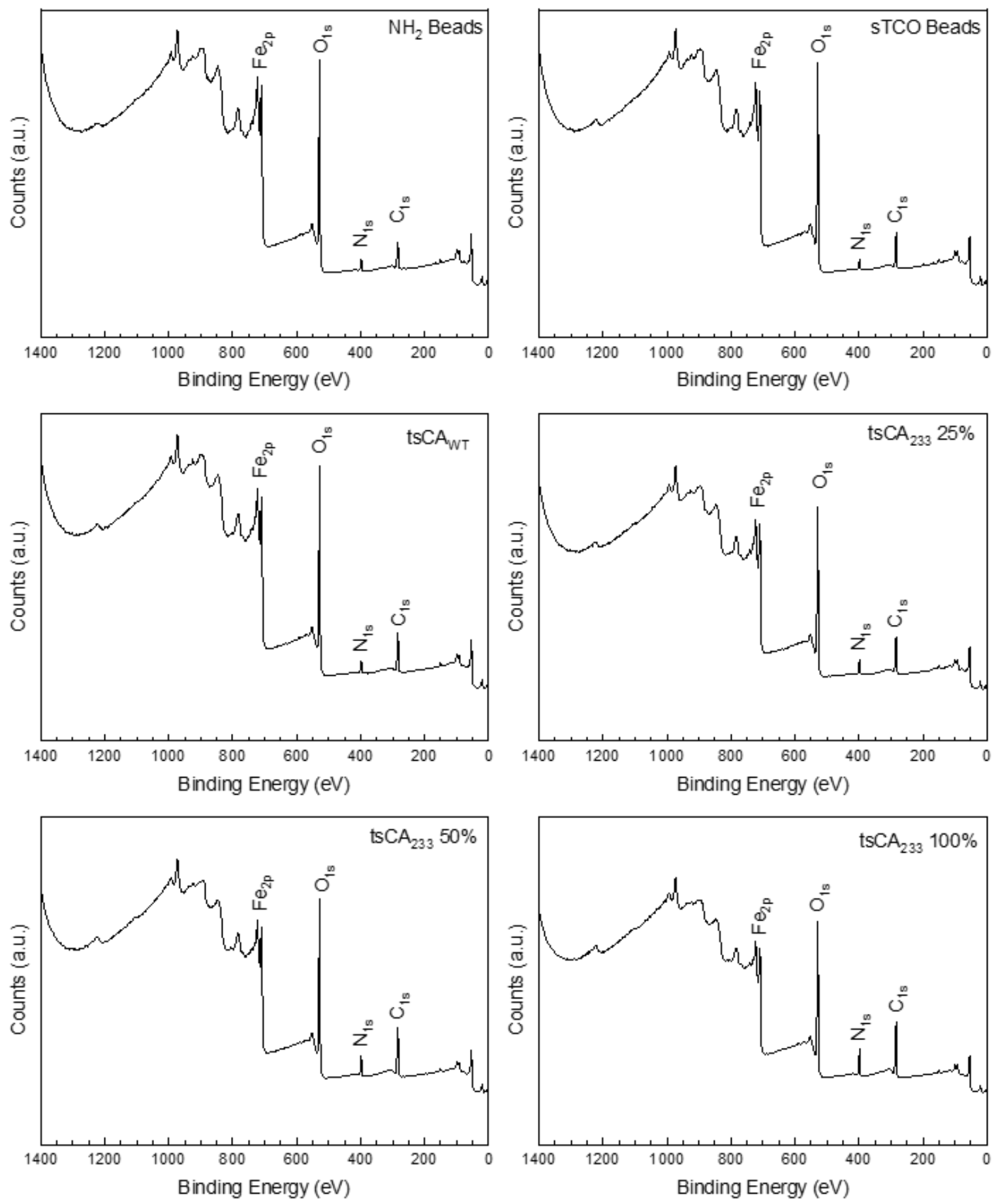

Figure S15. Plots of XPS survey spectra of $\mathrm{NH}_{2}$-beads under each loading condition described in this study. 

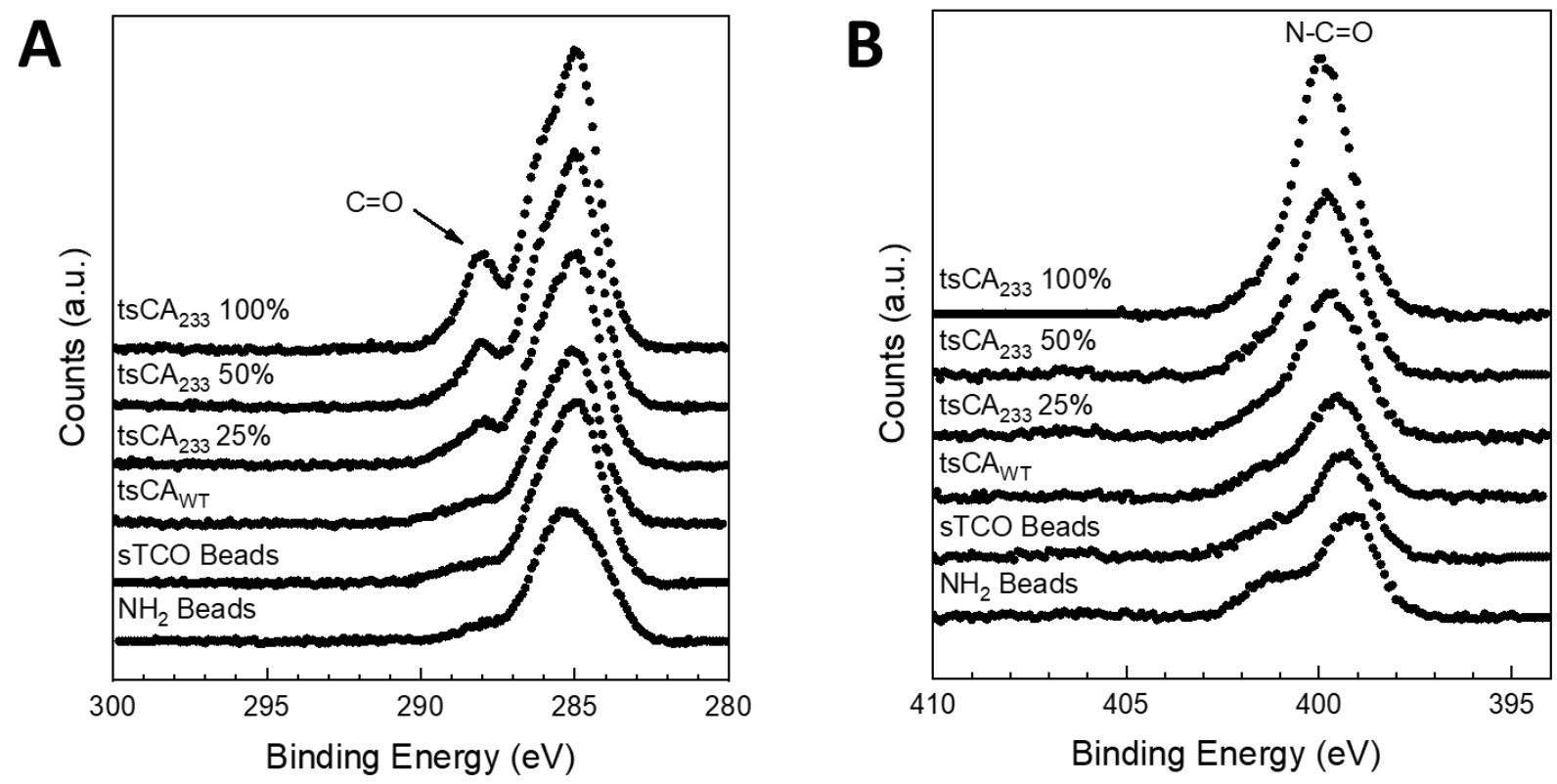

Figure S16. High-resolution XPS plots of peaks characteristic of protein addition ${ }^{90}$, including $\mathrm{C}_{1 \mathrm{~s}}$ (panel A) and $\mathrm{N}_{1 \mathrm{~s}}$ (panel B) of $\mathrm{NH}_{2}$-beads under each loading condition. (A) Only the addition of the ts $\mathrm{CA}_{233}$ protein at each load $(25 \%, 50 \%$, and $100 \%)$ contributes to the amplitude increase of the carbonyl $(\mathrm{C}=\mathrm{O})$ peak at $288.0 \mathrm{eV}$. (B) Only the addition of the tsCA $\mathrm{A}_{233}$ protein at each load $(25 \%, 50 \%$, and $100 \%)$ contributes to the amplitude increase of the amide $(\mathrm{N}-\mathrm{C}=\mathrm{O})$ peak at $400.0 \mathrm{eV}$. 


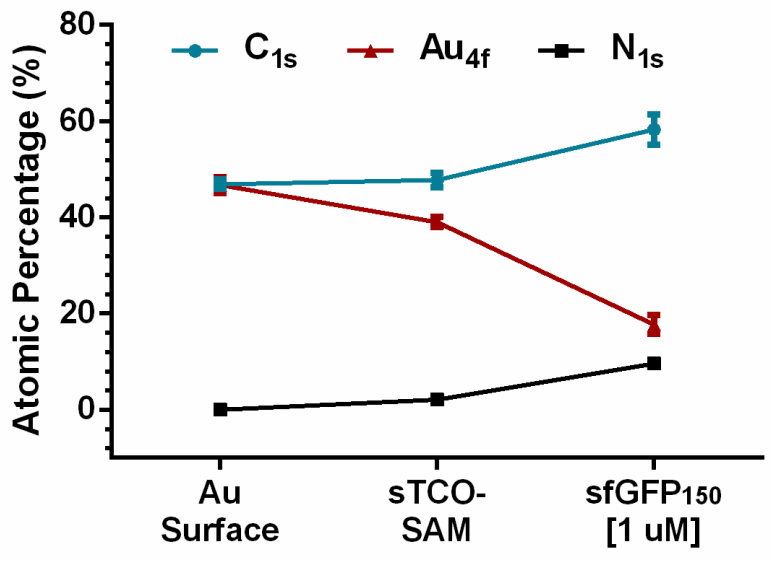

Figure S17. XPS Analysis of sTCO-SAMs. Plot of XPS survey scan atomic percentages of $\mathrm{C}_{1 \mathrm{~s}}$ (blue circles), $\mathrm{Au}_{4 \mathrm{f}}$ (red triangles), and $\mathrm{N}_{1 \mathrm{~s}}$ (black squares). 


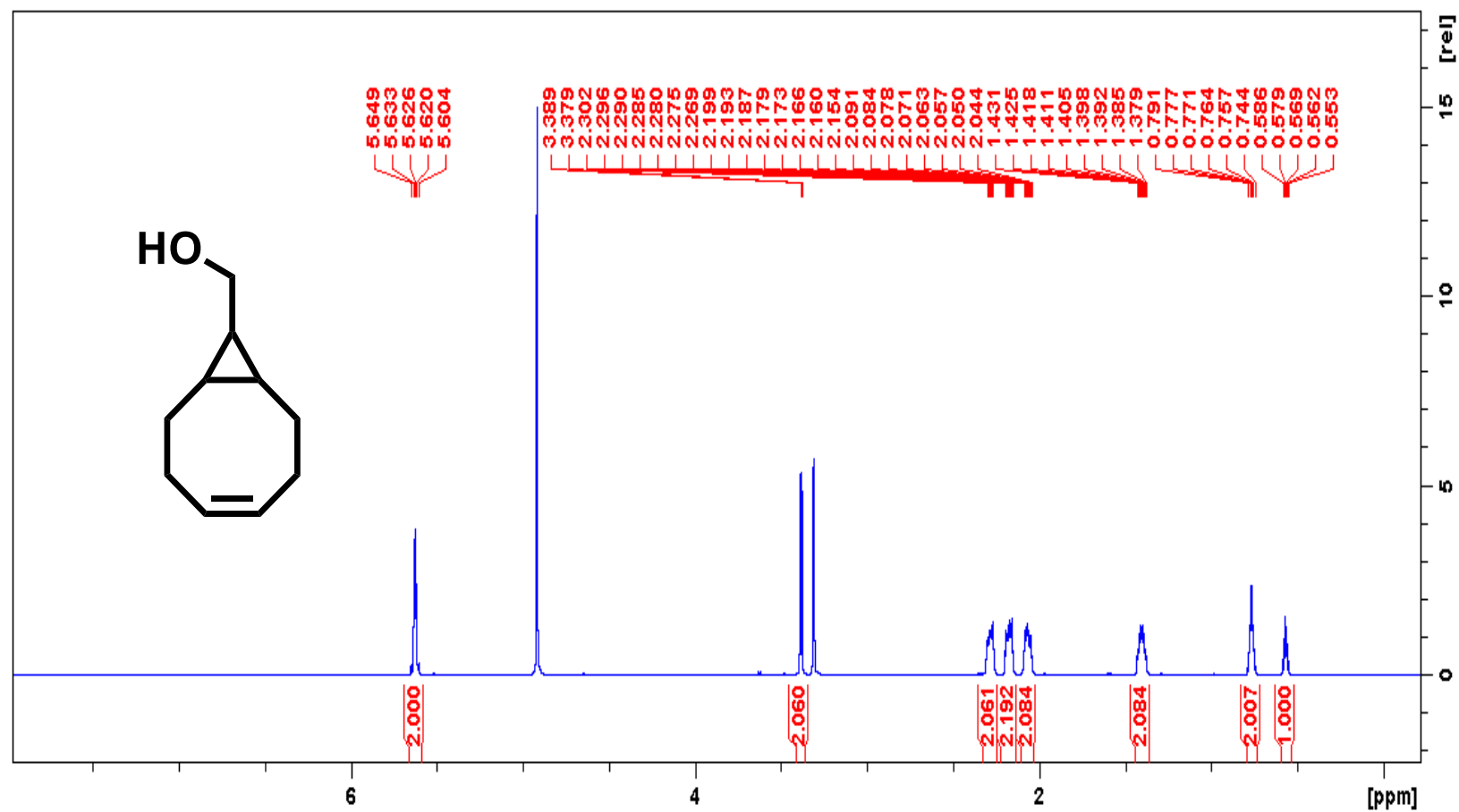

Figure S18. ${ }^{1} \mathrm{H}$ NMR spectra of $\operatorname{sCCO}(3)$ 


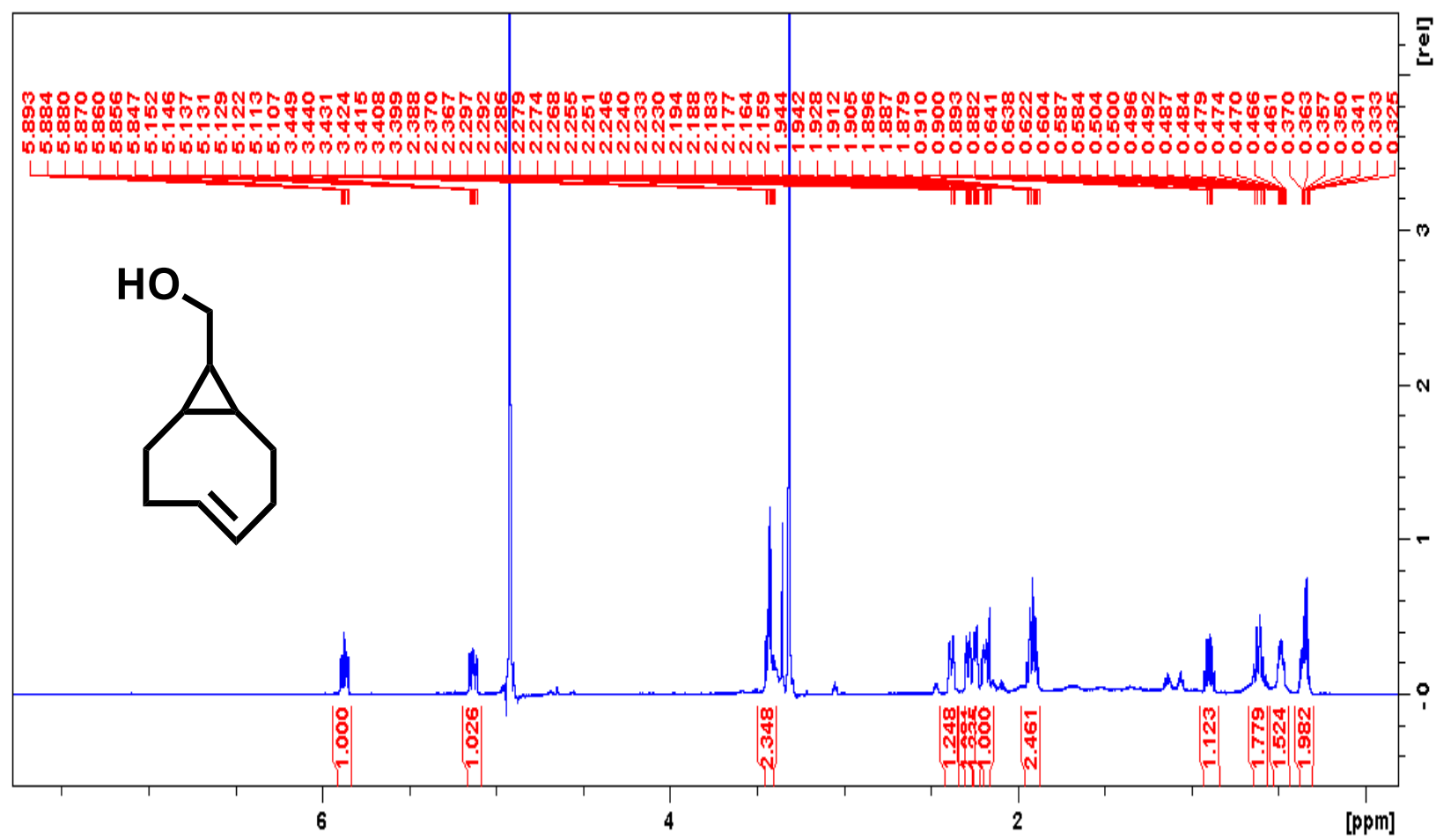

Figure S19. ${ }^{1} \mathrm{H}$ NMR spectra of sTCO (4) 


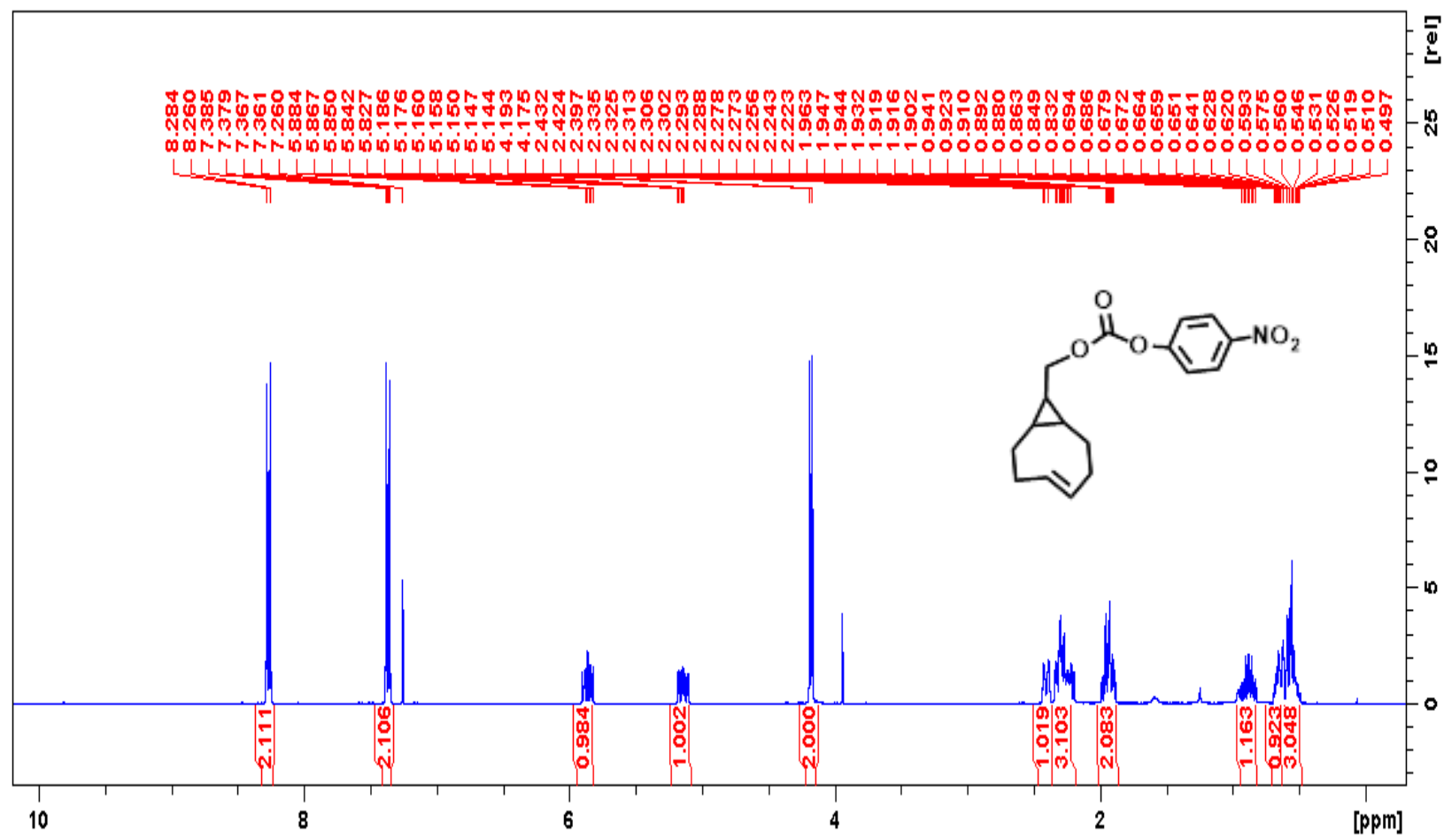

Figure S20. ${ }^{1} \mathrm{H}$ NMR spectra of activated ester of sTCO (1) 
A

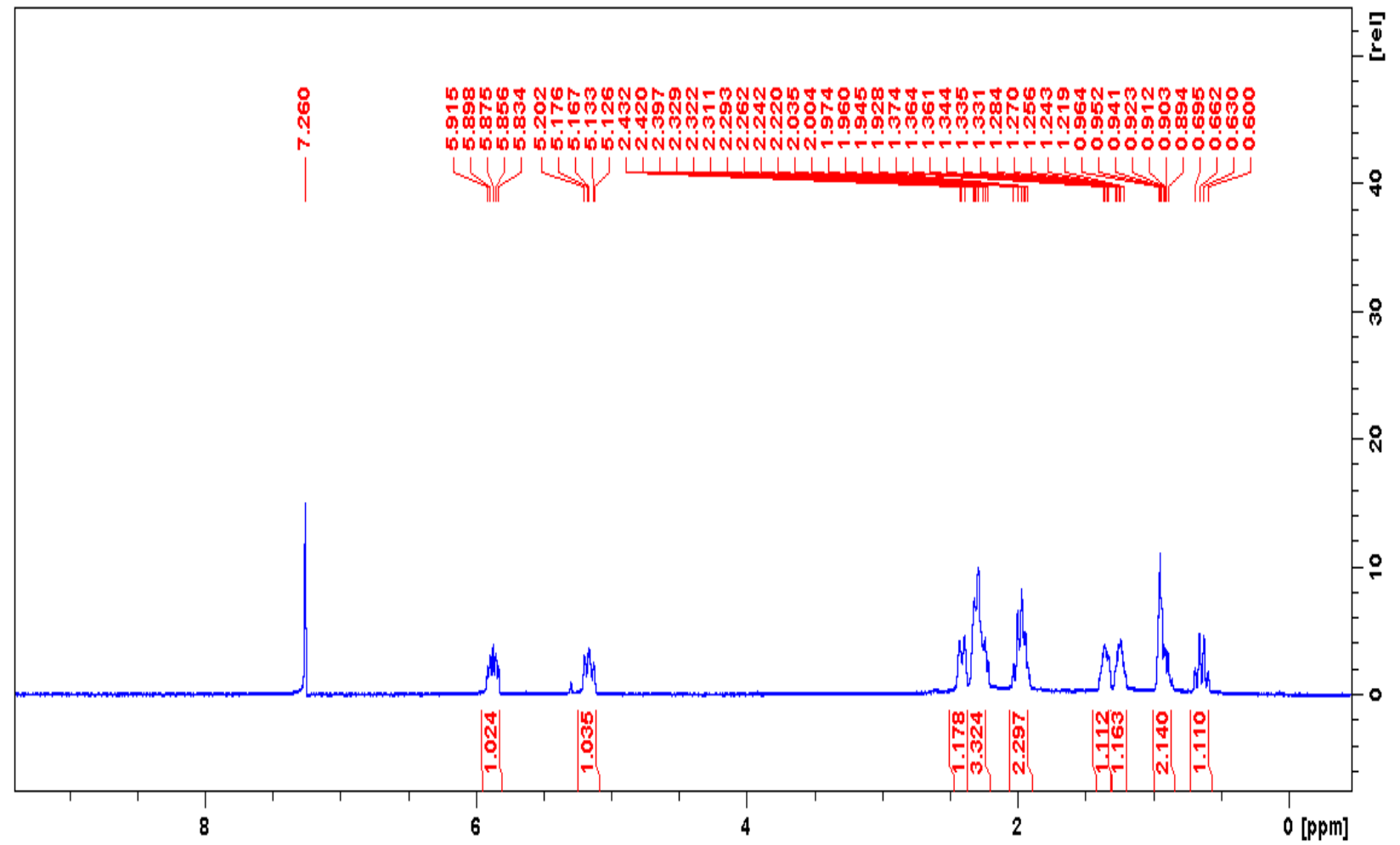

B

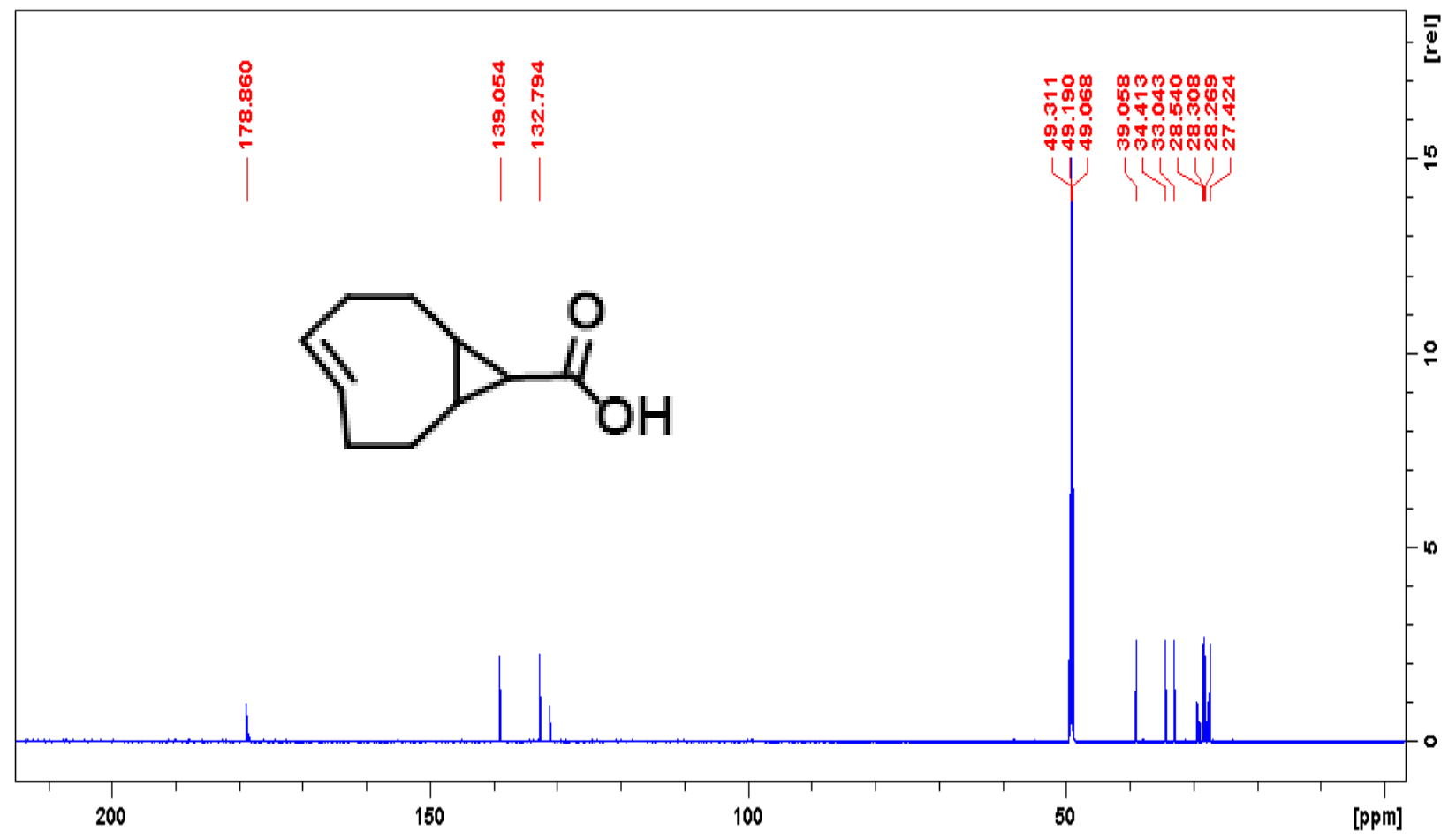

Figure S21. Chemical analysis of sTCO-CO ${ }_{2} \mathrm{H}(5)$. (A) ${ }^{1} \mathrm{H}$ NMR Spectra. (B) ${ }^{13} \mathrm{C}$ NMR Spectra 


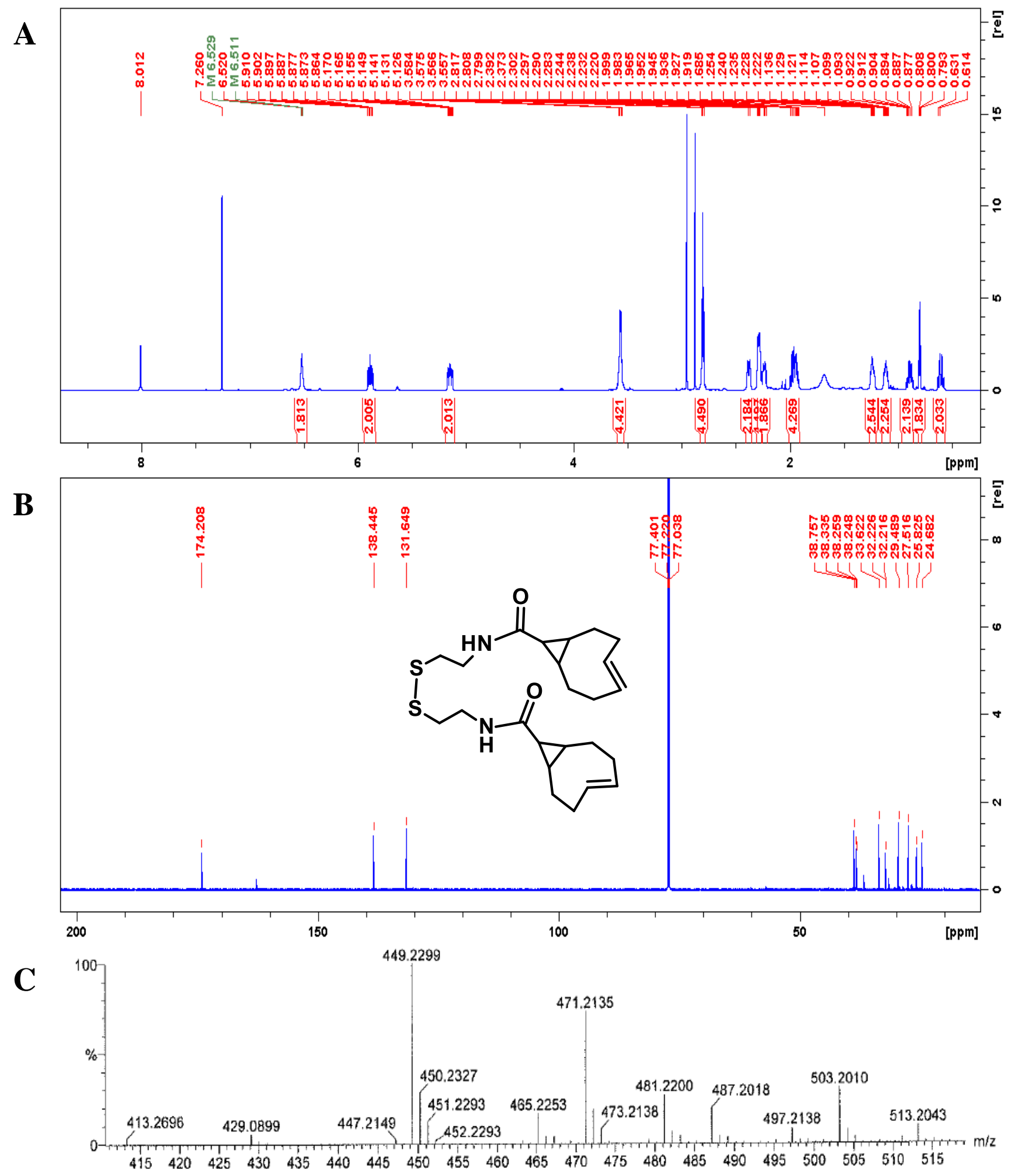

Figure S22. Chemical analysis of disulfide attached di-sTCO derivative (2). (A) ${ }^{1} \mathrm{H}$ NMR Spectra. (B) ${ }^{13}$ C NMR Spectra. (C) Mass Spectrogram. 

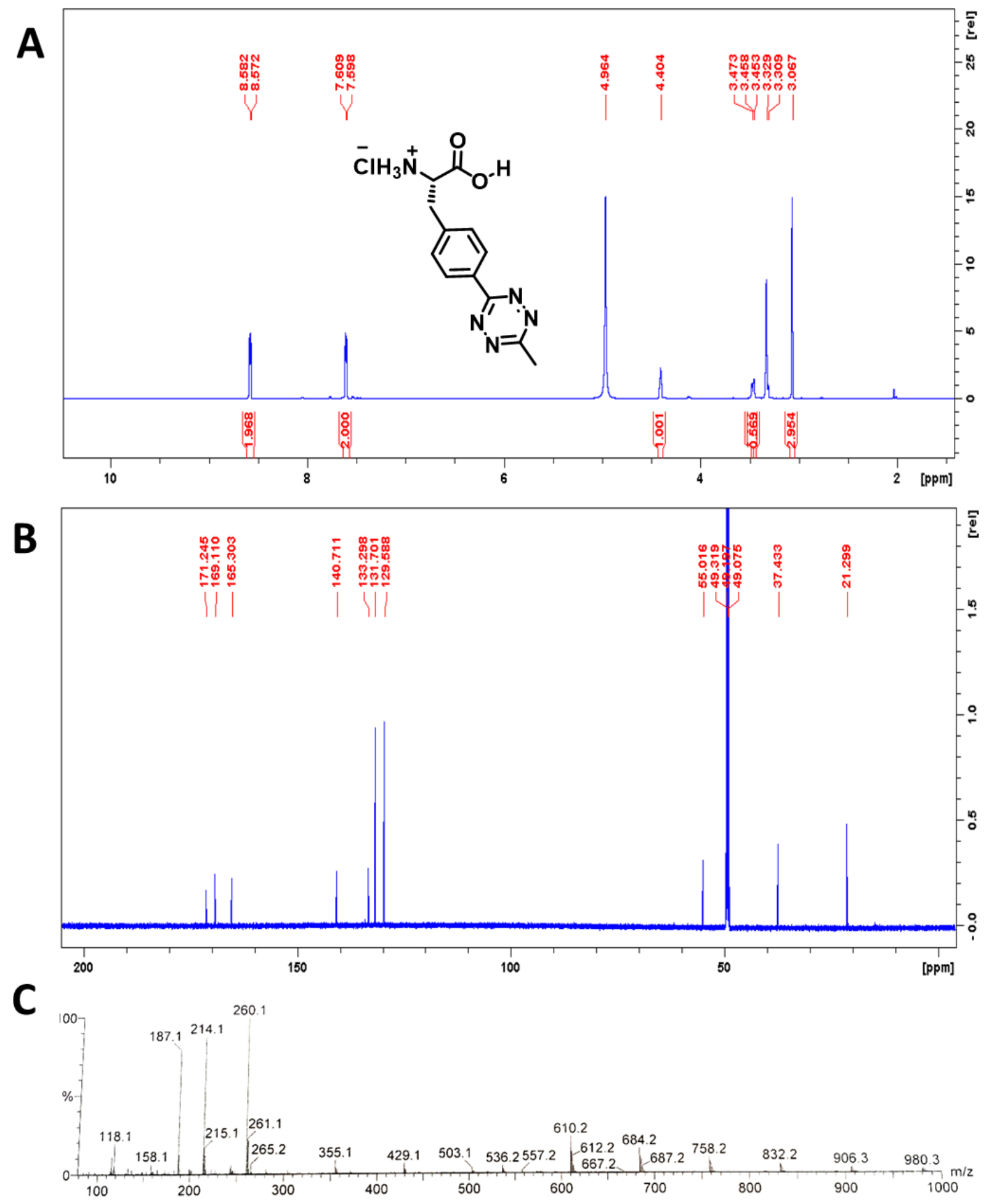

Figure S23. Chemical analysis of Tet2.0 (7). (A) ${ }^{1} \mathrm{H}$ NMR Spectra. (B) ${ }^{13} \mathrm{C}$ NMR Spectra. (C) Mass Spectrogram 


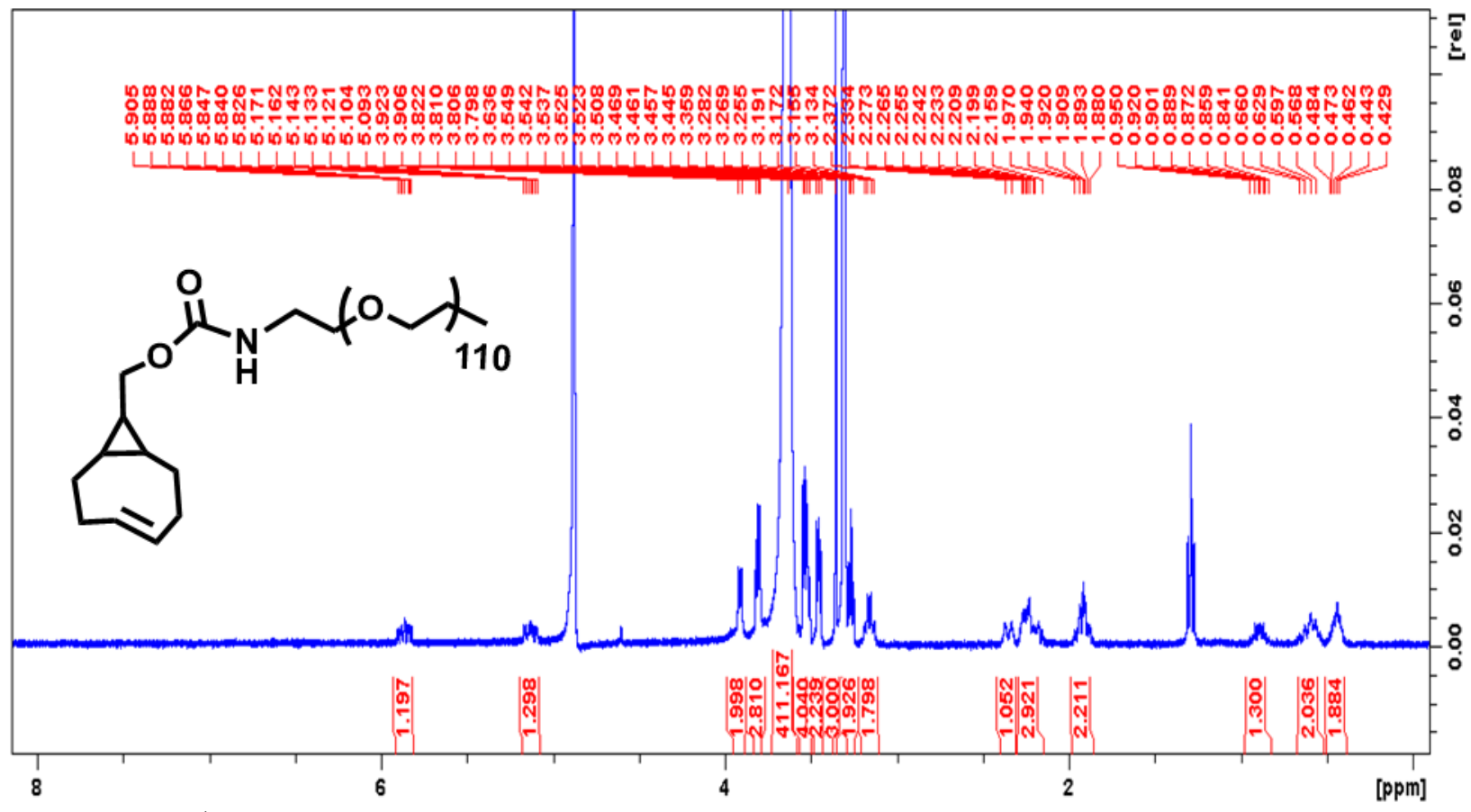

Figure S24. ${ }^{1} \mathrm{H}$ NMR spectra of sTCO-PEG ${ }_{5000}(\mathbf{8})$ 
Table S1. Primers, plasmids, and strains used in this study, including pertinent information

\begin{tabular}{|c|c|c|c|c|c|c|c|}
\hline \multicolumn{8}{|c|}{ Primers used in this study } \\
\hline \multicolumn{2}{|c|}{ Name } & \multicolumn{5}{|c|}{$\begin{array}{ll}\text { Sequence } \\
\end{array}$} & Length \\
\hline \multicolumn{2}{|c|}{ pBAD tsCA Fwd } & \multicolumn{5}{|c|}{ TTTTTGGGCTAACAGGAGGAATTAACCATGGCGCATCATTGGGGTT } & 46 \\
\hline \multicolumn{2}{|c|}{ pBAD tsCA Rev } & \multicolumn{5}{|c|}{ TCTTCTCTCATCCGCCAAAACAGCCAAGCTTTTAGTGATGGTGGTG } & 46 \\
\hline \multicolumn{2}{|c|}{ tsCA-TAG186 For } & \multicolumn{5}{|c|}{ GTCTGCTGCCGTAGAGCCTGGATTAC } & 26 \\
\hline \multicolumn{2}{|c|}{ tsCA-TAG186 Rev } & \multicolumn{5}{|c|}{ GTAATCCAGGCTCTACGGCAGCAGAC } & 26 \\
\hline \multicolumn{2}{|c|}{ tsCA-TAG233 For } & \multicolumn{5}{|c|}{ GAATTTCAATGGTTAGGGCGAGCCGGAAG } & 29 \\
\hline \multicolumn{2}{|c|}{ tsCA-TAG233 Rev } & \multicolumn{5}{|c|}{ CTTCCGGCTCGCCCTAACCATTGAAATTC } & 29 \\
\hline \multicolumn{2}{|c|}{ tsCA-TAG20 For } & \multicolumn{5}{|c|}{ GGCACAAAGATTAGCCAATTGCGAAG } & 26 \\
\hline \multicolumn{2}{|c|}{ tsCA-TAG20 Rev } & \multicolumn{5}{|c|}{ CTTCGCAATTGGCTAATCTTTGTGCC } & 26 \\
\hline \multicolumn{8}{|c|}{ Plasmids used in this study } \\
\hline \multicolumn{2}{|c|}{ Name } & Promoter & Resistance & Size (bp) & Addgene ID & \multicolumn{2}{|c|}{ Notes } \\
\hline \multicolumn{2}{|c|}{ pBAD-tsCA-WT } & $\operatorname{araBAD}$ & Ampicillin & 4757 & 105665 & \multicolumn{2}{|c|}{ Houses a copy of tsCA $\mathrm{wT}_{\mathrm{w}}$} \\
\hline \multicolumn{2}{|c|}{$\begin{array}{l}\text { pBAD-tsCA- } \\
\text { TAG186 }\end{array}$} & $\operatorname{araBAD}$ & Ampicillin & 4757 & 105837 & \multicolumn{2}{|c|}{$\begin{array}{c}\text { Houses a copy of tsCA } \mathrm{A}_{186} \text { with a } \\
\text { TAG site at position } 186\end{array}$} \\
\hline \multicolumn{2}{|c|}{$\begin{array}{l}\text { pBAD-tsCA- } \\
\text { TAG233 }\end{array}$} & $\operatorname{araBAD}$ & Ampicillin & 4757 & 105838 & \multicolumn{2}{|c|}{$\begin{array}{c}\text { Houses a copy of tsCA }{ }_{186} \text { with a } \\
\text { TAG site at position } 233\end{array}$} \\
\hline \multicolumn{2}{|c|}{$\begin{array}{l}\text { pBAD-tsCA- } \\
\text { TAG20 }\end{array}$} & $\operatorname{araBAD}$ & Ampicillin & 4757 & 105666 & \multicolumn{2}{|c|}{$\begin{array}{c}\text { Houses a copy of } \text { tsCA }_{186} \text { with a } \\
\text { TAG site at position } 20\end{array}$} \\
\hline \multicolumn{2}{|c|}{ pBAD-sfGFP-WT } & $\operatorname{araBAD}$ & Ampicillin & 4829 & 85482 & \multicolumn{2}{|c|}{ Houses a copy of sfGFP ${ }_{\mathrm{wT}}$} \\
\hline $\begin{array}{r}\mathrm{pBAD}-\mathrm{s} \\
150 \mathrm{~T}\end{array}$ & $\begin{array}{l}\text { GFP- } \\
\text { G }\end{array}$ & $\operatorname{araBAD}$ & Ampicillin & 4829 & 85483 & $\begin{array}{r}\text { Houses a copy o } \\
\text { TAG site at }\end{array}$ & $\begin{array}{l}\mathrm{FP}_{150} \text { with a } \\
\text { ion } 150\end{array}$ \\
\hline pDule-T & t2.0 & $\begin{array}{c}\operatorname{lpp}(\text { aaRS }) \\
g \ln S\left(\mathrm{tRNA}_{\mathrm{CUA}}\right)\end{array}$ & Tetracycline & 6333 & 85496 & $\begin{array}{l}\text { Houses a suppress } \\
\text { a Tet } 2.0 \text {-specific } \\
\text { cognate, reco }\end{array}$ & $\begin{array}{l}\text { air including } \\
\text { yrRS and a } \\
\text { RNA }_{\text {CUA }}\end{array}$ \\
\hline & & & Strain & used in thi & study & & \\
\hline Number & & lasmid 1 & Plasmid 2 & & sistance & No & \\
\hline 1 & $\mathrm{pB}$ & AD-CA-WT & N/A & & npicillin & Used for produc & of tsCA $\mathrm{WT}_{\mathrm{WT}}$ \\
\hline 2 & pBAD & -CA-TAG186 & pDule-Tet 2.0 & Ampicill & in/Tetracycline & Used for produ & of tsCA ${ }_{186}$ \\
\hline 3 & $\mathrm{pBAD}$ & -CA-TAG233 & pDule-Tet 2.0 & Ampicill & in/Tetracycline & Used for produ & of tsCA $\mathrm{A}_{233}$ \\
\hline 4 & pBAI & -CA-TAG20 & pDule-Tet2.0 & Ampicill & in/Tetracycline & Used for produ & of tsCA $\mathrm{CA}_{20}$ \\
\hline 5 & $\mathrm{pBA}$ & D-sfGFP-WT & N/A & & npicillin & Used for produc & of sfGFP ${ }_{W T}$ \\
\hline 6 & pBAD- & sGFP-150TAG & pDule1-Tet2.0 & Ampicill & in/Tetracycline & Used for produc & of $\mathrm{sfGFP}_{150}$ \\
\hline
\end{tabular}


Table S2. Sequences of genes used in this study. Highlighted in red are positions which were mutagenized to TAG codons and represent the position of Tet2.0

\begin{tabular}{|c|c|}
\hline \multicolumn{2}{|r|}{ Sequences of genes used in this study } \\
\hline $\begin{array}{c}\text { Encoded } \\
\text { Protein }\end{array}$ & Sequence \\
\hline 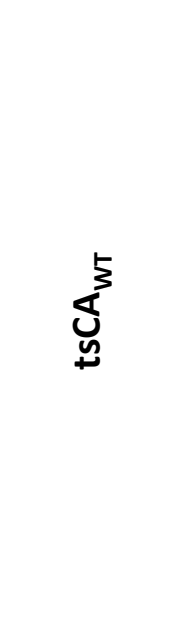 & $\begin{array}{l}\text { ATGGCGCATCATTGGGGTTACGGTAAACACAACGGTCCGGAGCATTGGCACAAAGATTTTCCAATTGCGA } \\
\text { AGGGCGAACGTCAAAGCCCGGTTGACATTGATACGCACACGGCAAAGTACGACCCGAGCCTGAAACCGC } \\
\text { TGAGCGTTTCCTATGACCAGGCTACGAGCCTGCGTATCCTGAACAATGGCCACACCTTCAACGTGGAGTTT } \\
\text { GATGATTCCCAAGATAAGGCGGTTCTGAAAGGTGTCCGTTGGATGGCACCTACCGCCTGATCCAATTTCA } \\
\text { CTTTCACTGGGGTAGCCACGACGGTCAGGGCAGCGAGCATACCGTGGACAAAAAGAAGTATGCAGCCGA } \\
\text { ACTGCACCTGGTGCATTGGAACACGAAGTACGGCGACTTCGGTAAAGCGGTCCAGCAACCGGACGGTCT } \\
\text { GGCTGTTCTGGGTATTTCCTGAAGGTCGGCAGCGCGAACCCGGTCTGCAGAAAGTGGTTGACGTGTT } \\
\text { GGACTCTATCAAGACCAAAGGCAAGAGCGCGGACTTCACCAATTTCGATCCGCGTGGTCTGCTGCCGGAG } \\
\text { AGCCTGGATTACTGGACTTATCCGGGCAGCCTGACCACCCCGCCATTGCTGGAGTGCGTGACCTGGATCGT } \\
\text { CTTGAAAGAACCGATCAGCGTTAGCTCTGAACAGGTCAGCAAGTTCCGCAAGCTGAATTTCAATGGTGAG } \\
\text { GGCGAGCCGGAAGAACCGATGGTCGATAATTGGCGTCCTACCCAACCGCTGAAAAACCGCCAGATTAAAG } \\
\text { CATCCTTTAAGCATCACCACCACCATCACTAA }\end{array}$ \\
\hline$\frac{0^{\frac{5}{5}}}{\frac{5}{5}}$ & $\begin{array}{l}\text { ATGGTTAGCAAAGGTGAAGAACTGTTTACCGGCGTTGTGCCGATTCTGGTGGAACTGGATGGTGATGTGA } \\
\text { ATGGCCATAAATTTAGCGTTCGTGGCGAAGGCGAAGGTGATGCGACCAACGGTAAACTGACCCTGAAATT } \\
\text { TATTTGCACCACCGGTAAACTGCCGGTTCCGTGGCCGACCTGGTGACCACCCTGACCTATGGCGTTCAGT } \\
\text { GCTTTAGCCGCTATCCGGATCATATGAAACGCCATGATTTCTTTAAAAGCGCGATGCCGGAAGGCTATGTGC } \\
\text { AGGAACGTACCATTAGCTTCAAAGATGATGGCACCTATAAAACCCGTGCGGAAGTTAAATTTGAAGGCGAT } \\
\text { ACCCTGGTGAACCGCATTGAACTGAAAGGTATTGATTTTAAAGAAGATGGCAACATTCTGGGTCATAAACT } \\
\text { GGAATATAATTTCAACAGCCATAACGTGTATATTACCGCCGATAAACAGAAAAATGGCATCAAAGCGAACTT } \\
\text { TAAAATCCGTCACAACGTGGAAGATGGTAGCGTGCAGCTGGCGGATCATTATCAGCAGAATACCCCGATTG } \\
\text { GTGATGGCCCGGTGCTGCTGCCGGATAATCATTATCTGAGCACCCAGAGCGTTCTGAGCAAAGATCCGAAT } \\
\text { GAAAAACGTGATCATATGGTGCTGCTGGAATTTGTTACCGCCGCGGGATTACCCACGGTATGGATGAACT } \\
\text { GTATAAAGGCAGCCACCATCATCATCACCATTAA }\end{array}$ \\
\hline
\end{tabular}


Table S3. Data and refinement statistics for tsCA structures ${ }^{\mathrm{a}}$.

\begin{tabular}{|c|c|c|c|c|c|}
\hline & \multicolumn{2}{|c|}{ tsCA $_{186}$} & \multicolumn{3}{|c|}{ tsCA $_{233}$} \\
\hline & $\mathrm{tsCA}_{186}$ & tsCA $_{186-\mathrm{sTCO}}$ & $\begin{array}{c}\text { tsCA }_{233} \\
\text { (Ordered } \\
\text { Tet2.0) } \\
\end{array}$ & $\begin{array}{c}\text { tsCA }_{233} \\
\text { (Disordered } \\
\text { Tet2.0) }\end{array}$ & $\mathrm{tsCA}_{233-\mathrm{sTCO}}$ \\
\hline Space group & $\mathrm{P} 2{ }_{1} 2_{1} 2_{1}$ & $\mathrm{P} 2{ }_{1} 2_{1} 2_{1}$ & $\mathrm{P} 2{ }_{1} 2_{1}$ & $\mathrm{C} 222_{1}$ & $\mathrm{C} 222_{1}$ \\
\hline \multicolumn{6}{|c|}{ Data Statistics } \\
\hline $\begin{array}{c}\text { Wavelength } \\
\text { (A) }\end{array}$ & 1.00 & 0.976 & 1.00 & 1.00 & 1.00 \\
\hline $\begin{array}{l}\text { Unit cell a, b, c } \\
\quad \text { axes }(\AA)\end{array}$ & $\begin{array}{c}61.44,93.68 \\
101.16\end{array}$ & $\begin{array}{c}\text { 65.33, 93.86, } \\
100.38\end{array}$ & $\begin{array}{c}44.14,69.08 \\
81.11\end{array}$ & $\begin{array}{c}44.42,72.46 \\
151.51\end{array}$ & $\begin{array}{c}44.08,72.46 \\
152.11\end{array}$ \\
\hline Resolution (Å) & $\begin{array}{l}37.25-1.50 \\
(1.54-1.50)\end{array}$ & $\begin{array}{l}65.33-1.60 \\
(1.63-1.60)\end{array}$ & $\begin{array}{l}40.56-1.01 \\
(1.04-1.01)\end{array}$ & $\begin{array}{l}37.88-1.25 \\
(1.27-1.25)\end{array}$ & $\begin{array}{c}37.66-1.30 \\
(1.32-1.30)\end{array}$ \\
\hline $\begin{array}{c}\text { Unique } \\
\text { reflections }\end{array}$ & $94059(6873)$ & $\begin{array}{l}82090 \\
(4002)\end{array}$ & $115504(1987)$ & $55819(483)$ & $52578(2377)$ \\
\hline Multiplicity & $12.6(10.9)$ & $14.0(12.5)$ & $10.7(1.9)$ & $10.2(9.4)$ & $10.8(11.9)$ \\
\hline Average I/o & $10.13(0.61)$ & $15.2(0.8)$ & $27.28(0.69)$ & $6.6(0.8)$ & $11.3(1.2)$ \\
\hline $\mathbf{R}_{\text {meas }}(\%)$ & $25.2(435.5)$ & $13.6(330.0)$ & $4(135.1)$ & $14.5(214)$ & $11.0(222)$ \\
\hline $\begin{array}{c}\text { Completeness } \\
(\%)\end{array}$ & $100(100)$ & $100(100)$ & $97.6(86.6)$ & $82.0(68.0)$ & $87.0(81.0)$ \\
\hline $\mathrm{CC}_{1 / 2}$ & $0.99(0.20)$ & $1.0(0.32)$ & $1.0(0.39)$ & $1.0(0.27)$ & $1.0(0.35)$ \\
\hline \multicolumn{6}{|c|}{ Refinement Statistics } \\
\hline $\begin{array}{l}\text { Amino acid } \\
\text { residues }\end{array}$ & 516 & 518 & 258 & 266 & 266 \\
\hline Solvent atoms & 579 & 630 & 443 & 362 & 393 \\
\hline Non-H atoms & 4807 & 5018 & 2768 & 2651 & 2697 \\
\hline $\begin{array}{c}\text { RMS bonds } \\
\text { (§) }\end{array}$ & 0.009 & 0.01 & 0.006 & 0.008 & 0.008 \\
\hline $\begin{array}{c}\text { RMS angles } \\
\left({ }^{\circ}\right)\end{array}$ & 1.03 & 1.05 & 0.96 & 1.01 & 1.01 \\
\hline$\langle\mathrm{B}\rangle\left(\AA^{2}\right)$ & 21.31 & 29.34 & 19.43 & 23.35 & 23.33 \\
\hline $\mathbf{R}_{\text {work }}(\%)$ & 17.15 & 16.35 & 10.02 & 16.63 & 15.40 \\
\hline $\mathbf{R}_{\text {free }}(\%)$ & 19.57 & 19.29 & 12.49 & 20.58 & 17.79 \\
\hline PDB code & $6 \mathrm{NJ} 2$ & 6NJ6 & $6 \mathrm{NJ} 3$ & $6 \mathrm{NJ} 5$ & $6 \mathrm{NJ} 4$ \\
\hline
\end{tabular}

\footnotetext{
${ }^{\mathrm{a}}$ Numbers in parentheses are in the highest resolution shell
} 
Table S4. Enzyme activity values (pmol PNP s${ }^{-1}$ ) presented in Figs. 4A and 4C. Note, enzyme activity values shown in Fig $4 \mathrm{~A}$ for tsCAwT and tsCA $\mathrm{CA}_{233}$ are the same as those presented in Fig. $4 \mathrm{C}$.

\begin{tabular}{|c|c|c|c|c|}
\hline tsCA Variant & Load & Free & Supernatant & Bead \\
\hline \multirow{2}{*}{$t s A_{W T}$} & $\mathbf{1 0 0} \%$ & $211.2( \pm 17.8)$ & $125.3( \pm 15.3)$ & $18.4( \pm 9.7)$ \\
\hline \multirow{3}{*}{$\mathrm{tsCA}_{186}$} & $\mathbf{1 0 0 \%}$ & $141.3( \pm 15.0)$ & $2.8( \pm 1.2)$ & $110.4( \pm 6.5)$ \\
\cline { 2 - 5 } & $\mathbf{5 0 \%}$ & $55.9( \pm 3.6)$ & $-0.4( \pm 0.9)$ & $37.6( \pm 4.9)$ \\
\cline { 2 - 5 } & $\mathbf{2 5 \%}$ & $20.5( \pm 1.6)$ & $-0.7( \pm 0.9)$ & $8.6( \pm 4.5)$ \\
\hline \multirow{4}{*}{$\mathrm{tsCA}_{233}$} & $\mathbf{1 0 0 \%}$ & $159.3( \pm 10.1)$ & $5.0( \pm 1.0)$ & $113.5( \pm 6.0)$ \\
& $\mathbf{5 0 \%}$ & $72.4( \pm 2.8)$ & $-3.8( \pm 4.6)$ & $58.9( \pm 7.2)$ \\
& $\mathbf{2 5 \%}$ & $36.7( \pm 1.2)$ & $-1.7( \pm 0.7)$ & $29.4( \pm 3.2)$ \\
\hline \multirow{3}{*}{$\mathrm{tsCA}_{20}$} & $\mathbf{1 0 0 \%}$ & $158.8( \pm 4.5)$ & $4.2( \pm 1.5)$ & $90.0( \pm 3.9)$ \\
& $\mathbf{5 0 \%}$ & $69.9( \pm 2.6)$ & $1.4( \pm 3.8)$ & $41.0( \pm 2.5)$ \\
& $\mathbf{2 5 \%}$ & $30.7( \pm 3.1)$ & $-1.1( \pm 0.4)$ & $14.3( \pm 5.9)$ \\
\hline
\end{tabular}




\section{Supplementary References}

(54) O'Brien, J. G. K.; Chintala, S. R.; Fox, J. M. Stereoselective Synthesis of Bicyclo[6.1.0]Nonene Precursors of the Bioorthogonal Reagents S-Tco and Bcn. The Journal of organic chemistry 2018, 83 (14), 7500-7503, DOI: 10.1021/acs.joc.7b02329.

(55) Royzen, M.; Yap, G. P. A.; Fox, J. M. A Photochemical Synthesis of Functionalized TransCyclooctenes Driven by Metal Complexation. Journal of the American Chemical Society 2008, 130 (12), 3760-3761, DOI: 10.1021/ja8001919.

(56) Popchock, A. R.; Jana, S.; Mehl, R. A.; Qiu, W. Engineering Heterodimeric Kinesins through Genetic Incorporation of Noncanonical Amino Acids. ACS Chemical Biology 2018, 13 (8), 2229-2236, DOI: 10.1021/acschembio.8b00399.

(57) Bryksin, A. V.; Matsumura, I. Overlap Extension Pcr Cloning: A Simple and Reliable Way to Create Recombinant Plasmids. BioTechniques 2010, 48 (6), 463-465, DOI: 10.2144/000113418.

(58) Stokes, A. L.; Miyake-Stoner, S. J.; Peeler, J. C.; Nguyen, D. P.; Hammer, R. P.; Mehl, R. A. Enhancing the Utility of Unnatural Amino Acidsynthetases by Manipulating Broad Substrate Specificity. Molecular BioSystems 2009, 5 (9), 1032-1038, DOI: 10.1039/B904032C.

(59) Studier, F. W. Stable Expression Clones and Auto-Induction for Protein Production in E. Coli. Methods Mol Biol 2014, 1091, 17-32, DOI: 10.1007/978-1-62703-691-7_2.

(60) Schindelin, J.; Arganda-Carreras, I.; Frise, E.; Kaynig, V.; Longair, M.; Pietzsch, T.; Preibisch, S.; Rueden, C.; Saalfeld, S.; Schmid, B.; Tinevez, J.-Y.; White, D. J.; Hartenstein, V.; Eliceiri, K.; Tomancak, P.; Cardona, A. Fiji: An Open-Source Platform for Biological-Image Analysis. Nature Methods 2012, 9, 676, DOI: 10.1038/nmeth.2019 https://www.nature.com/articles/nmeth.2019\#supplementary-information.

(61) Verpoorte, J. A.; Mehta, S.; Edsall, J. T. Esterase Activities of Human Carbonic Anhydrases B and C. The Journal of biological chemistry 1967, 242 (18), 4221-4229.

(62) Pocker, Y.; Stone, J. T. The Catalytic Versatility of Erythrocyte Carbonic Anhydrase. The Enzyme-Catalyzed Hydrolysis of P-Nitrophenyl Acetate. Journal of the American Chemical Society 1965, 87 (23), 5497-5498, DOI: 10.1021/ja00951a049.

(63) Biggs, A. I. A Spectrophotometric Determination of the Dissociation Constants of PNitrophenol and Papaverine. Transactions of the Faraday Society 1954, 50 (0), 800-802, DOI: 10.1039/TF9545000800.

(64) Bradford, M. M. A Rapid and Sensitive Method for the Quantitation of Microgram Quantities of Protein Utilizing the Principle of Protein-Dye Binding. Analytical Biochemistry 1976, 72 (1), 248-254, DOI: https://doi.org/10.1016/0003-2697(76)90527-3.

(65) Kabsch, W. Xds. Acta Crystallographica Section D 2010, 66 (2), 125-132, DOI: doi:10.1107/S0907444909047337.

(66) Battye, T. G.; Kontogiannis, L.; Johnson, O.; Powell, H. R.; Leslie, A. G. Imosflm: A New Graphical Interface for Diffraction-Image Processing with Mosflm. Acta crystallographica. Section D, Biological crystallography 2011, 67 (Pt 4), 271-281, DOI: 10.1107/s0907444910048675.

(67) The Ccp4 Suite: Programs for Protein Crystallography. Acta crystallographica. Section D, Biological crystallography 1994, 50 (Pt 5), 760-763, DOI: 10.1107/s0907444994003112. 
(68) Emsley, P.; Lohkamp, B.; Scott, W. G.; Cowtan, K. Features and Development of Coot. Acta crystallographica. Section D, Biological crystallography 2010, 66 (Pt 4), 486-501, DOI: 10.1107/s0907444910007493.

(69) Moriarty, N. W.; Grosse-Kunstleve, R. W.; Adams, P. D. Electronic Ligand Builder and Optimization Workbench (Elbow): A Tool for Ligand Coordinate and Restraint Generation. Acta crystallographica. Section D, Biological crystallography 2009, 65 (Pt 10), 1074-1080, DOI: 10.1107/S0907444909029436.

(70) Adams, P. D.; Afonine, P. V.; Bunkoczi, G.; Chen, V. B.; Davis, I. W.; Echols, N.; Headd, J. J.; Hung, L. W.; Kapral, G. J.; Grosse-Kunstleve, R. W.; McCoy, A. J.; Moriarty, N. W.; Oeffner, R.; Read, R. J.; Richardson, D. C.; Richardson, J. S.; Terwilliger, T. C.; Zwart, P. H. Phenix: A Comprehensive Python-Based System for Macromolecular Structure Solution. Acta crystallographica. Section D, Biological crystallography 2010, 66 (Pt 2), 213-221, DOI: 10.1107/s0907444909052925.

(71) Chin, J. W. Expanding and Reprogramming the Genetic Code of Cells and Animals. Annual review of biochemistry 2014, 83, 379-408, DOI: 10.1146/annurev-biochem-060713-035737. (72) Wang, L.; Schultz, P. G. A General Approach for the Generation of Orthogonal Trnas. Chemistry \& biology 2001, 8 (9), 883-890.

(73) Kelman, Z.; Naktinis, V.; O'Donnell, M. [32] Radiolabeling of Proteins for Biochemical Studies. In Methods Enzymol; Academic Press: 1995; pp 430-442.

(74) Du, Y. J.; Cornelius, R. M.; Brash, J. L. Measurement of Protein Adsorption to Gold Surface by Radioiodination Methods: Suppression of Free Iodide Sorption. Colloid Surface B 2000, 17 (1), 59-67, DOI: Doi 10.1016/S0927-7765(99)00053-3.

(75) Sheardown, H.; Cornelius, R. M.; Brash, J. L. Measurement of Protein Adsorption to Metals Using Radioiodination Methods: A Caveat. Colloids and Surfaces B: Biointerfaces 1997, 10 (1), 29-33, DOI: https://doi.org/10.1016/S0927-7765(97)00045-3.

(76) Holmberg, M.; Stibius, K. B.; Ndoni, S.; Larsen, N. B.; Kingshott, P.; Hou, X. L. Protein Aggregation and Degradation During Iodine Labeling and Its Consequences for Protein Adsorption to Biomaterials. Anal Biochem 2007, 361 (1), 120-125, DOI:

10.1016/j.ab.2006.11.016.

(77) Slocum, J. D.; Webb, L. J. A Double Decarboxylation in Superfolder Green Fluorescent Protein Leads to High Contrast Photoactivation. The journal of physical chemistry letters 2017, 8 (13), 2862-2868, DOI: 10.1021/acs.jpclett.7b01101.

(78) Smith, T. The Hydrophilic Nature of a Clean Gold Surface. Journal of Colloid and Interface Science 1980, 75 (1), 51-55, DOI: https://doi.org/10.1016/0021-9797(80)90348-3.

(79) Lloyd, B. P.; Bartlett, P. N.; Wood, R. J. Wetting of Surfaces Made of Hydrophobic Cavities. Langmuir 2015, 31 (34), 9325-9330, DOI: 10.1021/acs.langmuir.5b02107.

(80) Ping, Z. H.; Nguyen, Q. T.; Chen, S. M.; Zhou, J. Q.; Ding, Y. D. States of Water in Different Hydrophilic Polymers - Dsc and Ftir Studies. Polymer 2001, 42 (20), 8461-8467, DOI: Doi 10.1016/S0032-3861(01)00358-5.

(81) Baio, J. E.; Weidner, T.; Castner, D. G. Characterizing the Structure of SurfaceImmobilized Proteins: A Surface Analysis Approach. In Proteins at Interfaces Iii State of the Art; American Chemical Society: 2012; Chapter 35, pp 761-779.

(82) Franz, J.; Graham, D. J.; Schmüser, L.; Baio, J. E.; Lelle, M.; Peneva, K.; Müllen, K.; Castner, D. G.; Bonn, M.; Weidner, T. Full Membrane Spanning Self-Assembled Monolayers as Model Systems for Uhv-Based Studies of Cell-Penetrating Peptides. Biointerphases 2015, 10 (1), 019009-019009, DOI: 10.1116/1.4908164. 
(83) Zorn, G.; Dave, S. R.; Weidner, T.; Gao, X.; Castner, D. G. Direct Characterization of Polymer Encapsulated Cdse/Cds/Zns Quantum Dots. Surface science 2016, 648, 339-344, DOI: 10.1016/j.susc.2015.10.013.

(84) Rafati, A.; Shard, A. G.; Castner, D. G. Multitechnique Characterization of Oligo(Ethylene Glycol) Functionalized Gold Nanoparticles. Biointerphases 2016, 11 (4), 04B304-304B304, DOI: $10.1116 / 1.4967216$.

(85) Baio, J. E.; Weidner, T.; Baugh, L.; Gamble, L. J.; Stayton, P. S.; Castner, D. G. Probing the Orientation of Electrostatically Immobilized Protein G B1 by Iime of Flight Secondary Ion Spectrometry, Sum Frequency Generation and near-Edge X-Ray Absorption Fine Structure Spectroscopy. Langmuir 2012, 28, DOI: 10.1021/la203907t.

(86) Baio, J. E.; Weidner, T.; Brison, J.; Graham, D. J.; Gamble, L. J.; Castner, D. G. Amine Terminated Sams: Investigating Why Oxygen Is Present in These Films. Journal of Electron Spectroscopy and Related Phenomena 2009, 172, DOI: 10.1016/j.elspec.2009.02.008.

(87) Techane, S. D.; Gamble, L. J.; Castner, D. G. Multi-Technique Characterization of SelfAssembled Carboxylic Acid Terminated Alkanethiol Monolayers on Nanoparticle and Flat Gold Surfaces. The journal of physical chemistry. C, Nanomaterials and interfaces 2011, 115 (19), 9432-9441, DOI: 10.1021/jp201213g.

(88) Castner, D. G.; Hinds, K.; Grainger, D. W. X-Ray Photoelectron Spectroscopy Sulfur 2p Study of Organic Thiol and Disulfide Binding Interactions with Gold Surfaces. Langmuir 1996, 12 (21), 5083-5086, DOI: 10.1021/la960465w.

(89) Baio, J. E.; Weidner, T.; Ramey, D.; Pruzinsky, L.; Castner, D. G. Probing the Orientation of Electrostatically Immobilized Cytochrome $\mathrm{C}$ by Time of Flight Secondary Ion Mass Spectrometry and Sum Frequency Generation Spectroscopy. Biointerphases 2013, 8 (1), 18, DOI: $10.1186 / 1559-4106-8-18$.

(90) Roguska, A.; Pisarek, M.; Andrzejczuk, M.; Dolata, M.; Lewandowska, M.; Janik-Czachor, M. Characterization of a Calcium Phosphate-Tio2 Nanotube Composite Layer for Biomedical Applications. Materials Science and Engineering: C 2011, 31 (5), 906-914, DOI: https://doi.org/10.1016/j.msec.2011.02.009. 